Earth Sciences Doctoral School

Department of Physical Geography and Geoinformatics

Faculty of Science and Informatics, University of Szeged

\title{
ENVIRONMENTAL MODELLING AND SPATIAL LANDSCAPE ANALYSIS FOR THE CONTAMINATION RISK ASSESSMENT OF SENSITIVE AREAS
}

Ph.D. Dissertation

AHMED KORANY ABDELRAOF ABDELAAL

$\begin{array}{cc}\text { Supervisors: } & \text { Dr. Gyozo Jordan } \\ \text { Dr. Peter Szilassi } & \text { Researcher } \\ \text { Associate Professor } & \text { Institute for Geological and Geochemical } \\ \text { University of Szeged } & \text { Research, Hungarian Academy of Science } \\ \text { Department of Physical Geography and } & \end{array}$

Szeged, 2014 


\section{Tables of contents}

1 Introduction $\quad 3$

2 Evaluation of the decision support methods for the Environmental Risk 9

Assessment of contamination at mining sites
$2.1 \quad$ Landscape Ecology

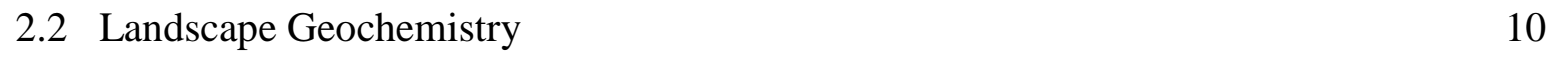

$\begin{array}{lll}2.3 & \text { Industrial Ecology } & 13\end{array}$

2.4 Geo-Environmental Model 14

2.5 Material Flow Analysis 16

2.6 Life Cycle Assessment $\quad 18$

2.7 Environmental Impact Assessment 20

2.8 Risk Assessment (RA) $\quad 21$

2.8.1 Risk Assessment Methods for Mining: a State-of-the-Art Review 23

3 Study area $\quad 29$

4 Data $\quad 32$

5 Methods $\quad 33$

5.1 Contamination Risk Assessment Methods in landscapes 33

5.1.1 EU MWD Pre-selection Protocol 33

5.1.2 EEA Preliminary Risk Assessment PRAMS Model 37

5.1.3 Risk Assessment Sensitivity analysis: numerical comparison of methods 37

5.2 Waste rock geochemical characterization and risk mapping 39

5.2.1 Sampling 39

$\begin{array}{lll}\text { 5.2.2 Laboratory analysis } & 41\end{array}$

6 Results 44

6.1 EU MWD Pre-selection Protocol risk assessment using the EU thresholds 44

6.2 EU MWD Pre-selection Protocol risk assessment using the local thresholds $\quad 50$

6.3 Pre-screening (Tier 0) EEA PRAMS Risk Assessment Model 51

6.4 Sensitivity and uncertainty analysis of the EU MWD Pre-selection Protocol 53

6.5 A preliminary Risk-based ranking based on the EU MWD Pre-selection Protocol 55

6.6 Pre-selection Risk assessment of the 30 mine-quarry waste sites 57

6.7 Linkage between the stream water quality variables (heavy metals) and the 64
landscape metrics

7 Conclusions $\quad 69$

8 Acknowledgments $\quad 73$

9 References $\quad 74$

10 Summary $\quad 88$

11 Összefoglalás $\quad 93$

Annex 1. The EU MWD Pre-selection Protocol Flowchart 99

Annex 2. Logic of the EU MWD Pre-selection Protocol 102 


\section{Introduction}

Mining has severe impacts on the environment, including contamination by toxic metals. Since most of the elements used by the society come from mineral extraction (76 out of 90 frequently used elements), mining of mineral resources provide essential raw material for economic development (COM(2005) 670). In this context, a recent Europe-wide survey identified widespread pollution problems caused by mining, abandoned mines in particular (COM (2003) 319). Apart from that abandoned mines are the same as active mines in terms of types of hazard and potential impact on the environment; their major problems are uncertainty in information and lack of control. Direct exposure to acid mine drainage (AMD) and sediments discharged from abandoned metal mines poses a serious hazard to aquatic biota and to humans (Peplow and Edmonds 2005; Panagopoulos et al. 2009; Lei et al. 2010; Sarmiento et al. 2011).

Due to great volumes and slow chemical processes, mineralised rock in mine workings and in mine waste can release toxic compounds for a very long time on the scale of centuries and thousands of years (BAT 2003). Thus, remediation of mine sites, including abandoned mines, has to consider long-term solutions and remediation technologies have to be sustainable for a long time (Sinding 1999; Panagopoulos et al. 2009). Younger et al. (2002) estimated that about 1,000 to $1,500 \mathrm{~km}$ of watercourses are polluted by metal mine discharges in the European Union (estimate is for the former EU 15). There are an estimated 3 million potentially contaminated sites in the whole European Union, of which about 250,000 are actually contaminated and in need of remediation (EEA, 2007). Around the mine site, soils and surface water in the receiving environment are often contaminated with harmful elements or compounds (Puura et al. 2002; Sarmiento et al. 2011). These contaminated sites act as secondary sources for pollution, especially for historic sites (Jordan and D'Alessandro 2004). Natural (geological) background contamination often present in mining areas adds to the complexity of the environmental assessment of contamination at mining sites. Recognising these problems, the EU Mine Waste Directive (Directive 2006/21/EC) prescribed the inventory of closed and abandoned waste facilities in Europe using the most appropriate risk assessment procedures and remedial actions having regard to the variation of geological, hydrogeological and climatological and land use, land cover conditions.

Significance of contamination risk posed by mining is also highlighted by large mine accidents such as those in Baia Mare, Romania in 2000 and in Aznalcollar, Spain in 1998 (Jordan and D'Alessandro 2004) and most recently the catastrophic release of 850 million cubic meters of alkaline $(\mathrm{pH}>13$ ) caustic red mud through the failed dam of the Ajka alumina plant depository on October 4, 2010 in Kolontar, Hungary, resulting in loss of 10 lives and injuring 150 persons and contamination of agricultural lands (Jordan et al. 2011).

The EU MWD (Directive 2006/21/EC) requires in Article 20 that "Member States shall ensure that an inventory of closed waste facilities, including abandoned waste facilities, which cause serious negative environmental impacts or have the potential of becoming in the medium or short 
term a serious threat to human health or the environment is drawn up and periodically updated." According to Article 21, such methodologies shall allow for the establishment of the most appropriate risk assessment procedures and remedial actions having regard to the variation of geological, hydrogeological, land use and cover and climatological characteristics across Europe. In the present risk assessment methodologies, spatial data are used such as the measured distance to the nearest settlements, surface water courses (streams and lakes), groundwater bodies and the national protected areas (Natura 2000 sites, etc) using the Proximity analysis tool within ArcGIS ${ }^{\circledR} 10$, and the topographic slope data calculated from the Hungarian national contour based military DEM 50m grid and census data for Hungary from 2009 available from the Hungarian Central Statistical Office. Data on the national protected areas (Natura 2000 sites, etc.) is available from the Hungarian Central Directorate of Water and Environment (VKKI). Location and status classification of groundwater bodies in Hungary under the Water Framework Directive (WFD) is available from VKKI, and from EEA website (Water base-Groundwater data tests). Land use/land cover data (LULC) maps at 1:100,000 scales are obtained from the European CORINE Land Cover website.

Contamination Risk Assessment (RA) is defined as the probability of adverse effects to humans and ecosystem resulting from exposure to environmental pollutants (Kolluru et al. 1996; Fergusson 1998; US EPA 1989; 1998; Di Sante et al. 2009; Fan et al. 2010). RA is concerned with the risk involved at a specific site, at a specific time, and due to specific causes. RA includes the steps of 1) hazard description, 2) dose/response (toxicity) analysis, 3) contaminant transport, 4) exposure assessment, 5) risk characterization, and 6) risk management (Van Leuwen and Hermens 1996; U.S. EPA 2002; 2007). Contamination risk exists for a site only if all the source, pathway and receptor components are present. While human health risk assessment (HHRA) studies the probability of impact on a single organism (U.S. EPA 1989; Gazdag and Sipter 2008), ecological risk assessment (ERA) studies the impact on organisms (U.S. EPA 1998; Yi et al. 2011). In the case of mine waste sites, for example, this means that a hazardous waste should be present such as an ore tailings pond, contamination transport should be enabled by air, surfaceand groundwater or direct contact to reach sensitive receptors such as settlements, protected natural, or semi-natural ecosystems or agricultural lands.

Regional RA is a quantitative methodology to estimate and compare the impacts of environmental problems that affect large geographic areas (Hunsaker et al. 1990; Landis 2005) and/or multiple contaminated sites (Pizzol et al. 2011). Limited financial resources restrict remediation of sites at regional scale, therefore, there is a strong need to develop methodologies that rank sites based on risk magnitude, rather than to produce absolute estimates of health/ecological impacts, or to prioritize the remediation actions (Long and Fischhoff 2000; Marcomini et al. 2009). Mine site characterization and risk-based ranking methods have been reviewed and evaluated by national and international efforts (Horvath and Gruiz. 1996; Sommer et al. 2003; Rapant et al. 2006; Bagur et al. 2009; deLemos et al. 2009; Broadhurst and Petrie 2010; Pizzol et al. 2011; Moreno-Jiménez et al. 2011; Turner et al. 2011; Yenilmez et al. 2011). 
Many research projects were carried out on regional mineral deposit mapping and mine site inventory in the Central and Eastern European countries (Jordan 2009). Numerous 'country specific' and regional studies were adopted for hazard (e.g.Sun Hong-fei et al. 2010), impact (e.g.Horvath and Gruiz 1996; Sommer et al. 2003; Hansen et al. 2008; Bagur et al. 2009; Zobrist et al. 2009; González et al. 2011), and risk assessment of mining sites (e.g. Komnitsas et al. 1998; Arquette et al. 2002; Passariello et al. 2002; Veliciu and Stratulat 2004; Rapant et al. 2006; Komnitsas and Modis 2006; Lim et al. 2008; Panagopoulos et al. 2009; Broadhurst and Petrie 2010; Luo et al. 2010; Moreno-Jiménez et al. 2011; Yenilmez et al. 2011). Also, many spatial methods for environmental RA have been developed (e.g. Slowanska 1997; deLemos et al. 2009; Sollitto 2010; Pizzol et al. 2011). U.S. EPA (2001) gives detailed description of risk-based assessment of mine sites. Moreover, as for the prioritization process, the Soil Thematic Strategy for soil protection (COM (2006) 231) and the EU MWD (Directive 2006/21/EC) point out the need to develop spatial risk-based methodologies for sustainable management of contaminated sites and mining waste sites at regional scale. The effort required to identify and prioritize contaminated sites in Europe is considerable (EEA 2005a).

In general decision support is concerned with helping decision makers solve problems and make decisions. Decision support provides a variety of data analysis, preference modelling, simulation, visualization and interactive techniques, and tools such as decision support systems, multiplecriteria modeling, group decision support and mediation systems, expert systems, databases and data warehouses. Decision support methods incorporate both data and models (Mladenic et al. 2003; Younger et al. 2005; Lavrač et al. 2007; Sahnoun et al. 2011; Klauer et al. 2012; Harp and Vesselinov 2012; Zaredar and Zarkesh 2012). A survey of decision-analysis applications, including many environmental examples, is given by Keefer et al. (2004). Lavrač et al. (2007) used the data mining and visualization techniques for decision support in planning and regional level management of Slovenian public health-care.

The DPSIR (Driving force, Pressure, State, Impact and Response) environmental reporting framework of the European Environmental Agency (EEA) (EEA 2005; Skoulikidis 2009) provides a convenient starting point for the discussion of decision support methods for environmental contamination of mines (Fig.1). Demand for mineral resources is the driving force that exerts pressure on the environment by mineral extraction, waste production and by various emissions. These activities impact the environment found in a given state prior to mining. Premining contamination baseline conditions such as natural or historic anthropogenic background pollutions, and state of human and ecosystem receptors provide reference for the assessment of impacts. Impacts by mining include natural resource exploitation (material removal or dislocation), biotic and abiotic environmental degradation and land use conflicts. Finally, these impacts trigger responses from the society in the form of new regulation, good management practices (including monitoring and remediation), and all actions that influence driving forces, pressures, state and impacts. 


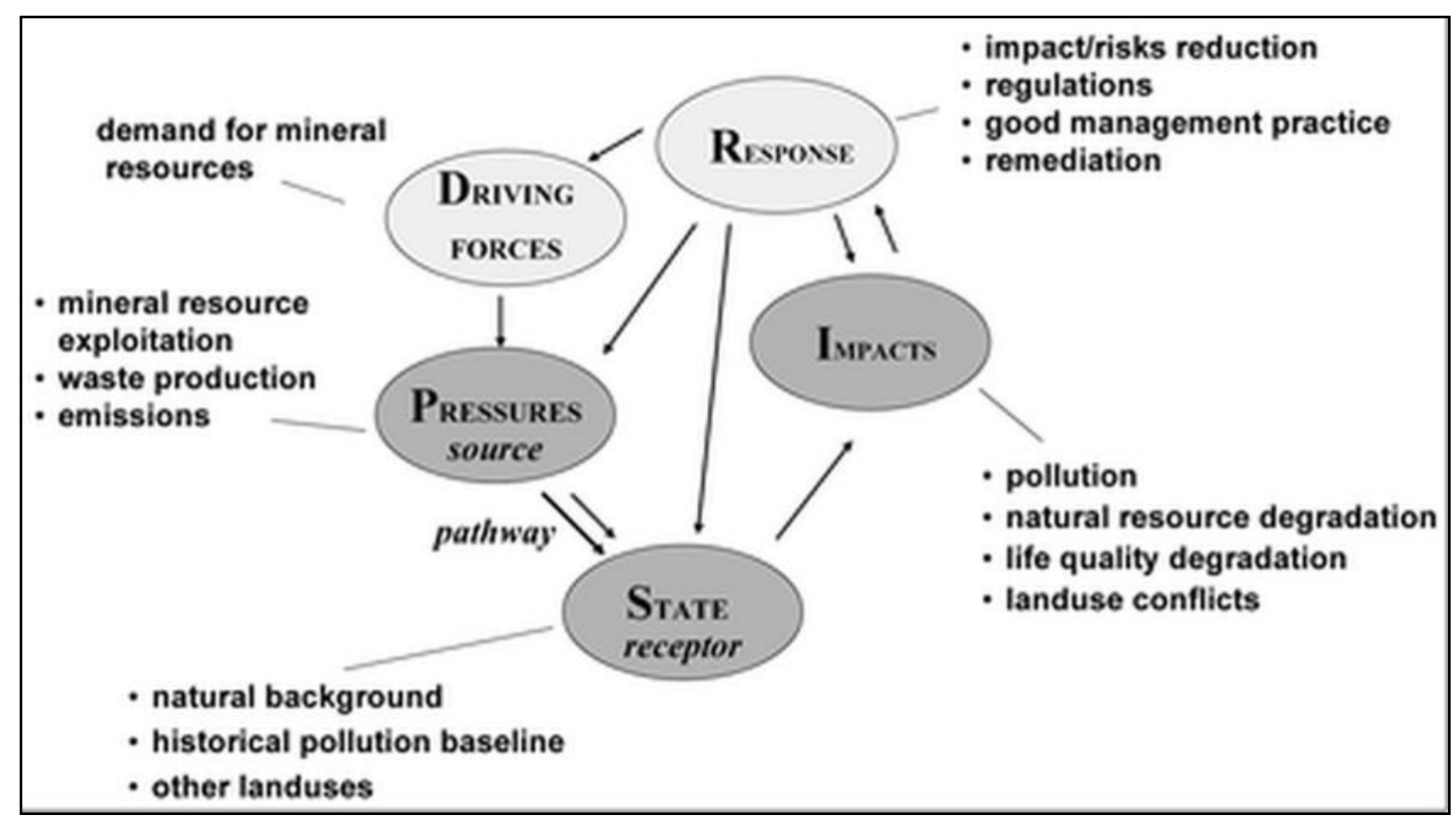

Figure 1. Schematic EEA DPSIR framework for mining. Light and dark shaded compartments are related to socio-economic and environmental systems, respectively (compare to Fig.2). The source-pathwayreceptor chain for contamination risk assessment is also shown.

The complex problem of mining contamination impacts requires methods that should be (1) holistic, i.e. address the problem in its integrated complexity in the total human ecosystem, and (2) direct decision support tools, i.e. environmental decisions can be directly based on their results., main approaches that meet these criteria are described and compared (Fig.2). Particular tools of sampling, sample analysis, modelling, prediction, treatment and remediation technologies are not detailed here. Indeed, the methods provide means to integrate these tools and they give a 'holistic' framework for their harmonised use for environmental assessment of mining.

Sinding (1999) considers environmental impact assessment, environmental management systems, environmental accounting, environmental audits and reports, and life cycle assessment as the most important methods for approaching direct scientifically-based decision support of the complex mining environmental problem. In this study only those methods are introduced in chapter 2 that meet both the decision support and the 'holistic' criteria as well. These are (1) landscape ecology (LE), (2) industrial ecology (IE), (3) landscape geochemistry (LG), (4) geoenvironmental models (GEMs), (5) environmental impact assessment (EIA), (6) environmental risk assessment (RA), (7) material flow analysis (MFA), and (8) life cycle assessment (LCA) (Fig.2). Environmental management systems (EMS), environmental accounting, environmental audit, environmental reports, technology assessment (TA), and other specific decision support and evaluation schemes such as benefit-cost analysis (BCA) and multi-criteria analysis (MCA) are methods for data gathering and evaluation to support and control decisions within the industry and thus these are not dealt with in the present study on environmental assessment of contamination at mine sites. 


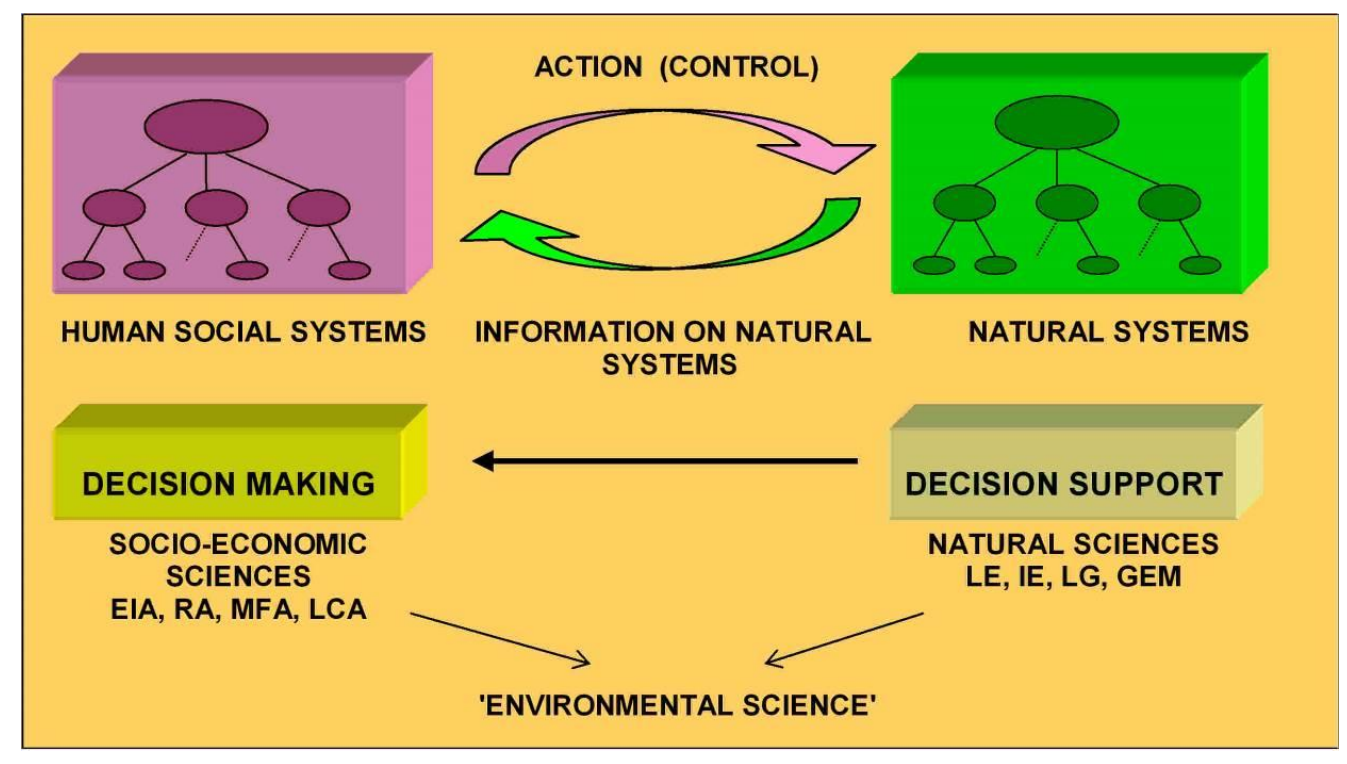

Figure 2. The environmental decision making process and the decision support role of sciences (after Jordan and Szucs 1997). Natural sciences deliver essential information on complex natural systems as input into decision making for the control of the environment within the human systems. Environmental decision support tools discussed in this paper are also shown: Landscape Ecology (LE), Industrial Ecology

(IE), Landscape Geochemistry (LG), Geo-Environmental Model (GEM), Environmental Impact Assessment (EIA), environmental Risk Assessment (RA), Material Flow Analysis (MFA), and Life Cycle Assessment (LCA).

The first objective of this study is the evaluation of the EU MWD Pre-selection Protocol (Stanley et al. 2011) by applying it to real-life cases and adopting it to country-specific conditions. The data derived for the implementation of the Protocol such as the distance to the nearest stream or the size of the contamination source mine waste site is compared to those resulted from the 'Pre-screening of problem areas' according to the European Environmental Agency (EEA) Preliminary Risk Assessment Model for Soil contamination in Europe (PRAMS) in order to assess the sensitivity of mine waste site risk assessment in response to various methods. Altogether 145 ore mine waste sites in Hungary were selected for scientific testing and evaluation using the EU MWD Pre-selection Protocol. Questions of the EU MWD Pre-selection Protocol are linked to a GIS system and key parameters such as the topographic slope and distance to the nearest surface and groundwater bodies, to settlements and the Natura 2000 protected areas were calculated and statistically evaluated in order to adjust the RA models to country-specific conditions in Hungary.

The second objective of this study is the heavy metal contamination risk assessment (RA) for a number of selected quarries in order to study the inert characteristics of the potentially generated mine wastes, in accordance with the EU MWD legislation. Altogether 30 waste sites (including both abandoned mines and active quarries) were selected for scientific testing using the Preselection Protocol. Ninety three field samples were collected from the waste sites including andesite, rhyolite, coal (lignite and black coals), peat, alginite, bauxite, clay and limestone mines. 
Laboratory analyses of the total toxic element content (aqua regia extraction), the mobile toxic element content (deionized water leaching) were carried out according to the Hungarian national standards (GKM Decree No. 14/2008. IV.3) concerning mining waste management. A detailed geochemical study together with spatial analysis using ArcGIS was performed to derive a geochemically sound contamination RA of the mine waste sites. Key parameters such as heavy metal content and distance to the nearest surface and ground water bodies, or to sensitive receptors such as settlements and protected areas, were calculated and statistically evaluated in order to calibrate the RA methods.

In the third objective of this study, the linkage between the water quality variables from streams near by the mining waste sites and the landscape metrics of 33 watersheds enclosing those mining sites. The water quality variables $\mathrm{Ni}, \mathrm{Mn}, \mathrm{Cr}, \mathrm{Zn}$ and conductivity that represent the total pollution of water in Hungary were investigated and analyzed. Several recent studies have shown the strongest statistical relationship between the landscape pattern and the water quality in case of the percentage cover of forests and the non-point source pollutions of water such as nitrate, nitrite contamination (e.g. Wu et al. 2012; Xiao and Ji 2007; Romic et al. 2007; Uuemaa et al. 2005; 2013). This is the reason for why, beside the landscape metric parameters, the percentage of the main land cover classes (such as artificial surfaces (CLC1), agricultural areas (CLC2) and forest and semi-natural areas (CLC3)) was investigated in the studied watersheds too. The following landscape indices; Total Number of Patches (NP), Core Area (CA), length of Total Edge (TE) Splitting Index (SPLIT), Division Index (DIVISION), Effective Mesh Size (MESH), Main Patch Size (MPS), Patch Size Standard (PSSD), Deviation Mean Patch Ratio (MPE), Mean Shape Index (MSI) Mean Perimeter Area Ratio (MPAR) and Mean Fractal Dimension Index (MFRACT), were calculated for each watershed based on regional scale 1:100,000 CORINE land cover database from years 2000 and 2006. The percentage area of the main CORINE land cover classes was also calculated, and its role on the water quality also has been investigated. The Vlate (vector-based landscape analysis tools extension) within ArcGIS $10^{\circledR}$ and the STATGRAPHICS $^{\circledR}$ software were used for spatial and statistical analyses. 


\section{Evaluation of the decision support methods for the Environmental Risk Assessment of contamination at Mining sites}

In order to evaluate some of the most important decision support methods that were developed and applied to mining contamination a thorough review has been published as a part of the $\mathrm{PhD}$ thesis (Jordan and Abdaal 2013) that compares the 'holistic' approaches including (1) landscape ecology (LE), (2) industrial ecology (IE), (3) landscape geochemistry (LG), (4) geoenvironmental models (GEM), (5) environmental impact assessment (EIA), (6) environmental risk assessment (RA), (7) material flow analysis (MFA), and (8) life cycle assessment (LCA).

\subsection{Landscape Ecology}

Landscape Ecology (LE) provides the most complex decision-support landscape modelling and mapping techniques available among environmental sciences. LE differs from ecology in that (1) unlike ecology, LE studies the interaction of environmental systems and socio-economic systems, and (2) it studies landscapes that are functional units of ecosystems plus the abiotic environment and human factors. The largest ecosystem is the total human ecosystem, which includes the biosphere and the human social systems (Naveh and Liebermann 1994). Processes are described by ecological and mathematical systems analysis methods to study matter, energy and information transport within and between abiotic and biotic natural and social systems. Landscape ecological maps are often produced with GIS technology (Haines-Young et al. 1993; Aspinall and Pearson 2000) and show stability and/or sensitivity of ecosystems, human pressures on landscapes (level of hemeroby) or the delineation of the homogenous landscape units (ecotops). Some of these maps show and delineate the main spatial and structural elements of the landscape pattern such as patches matrix, edges (ecotones) ecological barriers, and corridors (Forman and Godron 1986; Forman 1995). In LE functioning of landscapes such as urban, agricultural or industrial areas are described by reservoir, flux rates, turn-over analysis, feedback loops, etc. (Naveh 2000). Such holistic LE together with other mission-driven trans-disciplinary environmental sciences could serve as a catalyst for the urgently needed post-industrial symbiosis between nature and human society. The application of LE knowledge, the principles of planning landscapes in general, and planning ecological network in particular meet the requirements of sustainable land use developments, ecological conservation, aesthetic values, recreation, economic and environmental considerations (Leitão and Ahern 2002; Uy and Nakagoshi 2008).

Many authors underlying that there is a very strong connection between the spatial pattern of the landscapes and as indicators of its main characteristics (ecological sensitivity and ecological conditions, level of hemeroby etc.). It is a so called "pattern and process" paradigm (Romic et al. 2007; Uuemaa et al. 2005), which has been showed in many mainly ecological case studies (e.g. Uuemaa et al. 2009; 2013). Although most of the authors are focusing on the spatial landscape analyses mainly from ecological point of view, it is not questionable, that the spatial characteristics of the landscapes have also very strong influence on its geochemical characteristics such as the surface and subsurface runoff pathways of the non-point pollutions.

The authors have found different level of correlations between the water quality datas and the 
class, landscape level ${ }^{1}$ and landscape indexes, which describe the spatial characteristics of the landscapes (Xiao and Ji 2007; Wu et al. 2012). Some authors underlying that the percentage of different land cover classes (for instance the forests) has very strong impacts on the geochemical transport processes (Xia et al. 2012).

Since environmental regulations and management acts upon these elements and are influenced by them, approaches based on LE are particularly efficient for decision support regarding the impact assessment of mining contamination and the design of remediation and monitoring activities.

An application of LE analyses, and mapping for the mine environmental impact assessment is provided by Jordan and Szucs $(2002 ; 2011)$ who used LE analyses in combination with landscape geochemistry, geochemical modelling and GIS methods to study mining contamination impact in mining catchments. Based on this work, Jordan et al. (1997) used landscape ecological methods to characterise AMD impacted natural wetlands and to conclude on wetland stability with respect to sulphide-bound and organic-bound heavy metals in the organic-rich reducing sediments. Spatial variation and relative position of geochemical based landscape units which has different geochemical properties, such as reducing wetlands, oxidising streams, eroding hill slopes and accumulative lakes were studied for their spatial connectivity by surface transport processes (see Fig.3). While detailed geochemical modelling suggested immobility of AMD heavy metals in the studied organic sediments of the wetland environment, the whole wetland landscape as an ecosystem and thus the accumulated sedimentary metals proved to be unstable on the long-term due to sensitivity to climatic and hydrologic variations of the whole wetland (Jordan et al. 1997).

In order to face the challenge of landscape ecological analyses to be integrative with decision making processes, environmental modelling and GIS (Aspinall and Pearson 2000), transdisciplinary discipline in the sense of Naveh (2000), we need more 'assessment science', i.e. the development of conceptual frameworks (e.g. Pauleit and Duhme 2001; Larondelle and Haase 2012), 'indicator communication' (Pykh et al. 1999), but also more scientifically educated planners and vice versa in the triangle of social perception, valid knowledge and experience for landscape management (Lenz and Peters 2006).

\subsection{Landscape Geochemistry}

While landscape ecology has developed complex landscape modelling and spatial analysis methods in an ecological context, Landscape Geochemistry (LG) has the complex toolbox for modelling and mapping geochemical systems as a relevant element of the whole landscape system (Fortescue 1980; Jordan and Szucs 2002; 2011). Ostaszewska (2010) described the theoretical foundations of the geochemical based landscape studies and analyses its methodology. Landscape geochemistry focus is on mainly the material flow analysis and abiotic processes (Fortescue 1992). The two essential steps are (1) the identification of the geochemical character of an area (such as soil and groundwater $\mathrm{pH}$, Eh and adsorption properties), and (2) the analysis

\footnotetext{
${ }^{1}$ The landscape indexes can be calculated in three levels: patch, class, or landscape level. We can calculate the class level with the average of the patch level indexes for each land cover classes (forest, arable land etc.). The landscape level index means the average of each patch level indexes for the whole study area (landscape unit, or watershed etc.)
} 
of the spatial topological relations of these geochemically homogeneous areas (geochemical landscape units) by geochemical transport and reaction processes (Jordan and Szucs 2011; Kauppila et al. 2011; Goldhamber et al. 2009). The geochemical character of an area is defined by the physico-chemical properties of landscape components (such as barerock, soil, ground and surface water, biosphere and atmosphere) and their spatial relationship relative to matter transport processes. Soil characteristics such as the criterion for determining the lateral boundaries of the, geochemical landscape units which are areas homogeneous with respect to matter transport pattern (Glazovskaya 1963). Elementary homogenous geochemical units of the landscape extend vertically from the top of unweathered rock to the uppermost level of vegetation cover.

In order to simplify mapping of soil types and soil properties, soil and land cover types are clustered into three groups on the basis of the transport pattern of chemical elements. Where the water table is always below the daylight surface, an eluvial geochemical units of landscape characterised by downward salt movement in well-drained soils is formed (Fig.3). Eluvial geochemical units of landscape are found in more elevated topography where ground water table lies deep below the surface and exerts no influence on vegetation or soil. Chemical composition of sediments, soils and plants (plant ash) depends mainly on the chemical composition of underlying rocks. In eluvial geochemical units of landscape, the migration of substances takes place mainly in the oxidising environments. If the water table and the topographic surface coincide a super-aqual geochemical units of landscape (for instance: bog, marsh or flood plain) appears, where the dominant pattern of salt movement is upward and horizontal (Fig.3). Superaqual geochemical units of landscape form in low-lying topography where ground water lies near the surface so that it can rise by capillarity to the root zone. Such geochemical units of landscape are characterised by accession of chemical elements from the adjoining landscapes. A lake or stream environment, where the water table is above the land surface, is called an aqual geochemical unit of landscape characterised by circular salt movement. The chemistry of the Aqual geochemical unit of landscape is strongly influenced by the geochemical characteristics of the upstream geochemical units of landscape and by the underlying rocks in groundwater discharge areas. Classification of geochemical units of landscape has been extended with the consideration of horizontal material flow characteristics in a way analogous to the soil catena concept of soil science (Glazovskaya 1963; Gerrard 1992).

Geochemical landscape classes can be extended with the 'trans-'prefix emphasising that the given geochemical units of landscape is characterised by simultaneous accession and withdrawal or by simple through flow of substances. For example, eluvial landscapes are subdivided as eluvial, trans-eluvial and eluvial-accumulative landscapes on hill tops where erosion and downward movement of elements dominates, on hill slopes where down-gradient throughflow dominates and in valleys which are characterised by deposition, respectively (Glazovskaya 1963, Fig.3). On the basis of transport intensities in surface waters, active stream segments are classified as trans-aqual landscapes while lakes and stagnant waters are aqual landscapes (Fig.3). Similarly, super-aqual and trans-super aqual landscapes are distinguished. 


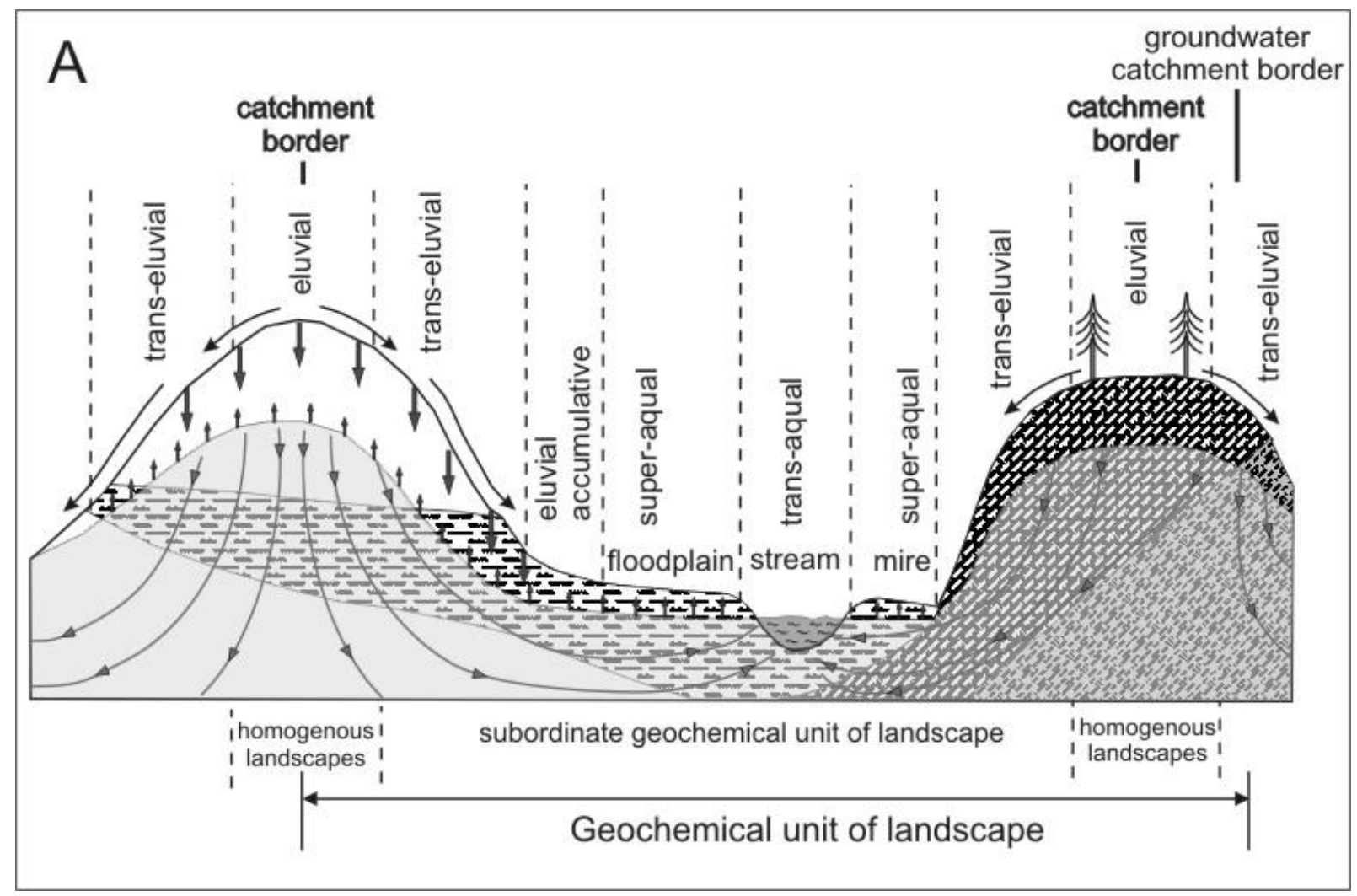

Figure 3. Topology of geochemical landscapes (after Glazovskaya 1963). Dimmed area: groundwater saturated zone. Sub-vertical arrows: surface run-off, infiltration and groundwater flow. Geochemical landscape is a collection of landscapes connected by matter transport and flow. See text for details.

Spatial pattern (topological relations) of these geochemically homogeneous areas by geochemical transport and reaction processes are determined by transport modelling (Jordan et al. 1997). Those elementary geochemical units of landscape that are geochemically related by transport processes (areas at recharge and discharge regions of the same groundwater system, for example) form a geochemical units of landscape (Fig.3). By the superimposition of homogeneous elementary geochemical units and transport models, geochemical barriers and corridors can be easily predicted and described, for example, fundamental in mine contamination assessment (Jordan and Szucs 2011) (Fig.3). On this basis, LG studies geochemically 'sub-ordinate' landscape units as well where the geochemistry of the area such as a stream segment is influenced by other geochemically homogenous units of landscape such as an area with mineralisation or a mine upslope.

LG study includes the analysis of liberation, transport and deposition of elements and compounds along the source-pathway-receptor chain (Fig.4) by the subsequent investigation of (1) landscape structure (especially the land cover pattern) described in terms of geochemical abundances of elements and compounds and geochemical gradients, (2) geochemical functions of landscapes has been described in terms of element migration (chemical reactions), geochemical flows (transport processes), landscape geochemical barriers and landscape classification, and (3) 
geochemical based landscape evolution described using historical geochemistry (Jordan et al. 1997). For example, Bradshow (1975) used LG to study and map secondary accumulation of heavy metals in sediments deposited down-slope from mineralisations. He used LG to distinguish between natural background and mine pollution. Szucs et al. (2002) used LG and GIS technology for the spatial analysis of heavy metal distribution in stream water and sediments impacted by metal mining.

Since LG is a geochemical modelling tool and essentially a spatial analysis method, it enables contamination fate prediction along the source-pathway-receptor line (Fig.4). Application of LG to regional scales (Smith et al. 2005) and combination with quantitative transport models (van Rompaey et al. 2005) are intensively researched areas. Spatial geochemical monitoring combined with bio-geochemical criteria of threshold concentrations seems to be a helpful tool for decision making on operation and remediation of the mining sites to provide a long-term ecologically sustainable development (Korobova 2010). Moreover, preparation of a systematic multi-media (surface and groundwater, soil and stream sediment) multi-determinand global geochemical database would make a major contribution to improving environmental quality worldwide. Such a programme could involve all countries with the communication of methods, data and information (Plant et al. 2001).
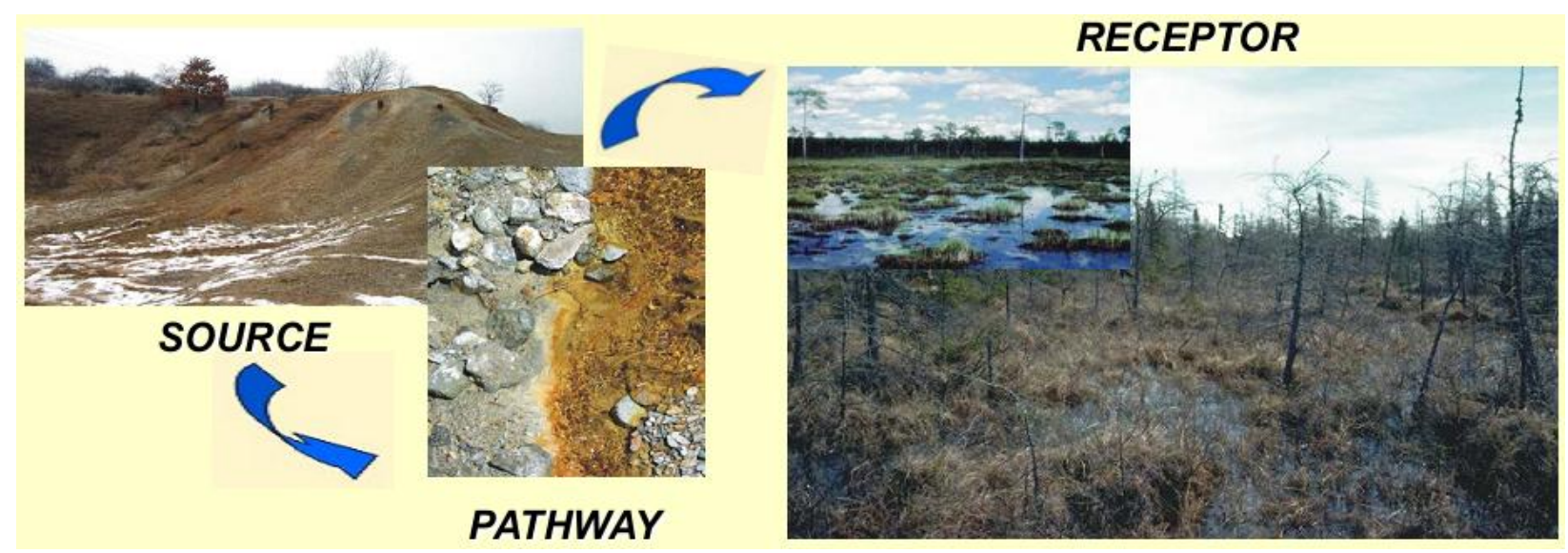

Figure 4. A simple scheme for the source-pathway-receptor chain.

\subsection{Industrial Ecology}

Industrial ecosystem is defined as the system including all the components that are ensuring the ecological sustainability of the industrial system (White 1994; Fanga et al. 2007; Despeisse et al. 2012). Industrial Ecology (IE) limits its scope to the study of industrial activities in relation to ecosystem sustainability. IE is defined as the study of the flows of material and energy in the industrial and consumer activities, of the effects of these flows on the environment, and of the influences of economic, political, regulatory and social factors on the flow, use and transformation of resources (Erkman and Ramaswamy 2001; Korhonen et al. 2004; Fanga et al. 
2007; Okkonen 2008). IE is a well-documented approach with numerous examples of application at inter-enterprise level (Ayres and Ayres 2002; Ehrenfeld and Gertler 1997; Graedel and Howard-Grenville 2005). Its key feature lies in the integration of various components of a system to reduce its net resource input as well as pollutant and waste outputs. Shmelev (2012) introduced the conceptual foundations of industrial ecology, an interdisciplinary field that draws parallels between the natural life processes of organisms, their use of energy and resources and the interactions between them and the world of enterprises that also interact, use energy and resources and differ from natural entities in peculiar ways. IE aims to inform decision-making about the environmental impacts of industrial production processes by tracking and analyzing resource use and flows of industrial products, consumer products, and wastes. Quantifying the patterns of use of materials and energy in different societies is one area of research in IE. Inputoutput models, often incorporating both MFA and LCA data, analyze the effects on the environment of alternative consumption and production decisions. IE makes use of this array of top-down and bottom-up approaches, all of which are grounded in its origins in the ecology of the industrial system (Duchin and Levine 2008).

IE seeks to optimise the total industrial material cycle from raw material to finished products to ultimate disposal of wastes. IE has two underlying principles (Feoli 2002). First, the recognition of the similarity of industrial systems and ecosystems. This enables the study of industrial development towards 'self-sustainability', control and regulations. Second, analysis of the 'ecological footprint', i.e. the area and resources necessary to support the industrial system in its complete functionality. An industrial system is more 'eco-efficient' if its ecological footprint is lower than those of others. It follows that the sustainability of a given industrial system by a given area is achieved only if the rate of depletion of renewable resources of the area utilized by the industrial system is lower than or equal to the rate of their renovation. Feoli (2002) investigated the use of IE for mining and concluded that this method suggests a theoretical framework that foresees a set of actions to avoid the accumulation and dispersal of waste in the environment and limit pollutant release from industrial plants. He suggested ways for the use of IE for bio-remediation of mine waste sites and abandoned mine sites. He concluded that similar to ecological life cycle studies of ecosystems and materials turnover, life cycle assessment of processed materials (products) and of the industrial system itself is a fundamental tool to assist mine impact assessment. IE may offer options, which are not only effective for protecting the environment but also for optimizing the use of scarce resources. Thus, IE is especially relevant in the context of developing countries, where growing populations with increasing economic aspirations should make the best use of limited resources (Erkman and Ramaswamy 2001).

\subsection{Geo-Environmental Model}

The United States Geological Survey (USGS) has developed the Geo-environmental Model (GEM) tool in order to analyse and predict environmental impacts of mineral deposits and extraction (Wanty et al. 2002). The principle is that enough knowledge on the economic characterisation of mineral deposit has accumulated including geological, mineralogical, 
geochemical information that enables not only the economic but the environmental classification of deposit types. For the geo-environmental characterisation of deposits the most important parameters are deposit and host-rock geology and mineralogy, alteration styles and trace-element chemistry (Wanty et al. 2002). These parameters are the basis of the well-established economic classification of deposits, as well (Cox and Singer 1986).

Recognising a deposit as belonging to a certain deposit class can predict the physico-chemical and spatial characteristics of the deposit, including natural background, acid generating and neutralising potential, hydrochemistry, composition of waste rock and tailings, etc. This is the source or hazard characterisation by geo-environmental models. The various deposit types can be ranked based on nature and extent of alteration, mineral assemblage, metals present in the minerals, presence of acid-generating minerals like pyrite and on the natural acid-consuming capacity of the host rock. In this ranking, for example, deposits rich in pyrite and metals but poor in acid-consuming minerals are ranked as most likely to cause environmental problems, while pyrite-poor deposits being the least dangerous. Often, a unique suite of element concentrations and other physical and chemical properties of water and rocks that come into contact with specific types of mineralised rock in a given region comprise the 'environmental signature' of that rock package.

Among the environmental parameters the most important are, geomorphological characteristics, hydrology, mining and milling methods, climate, latitude and altitude (Wanty et al. 2002). The last three parameters may be the primary controlling factors of the weathering of the ore deposit. These parameters define the 'ecoregion' of the deposit, i.e. the geomorphologic (physiographic) unit it belongs to. The geologic framework, climate, latitude and altitude determine the weathering behaviour of the rocks and mine derived wastes, and their influence on water quality and on soil. In this way, potential impacts of mining can be predicted by geo-environmental models. This is the impact characterisation by geo-environmental models. The purpose of a geoenvironmental model is (Wanty et al. 2002):

- to understand environmental behaviour of mineralised areas, and to anticipate the chemical and mechanical weathering behaviour of rocks within and around a given mineral deposit in a given climatic regime,

- $\quad$ to identify areas with high natural background,

- $\quad$ to determine baseline conditions prior to mining, and

- $\quad$ to anticipate mitigation or remediation requirements for future mines, and mine closing.

A well-documented example for GEM application is provided by the joint USGS-MAFI (United States Geological Survey - Geological Institute of Hungary) project results for the Recsk-Lahoca hydrothermal and Gyongyosoroszi polymetallic deposits in the Matra Mts. in Hungary (Odor and McCammon 1999). The Lahoca deposit with quartz-alunite and advanced-argillic alteration was ranked as most likely to cause pollution problems in the Matra Mts. because intensely acidic 
mineralising/altering fluids consumed whatever natural acid-neutralisation capacity the host rock may have had prior to mineralisation (Odor and McCammon 1999). These waters are characterised by extremely low $\mathrm{pH}(<3)$ and high metal concentrations. Geochemical studies by Odor et al. (1998) and Jordan et al. (2003) on the environmental signatures of mineral deposits in the Matra Mts. confirmed the predictions of geo-environmental models.

\subsection{Material Flow Analysis}

Material Flow Analysis (MFA) (or Substance Flow Analysis, SFA) limits its scope to the study of industrial activities in relation to matter transport and transition processes between socioeconomic systems and the environment. Bouman et al. (2000) made a first step in bridging the gap between the various types of analysis of material flows in the economy, by discussing the main differences and similarities of three often employed model types: SFA, LCA (Fig.5) and partial economic equilibrium analysis. An extensive literature is devoted in particular to MFA, the collection of data describing the flows of specific materials from sources to sinks within some portion of the global industrial system (Duchin and Levine 2008).

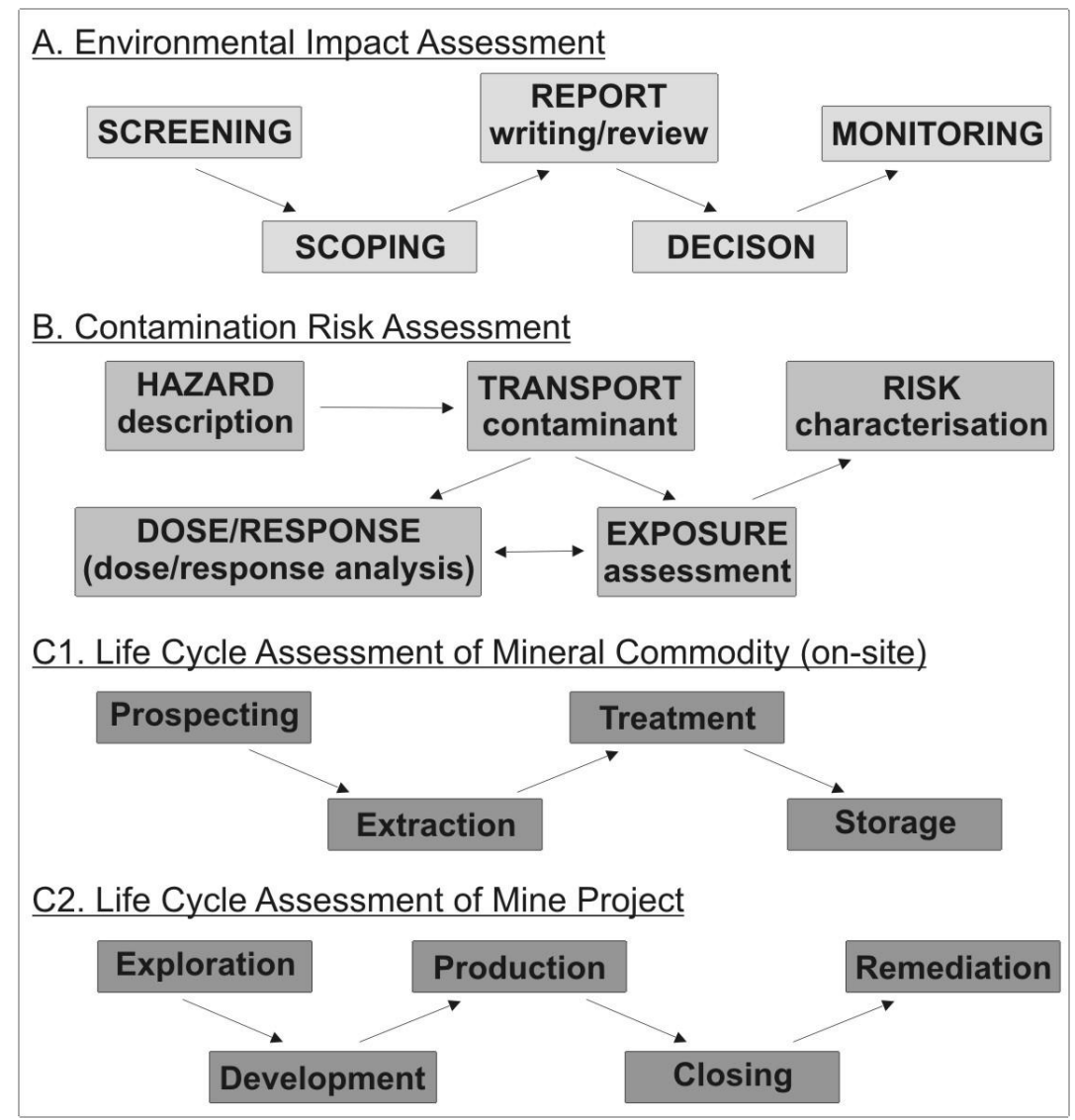

Figure 5. The major steps in A. Environmental Impact Assessment, B. Contamination Risk Assessment, and C. Life Cycle Assessment procedures. C1: Product life cycle assessment. C2: Asset life cycle assessment. See text for details.

The most wide-spread methodology for the assessment of material flows is economy-wide material flow analysis (EW-MFA), which stands as a basis for the compilation of a set of material 
flow indicators and their relations to other socio-economic variables and their possible application in policies (Kovanda et al. 2009). Physical input-output analysis and materials balance methods form a set of related tools for analysis in which flows and accumulations of a substance are studied both within the economic and the environmental systems. Substances cover elements, compounds, group of similar compounds (such as nitrates), and mixture of compounds (such as those contained in mining waste). The MFA is essentially a book-keeping method, recording the inputs and outputs of a substance to and from processes in economic and environmental systems (e.g. Mukherjee et al. 2008; Sundseth et al. 2012; Ziemanna et al. 2012). Given the law of mass conservation, MFA can detect leaks and accumulations using ratios of different inflows and outflows. Thus, MFA covers the life cycle of a substance in a given geographic unit (e.g. Scasny et al. 2003; Browne et al. 2011). A simple scheme for material flow analysis with special respect to mine wastes is given in Fig. 6.

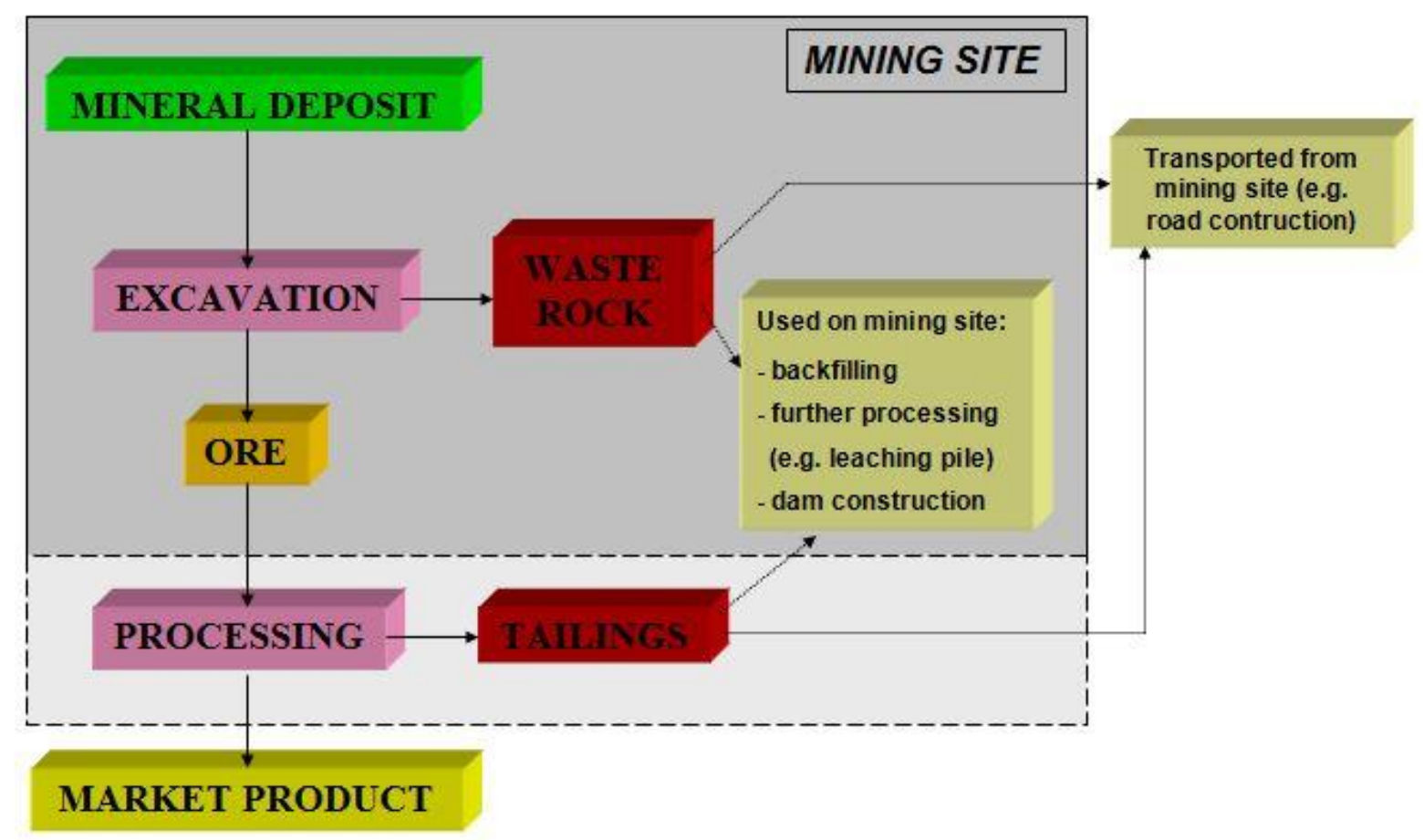

Figure 6. Schematic representation of material flow and mine waste streams in the extractive industries for Material Flow Analysis. Dashed line indicates that processing can take place inside or outside of the excavation site (e.g. for bauxite mining) as well. Dark shading indicates mining waste (waste rock and tailings).

The MFA has proved to be a useful tool on providing quantitative information of the flow of substances through an economic to an environmental system (Li-Teh et al. 2007). Based upon the supply-and-demand theory of MFA, researchers have successfully conducted an overview of the use of materials in many industries, the construction industry being one of these. Therefore, this study established a set of analytical processes by way of MFA for identifying the pollution source of Cd in soil in Taiwan (Li-Teh et al. 2007). Reisinger et al. (2009) discussed the support for 
environmental policy decisions that can be provided by substance flow analysis (SFA). While, flows and stocks of lead $(\mathrm{Pb})$, cadmium $(\mathrm{Cd})$ and mercury $(\mathrm{Hg})$ are investigated through the Austrian economy and environment. The material flow analysis and decomposition method are used to calculate the direct material input (DMI) of 14 typical mining cities in Northeast China in 1995-2004 and to analyze the dematerialization and its driving factors in the different types of mining cities oriented by coal, petroleum, metallurgy and multi-resources (Qiu et al. 2009).

A detailed discussion of MFA in the broader context of global biogechemical cycles is given by Butcher et al. (1992) and Schlesinger (1991) where coupled reservoirs, turnover- and residence and response time, coupled cycles, steady state, and other important aspects of MFA are discussed. Metals are often liberated by mining together with sulphur by the oxidation of reduced metal-sulphide minerals: thus coupling of global S cycle and metal cycles for impact assessment of mining is important (Jordan 2004a; Hu et al. 2008). For example, sulphides are oxidised to sulphuric acid that keeps most of the metals in mobile form in AMD and terrestrial aquatic environment. Along the industrial processing pathway of sulphide bearing mineral resources (such as sulphide ore smelting, coal and petroleum combustion) sulphur oxides are emitted to the atmosphere that turn into $\mathrm{SO}_{4}$ and cause acid rain. Acid rain in turn, increases chemical weathering of metal-bearing rocks and causes general acidification of terrestrial environments that leads to mobilisation of metals from sediments and soils into solutions. This has the effect of increasing bioavailability of metals in toxic concentrations, on one hand, or the depletion of metals in the substrate leading to deficiencies of biota, on the other hand. A geochemical mapping study in Sweden (Frank 1986; Selinus 1988) has shown that acidification mobilizes cadmium and results in a regional increase in cadmium in plants and moose in areas most affected by acid rain. Although global material cycles do not have direct application at the site scale, legislation on mine site emissions should be guided by the observation of total global impacts (Kyoto Protocol 1992). Such global material cycle schemes can be also used for the identification of major compartments, geochemical reactions and material flow directions at the site scale (e.g. Jordan et al. 1997).

\subsection{Life Cycle Assessment}

Product life cycle assessment (LCA) focuses on the product itself rather than the production site or process (UNEP 1996). LCA involves the analysis of all impacts created by a product 'from cradle to grave' (e.g. Field et al. 1993; Udo de Haes et al. 2000; Baumann and Tillman 2004; Nowack et al. 2012). LCA thus covers the life cycle of a product without reference to any geographical unit. LCA has mainly been applied to products. However, recent literature suggests that it can assist in identifying more sustainable options in process selection, design and optimization (Azapagic 1999; Cleary 2010; Liu et al. 2011). Rebitzer et al. (2004) introduced the LCA framework and procedure, outlines how to define and model a product's life cycle, and provides an overview of available methods and tools for tabulating and compiling associated emissions and resource consumption data in a life cycle inventory (LCI). It also discussed the application of LCA in industry and policy making. LCA may provide quantitative or qualitative 
results (French and Geldermann 2005). LCA is an iterative process and involves stages of (1) scope definition, (2) inventory analysis (this is the main part including process flow chart construction, data collection, defining system boundaries and data processing), (3) impact assessment (including classification, characterisation and valuation), and (4) improvement assessment (Fig.5). LCA enables the comparison of the impacts of similar products, or an estimation of the total impact of a given product (Welford 1996). Site-specific LCA is recommended by Schaltegger (1997).

According to Sinding (1999) 'traditional' LCA, i.e. dealing with a specific product seems unsuitable for use in a mining context because mining is only the first stage of product life cycle and thus it is only a part of the complete cycles. Basson and Petrie (2007) presented an approach for the integrated consideration of both technical and valuation uncertainties during decision making supported by environmental performance information based on LCA. The results of the case study decision suggest that stakeholder involvement in preference modelling is important, and that the 'encoding' of value judgments and preferences into LCA environmental performance information is to be avoided. LCA is becoming an increasingly widespread tool in support systems for environmental decision-making regarding the cleanup of contaminated sites (Lemming et al. 2010).

Asset life cycle analysis of mining includes exploration (discovering natural resources), appraisal (assessing natural resources), development (design and construction of production facilities), production, closure (decommissioning of production and waste facilities) and after-care (sustainable remediation) (Fig.5). The mining/quarrying industry is a sector of industry where there are very few LCA tools, and where the role of LCA has been poorly investigated. A key issue is the integration of three inter-dependent life cycles: Project, Asset and Product. A common methodology was implemented within the Sustainable Aggregates Resource Management (SARMa) Project in order to boost adoption of LCA in the aggregate industry in South Eastern Europe (Blengini et al. 2012). Today, mining waste management is an integrated part of the life cycle of a mine. The 'cradle to grave' approach is generally applied to the planning of new mine sites. This means that various closure options are considered and evaluated in depth even before the mining activity starts, also called 'design for closure'. In early phases of asset life cycle, impacts can only be roughly estimated and decisions involve high uncertainty, while in latter phases more accurate estimates can be made (Ritsema 2002). Ritsema (2002) concludes that there is a need for a systematic and integrated approach in assessing of impacts throughout the asset life cycle of mining operations. Despite intensive research towards the development of a comprehensive LCA methodology, there has not been a development of holistic life cycle assessment system for the extractive industries, accounting for all stages of the mining activities, from exploration and development of a mineral deposit, to mining, processing of the ore, production of the concentrate, waste disposal, remediation, environmental monitoring, decommissioning and long-term control and monitoring of the impacts. 
The US EPA's National Risk Management Research Laboratory developed a municipal solid waste decision support tool (MSW-DST). The environmental methodology is based on the use of LCA and the cost methodology is based on the use of full-cost accounting. Life cycle inventory (LCI) environmental impacts and costs are calculated from the point of collection, handling, transport, treatment, and disposal (Thorneloe et al. 2007). They demonstrated how the MSWDST can be used to identify and balance multiple criteria (costs and environmental impacts) when evaluating options for materials and waste management.

\subsection{Environmental Impact Assessment}

Environmental Impact Assessment (EIA) identifies environmental effects of one anthropogenic activity, usually at one specific location, and at one point in time. EIA is used as an aid to public decision making on larger projects, both public and private. EIA is mainly a project management tool in the sense that it allows the decision maker to approve, redesign or reject a project. Although the environmental impact assessment based on the recent environmental databases, it is just estimation for the future environmental impacts of the planned anthropogenic and economic activity. EIA consists of the screening, scoping (Beanlands 1988), report writing (Wathern 1988), report review, decision making and monitoring steps, according to the EU EIA Directive (Directive 85/337/EEC; Directive 2001/42/EC; Hungarian Directive 314/2005. (XII. 25) Korm. Rendelet; Wood, 1995,) (Fig.5). The Directive requires the description of likely significant effects of the project including any direct (Bisset 1984), indirect (Wathern 1984a), secondary, cumulative, short, medium and long term, permanent and temporary, positive and negative effects, for the 'extractive industry' project. All stages of the whole mine project life cycle should be studied for expected impacts which is the subject of asset life cycle assessment as described below.

Pre-project baseline studies describing the state of the environment are important to provide a basis for monitoring the impacts of each mining stage (e.g. Horvath and Gruiz 1996; Panagopoulos et al. 2009; González et al. 2011). Impact analysis, modelling and prediction results reported in the environmental impact statement (EIS) should describe impact mitigation alternatives for the mining project, as well (e.g. Hansen et al. 2008). Separate impact studies are often carried out for human health impact assessment (Gild 1984; Peplow and Edmonds 2005; Rapant et al. 2006; Samadder 2011), social impact assessment (SIA) and ecological impact assessment (Wathern 1984b; Gzyl 1990; Zobrist et al. 2009). Norton (1984) suggests the use of system analysis methods for ecological impact assessment, similar in principle to the above described LE, IE, LG and GEM methods. Mitigation of mining impacts can mean avoidance (using an alternative action), prevention, reduction (lessening the severity of an impact) or remedy (enhancement or compensation). Mitigation measures themselves can have impacts that also have to be identified. EIA 'monitoring' interests both impacts and implementation of a mining project in accordance with the required environmental measures. 
Clear difference has to be made between the magnitude and the significance of impacts. Various weighting and ranking systems have been proposed for ranking impact magnitude and significance. The most commonly used methods of ranking apply (1) checklist of potential impacts, (2) the Leopold matrix listing actions and environmental factors, and (3) networks that can identify indirect impacts as well (Bisset 1980; Atkins 1984; Wathern 1988). Weaver and Caldwell (1999) discussed in detail the application of these methods for EIA of mining projects and concluded that mining EIA has to consider (1) site-specific features, (2) the whole mining life cycle under the principle of 'design for closure', (3) differences between mining and processing methods (such as underground vs. surface mining, cyanide leaching, etc.), and their specific impacts, (4) thorough baseline surveys, (5) alternatives for methods and management practices (alternatives are not valid for location in case of mining and mine waste management), (6) special spatial and temporal scales of mining, and (7) residual impacts for impact mitigation. In addition, mining waste and management facilities may require separate EIA as described by Eduljee (1999).

Alternative approaches, cumulative and synergic impacts, ancillary impacts, regional and global impacts and impacts that are not linked with the planning but management practices may all be better assessed initially at policy, plan or programme level, rather than at the project level (Wood 1995). This is the subject of Strategic Environmental Assessment (SEA) (Directive 2001/42/EC) that is primarily used for sectoral activities such as the extractive industries as a whole. Also, environmental assessment of land use plans can use SEA to study arrangements of land use units, such as mining and agriculture, and to study some significant synergistic and cumulative impacts that cannot be satisfactorily considered in sectoral or project EIA (Wood 1995). It is important to mention that the SEA is more flexible than the EIA, and while the EIA aim to decide that the planned human (anthropogenic) activity is acceptable or not for the environmental point of view, the SEA help the decision making process. SEA is an important tool for the landscape planners to find the more environmental friendly, sustainable way of the economic development. De Jongh (1988) studied uncertainty in EIA and concluded that one of the major problems is that EIA is mainly concerned with expected events, while the problems associated with projects are likely to come from unexpected or low-probability events, such as mine tailings dam accidents. In this context, the scoping process, for example, is essentially a means of reducing uncertainty concerning values. He suggests the application of rigorous decision analysis methods and statistical characterisation in EIA steps. This is in fact the subject of risk assessment.

\subsection{Risk Assessment}

According to Smith (1996), hazard is defined as a potential threat to humans and their welfare arising from a dangerous substance that may cause loss of life injury, property damage and other community losses or damage. While risk is defined as the combination of the probability of hazardous event and integrative consequences. Risk assessment (RA), defined in its broadest sense, deals with the probability of any adverse effects. Various types of risk to be considered at the mine project life cycle include regulatory risk, engineering risk, facility risk, financial risk, 
human health risk and ecological risk (SENES 2000). Risks posed by regular or accidental contamination emissions to human beings (human health risk assessment, HHRA) or to ecosystems (ecological risk assessment, ERA) are studied by mine RA. While human risk assessment studies the probability of impact on a single organism (U.S. EPA 1989), ecological risk assessment studies the impact on multiple organisms (U.S. EPA 1998). A difficulty in ERA is the choice of receptors such as fish species in stream water that are indicators of total risk to the ecosystem.

Although risk assessment is not directly related to one economic activity, RAs are concerned with the risk involved at a specific site, at a specific time, and due to specific causes. Contamination risk is the combined effect of the probability of contamination and the significance of toxic impacts. This is studied through the pathway from (1) hazard description, through (2) dose/response (toxicity) analysis, (3) contaminant transport, (4) exposure assessment, to (5) risk characterization, and (6) risk management (van Leuwen and Hermens 1996; U.S. EPA, 2007) (Fig.5). SENES (2000) gives an in-depth overview of risk assessment for AMD. The study concludes that RA of AMD is not different from RA used for any other waste. The study argues that for efficient AMD treatment, practice should move from pure RA to complex risk management. RA is not designed to study risks of indirect impacts of pollution. Risk scoring systems specifically developed for mine sites and contaminated lands are provided by, for example, Pioneer Technical Services (1994) (the AIMSS method) and Quercia et al. (2004) (the PRAMS method) for the U.S.A. and EU applications, respectively. For example in the frame of ERA, acidification of waters can have direct toxic effect on aquatic biota. However, acidification can lead to the secondary release of heavy metals from sediments thus becoming available for human metal toxicity. Also, hazard of AMD release might be reduced by remediation of waste dumps, for example, but secondary sources of metals remain in lands around the site that were polluted during active mining (U.S. EPA 2002). This requires a separate RA of contaminated sites (CARACAS 1999).

At the exposure assessment part of RA, temporal aspects and stability are also important. While heavy metals in AMD can be efficiently retained in nearby organic-rich wetland sediments for example, climatic change or anthropogenic activity can lead to a drop in groundwater levels that in turn leads to erosion and oxidation of reduced sediments thus exposing metals to human intake (e.g. Jordan et al. 1997). Pre-mining natural pollution (source from the geochemical background) can already have local or regional adverse effects on human health for example. Effects of mining can be measured only relative to existing impacts. This makes the study of differences between natural and mine-induced pollution pathways essential both in EIA baseline studies and risk assessment for mining.

Both EIA and RA are concerned with the likely consequences of environmental change. According to Andrews (1988), EIA and RA are complementary to each other. Unlike RA, EIA focuses on the environmental fate of contaminants, rather than the effects on health and 
ecosystems. Integration of quantitative methods of RA into the broad framework of EIA might be a way of further improvement to support environmental planning and assessment for mining.

\subsubsection{Risk Assessment Methods for Mining: a State-of-the-Art Review}

Risk assessment is required by EU Mine Waste Directive (Directive 2006/21/EC) for the 25 Member States by end of 2012. Due to the outstanding importance of RA for mining, methods are reviewed briefly below.

The Hazard Ranking System (HRS) is a simple scoring system US EPA uses to evaluate relative threats to public health and the environment posed by threatened releases of hazardous substances (US EPA 1992). Hazardous waste sites scoring at least 28.5 are eligible for placement on the National Priorities List (NPL), which designates those sites representing the highest priority for further assessment.

The Abandoned and Inactive Mines Scoring System (AIMSS) (Pioneer Technical Services 1994) is based on the Comprehensive Environmental Response, Compensation, and Liability Act (CERCLA) - HRS (US EPA 1991; 1992) with significant modifications employed to fit mining scenarios. This model provides a numeric score for each site analysed, enabling relative ranking of the sites, with no absolute measure of risk implied. Montana's AIMSS is a fully developed and implemented prioritization-pre-screening methodology which has allowed the state to establish a ranked list of $90-95 \%$ of the worst mines in the Montana State based on a previously developed inventory of 6,000 abandoned mine sites and extensive site characterization data. 273 sites were ranked in 1993 plus 58 sites were processed in 1994 and 50 sites eliminated due to comparatively low risk. In total 280 mine sites were selected in the final inventory of problem sites.

A review and analysis of the available relative risk assessment procedures for preliminary and simplified risk assessment of contaminated sites were published in a report of the European Environment Agency (EEA 2005a). The review allowed identifying and listing the most common parameters used in the reviewed methodologies in order to support the development of a relative risk-based methodology called Preliminary Risk Assessment Model (PRAMS) for the identification and assessment of problem areas for soil contamination in Europe (EEA 2005b). The PRAMS model consists of two tiers, Tier 1 and Tier 2 that can be applied subsequently or independently. Both tiers lead to an assessment and ranking of sites by Human health and Ecological risk scores.

The International Commission for the Protection of the Danube River (ICPDR) has established M1 methodology for the pre-assessment of contaminated sites in flood risk areas, in September 2004. M2 methodology was developed taking into account the safety measures (SM) at the site and the risk of flooding (FP) (ICDPR 2006). The contaminated sites are classified into priority classes (by considering the determined M2-value). For all contaminated sites within the priority classes 1, 2 or 3 preventive and/or remediation measures have to be set at the sites to improve the 
safety of the contaminated site and to reduce the risk of contamination related on waters. In a further step ICPDR developed a checklist for site inspections of high risk contaminated sites in flood risk areas. The checklist (Fig.7) includes general information for proposed safety measures, which allow the competent authorities to reduce the risk at a contaminated site in flood risk areas and to increase public safety and to protect the environment in the Danube River Basin. This checklist serves as a hand guide for a desk-study and for a first visit of sites, suspected to be contaminated by substances hazardous to water.

The Historic Mine Sites Inventory and Risk Classification Scoring System (HMS-IRC) (Irish EPA 2009) is developed by the Geological Survey of Ireland (GSI), Environmental Protection Agency (EPA) in order to conduct the inventory of closed waste facilities for Ireland. This method includes 1) preliminary screening and site selection, 2) source-pathway-receptor model, and 3) risk ranking system. In total 220 mine sites are located across Ireland registered in GSI database. Expert judgment is applied to the database to extract a list of sites that should be included in the risk ranking of sites. The Irish EPA used a combination of expert judgment and assessment criteria (Grennan 1996) to derive a Pollution Index Number (PIN) ranging from 1 to 9 for the selected 128 sites. For example, sites with PIN 1 include all recently closed large-scale basemetal mines and major coalfields where significant volumes of waste are present and the AMD potential is high. The pre-screening and site selection process identified 110 mine sites for further investigation.

The European Commission has established the Inventory of Closed Waste Facilities Ad-hoc Group (AHG) of the Technical Adaptation Committee for Directive 2006/21/EC in order to facilitate the implementation of Article 20 of the Directive by Member States by end of 2012. The Directive requires the application of risk assessment methods in the inventory of abandoned and closed waste facilities that have either known impacts or have the potential of impacting the environment. The Ad-hoc Group developed the EU MWD Pre-selection Protocol (Stanley et al. 2011) and it is based on a 'YES-or-NO' questionnaire (Annex 1). The Protocol consists of 18 questions using simple criteria available in existing databases readily enabling the preliminary screening of the mine waste sites for environmental risk. Questions include the toxic element content of the mine waste, the size of the waste facility, if the waste heap is covered, or if the site is within $1 \mathrm{~km}$ from the nearest water course or settlement. Screening should result in the elimination of those sites which do not cause or have the potential to cause a serious threat to human health and the environment from the inventory of closed waste sites. Even if a waste facility passes the pre-selection protocol and it is classified as 'examine further', it does not mean that the closed waste facility will necessarily be included in the final inventory. In case of lack of knowledge or information, i.e. in the presence of uncertainty, a 'unknown' response is entered for the particular parameter which is the same as a YES response and the site is selected for further examination which is a precautionary position. 




Figure 7. Flowchart (checklist) of the ICPDR-M2 assessment of contaminated sites in flood risk areas (ICPDR 2006). 
The Spatial decision support sYstem for Regional rIsk Assessment of DEgraded land (SYRIADE) methodology developed by Consorzio Venezia Ricerche in collaboration with the European Commission is presented by Pizzol et al. (2011) for ranking potentially contaminated sites using spatial information and analysis. The developed methodology and tool are both flexible and easy to adapt to different regional contexts, allowing the user to introduce the regional relevant parameters identified on the basis of user expertise and regional data availability. The used GIS functionalities, integrated with mathematical approaches, allowed to spatially link the three essential elements of the risk analysis (source, pathway, receptor) within the region of concern, to assess the risks posed by all contaminated sites in the region and, finally, to provide a risk-based ranking of the potentially contaminated sites (Pizzol et al. 2011).

The Crown Land Restoration Branch (CLRB) of the British Columbia Ministry of Agriculture and Lands is responsible for managing thousands of historic and abandoned mine sites on provincial lands (Power et al. 2010). For mine sites, CLRB uses information in the Historic Mines Atlas Database as an initial coarse screen to identify the subset of mine sites that have the highest potential to pose environmental or human health risks from contamination, based on easily available information. CLRB developed a Risk-Ranking Methodology (RRM) which was implemented in 2007/2008 with an emphasis on historic mine sites because of the significant number of sites and related potential risk. The RRM consists of 3 main components: 1) collection of key information from each site based on a risk-based Preliminary Site Investigation (PSI), 2) compilation of that information in a spreadsheet tool for internal use by CLRB, and 3) a workshop engaging environmental professionals to rank the sites and identify potential management options. PSIs in British Columbia focus on identifying potential historic and current sources of contamination, and involve a yes/no characterization of the presence of contaminants at concentrations greater than provincial standards. For each site, several types of information are collected from available sources (e.g., online databases) and during a field visit. A conceptual site model is developed, as part of the risk-based PSI, describing contaminant sources, contaminant fate and transport pathways, receptors, and exposure pathways (Power et al. 2010).

The British Geological Survey (BGS) established a project to develop an initial screening tool (IST) to assist the planning community in the assessment of the potential risk to ground and surface waters from contaminants (Marchant et al. 2011). IST follows the source-pathwayreceptor paradigm and takes the prioritisation approach into the 3D environment. IST collates and interrogates a range of geoscientific information, including contaminant scale, geological, historical land use, groundwater level and hydrogeological domain data. The IST surface water pathway evaluation factors consist of: proximity, flood potential and topography, and include a classification of the surface water receptor based on large river (greater than $33 \mathrm{~m}$ wide), small river (10-33 m wide), large stream (3-10 m wide), small stream (less than $3 \mathrm{~m}$ wide), wetlands, docks, pond, land drain and ditch. The IST groundwater receptor evaluation factors include proximity, the classification of principal aquifers and secondary aquifers and the permeability of receiving aquifers. IST facilitates the ranking of various proposed development scenarios through 
a semi-quantitative assessment of contamination potential, providing planners with reports on the type, spatial distribution and hazards associated with potential contaminant sources within their area. Moreover, the IST comprises a GIS application designed to support decision-making with respect to the protection of groundwater and surface water (Marchant et al. 2011).

A GIS based tool described by Turner et al. (2011) is used to prioritize mine waste tips as potential pollutant sources in five river catchments of south west England. The work incorporates data on the location of abandoned mine sites collated by the British Environment Agency (EA) into a GIS model on the basis of three key parameters: proximity of each waste tip to the nearest watercourse or body, the area occupied by the waste tip and the slope of the drainage pathway. The methodology is a systematic and rapid screening tool.

Table 1 provides a comparison of the key parameters of some 11 recognized methods for prescreening RA of mine waste sites. For the source parameters, size (area and volume), heavy metal content, and the waste type (tailings lagoon or heap) are the most commonly included parameters. While the slope is included in four RA methods (the EU MWD Pre-selection Protocol (Stanley et al. 2011), PRAMS EEA 2005c, HMS-IRC Irish EPA 2009 and Turner et al. 2011), rehabilitation is included only in the EU MWD Pre-selection Protocol (Stanley et al. 2011) and in Di Sante et al. (2009). For the pathway parameters, surface water (lakes and streams), air, groundwater and direct contact are included in most of the RA methods. While distance to the nearest surface water bodies is included in six RA methods only (EU MWD Pre-selection Protocol (Stanley et al. 2011), AIMSS Pioneer Technical Services 1994, PRAMS EEA 2005c, HMS-IRC Irish EPA 2009, Turner et al. 2011 and Pizzol et al. 2011). Permeability of layers below the waste site is included only in two RA methods (EU MWD Pre-selection Protocol (Stanley et al. 2011), and PRAMS EEA 2005c), while erosion/wind transport is included only in Pizzol et al. 2011 (Table 1). For the receptor parameters, human (health, population), ecosystem, groundwater, surface water and toxicity analysis are included in most of the RA methods. It is interesting that vulnerability (sensitivity) is included only in three RA methods (HMS-IRC Irish EPA 2009, Fan et al. 2010 and Pizzol et al. 2011). 
Table 1 Comparing the key parameters of some recognized pre-screening RA methods for mine waste sites.

\begin{tabular}{|c|c|c|c|c|c|c|c|c|c|c|c|c|c|}
\hline 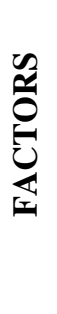 & Key parameters & 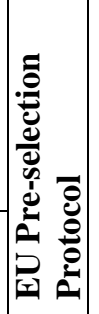 & 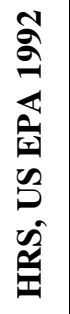 & 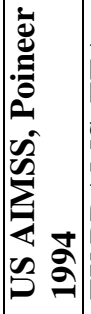 & 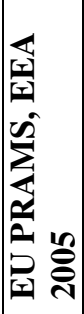 & 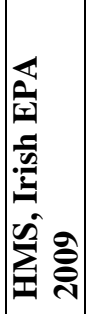 & 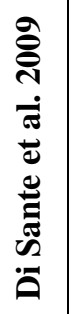 & 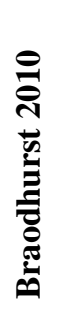 & 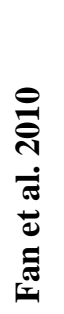 & 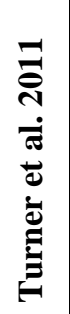 & 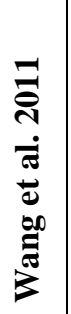 &  & 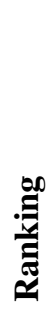 \\
\hline \multirow{10}{*}{  } & Size: Area & $\mathrm{X}$ & $\mathrm{X}$ & $\mathrm{X}$ & $X$ & $X$ & & & $\mathrm{X}$ & $\mathrm{X}$ & & $\mathrm{X}$ & 8 \\
\hline & Heavy metals (total) & $\mathrm{X}$ & & $\mathrm{X}$ & $\mathrm{X}$ & $\mathrm{X}$ & & $\mathrm{X}$ & & & $\mathrm{X}$ & $\mathrm{X}$ & 7 \\
\hline & Size: Volume $\left(\mathrm{m}^{3}\right)$ & $\mathrm{X}$ & $\mathrm{X}$ & $\mathrm{X}$ & $\mathrm{X}$ & $\mathrm{X}$ & & & & & & $\mathrm{X}$ & 6 \\
\hline & Waste type (tailings lagoon or heap) & $\mathrm{X}$ & & $\mathrm{X}$ & $X$ & $X$ & & $\mathrm{X}$ & & & & & 5 \\
\hline & Soil & & $\mathrm{X}$ & & $\mathrm{X}$ & & $\mathrm{X}$ & & $\mathrm{X}$ & & $\mathrm{X}$ & & 5 \\
\hline & Slope & $\mathrm{X}$ & & & $\mathrm{X}$ & $\mathrm{X}$ & & & & $\mathrm{X}$ & & & 4 \\
\hline & Mining: Years of activity & & & & $\mathrm{X}$ & $\mathrm{X}$ & & & & & & $\mathrm{X}$ & 3 \\
\hline & Sulphide Minerals & $\mathrm{X}$ & & & & & & $\mathrm{X}$ & & & & & 2 \\
\hline & Chemicals (processing) & $\mathrm{X}$ & & & & & & $\mathrm{X}$ & & & & & 2 \\
\hline & Rehabilitation & $\mathrm{X}$ & & & & & $\mathrm{X}$ & & & & & & 2 \\
\hline \multirow{10}{*}{  } & Surface water (lakes and streams) & $\mathrm{X}$ & $\mathrm{X}$ & $\mathrm{X}$ & $\bar{X}$ & $\mathrm{X}$ & $\mathrm{X}$ & & & $\mathrm{X}$ & $\mathrm{X}$ & $\mathrm{X}$ & 9 \\
\hline & Air & $\mathrm{X}$ & $\mathrm{X}$ & $\mathrm{X}$ & & $\mathrm{X}$ & $\mathrm{X}$ & & $\mathrm{X}$ & & & $\mathrm{X}$ & 7 \\
\hline & Groundwater & $\mathrm{X}$ & $\mathrm{X}$ & $\mathrm{X}$ & & $\mathrm{X}$ & & & $\mathrm{X}$ & & & $\mathrm{X}$ & 6 \\
\hline & Direct contact & $\mathrm{X}$ & & $\mathrm{X}$ & $\mathrm{X}$ & $\mathrm{X}$ & $\mathrm{X}$ & & $\mathrm{X}$ & & & & 6 \\
\hline & Distance to surface water bodies & $\mathrm{X}$ & & $\mathrm{X}$ & $\mathrm{X}$ & $\mathrm{X}$ & & & & $\mathrm{X}$ & & $\mathrm{X}$ & 6 \\
\hline & Distance to groundwater bodies & $\mathrm{X}$ & & $\mathrm{X}$ & & $\mathrm{X}$ & & & & & & & 3 \\
\hline & Distance to the nearest settlements & $\mathrm{X}$ & & & $\mathrm{X}$ & $\mathrm{X}$ & & & & & & & 3 \\
\hline & Distance to Natura 2000 sites & $\mathrm{X}$ & & & $\mathrm{X}$ & & & & & & & $\mathrm{X}$ & 3 \\
\hline & Permeability of layers beneath the site & $\mathrm{X}$ & & & $\mathrm{X}$ & & & & & & & & 2 \\
\hline & Erosion/wind transport & & & & & & & & & & & $\mathrm{X}$ & 1 \\
\hline \multirow{7}{*}{ 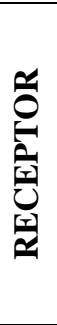 } & Human (health, population) & $\mathrm{X}$ & $\mathrm{X}$ & $\mathrm{X}$ & $\mathrm{X}$ & $\mathrm{X}$ & $\mathrm{X}$ & $\mathrm{X}$ & $\mathrm{X}$ & & & $\mathrm{X}$ & 9 \\
\hline & Ecosystem (protected) & $\mathrm{X}$ & $\mathrm{X}$ & $\mathrm{X}$ & $\mathrm{X}$ & $\mathrm{X}$ & $\mathrm{X}$ & & & & $\mathrm{X}$ & $\mathrm{X}$ & 8 \\
\hline & Groundwater & $\mathrm{X}$ & $\mathrm{X}$ & $\mathrm{X}$ & & & $\mathrm{X}$ & & $\mathrm{X}$ & & & $\mathrm{X}$ & 6 \\
\hline & Toxicity analysis & & $\mathrm{X}$ & $\mathrm{X}$ & & $\mathrm{X}$ & $\mathrm{X}$ & $\mathrm{X}$ & $\mathrm{X}$ & & & & 6 \\
\hline & Surface water & $\mathrm{X}$ & & & & & $\mathrm{X}$ & & & $\mathrm{X}$ & $\mathrm{X}$ & $\mathrm{X}$ & 5 \\
\hline & Land use & $\mathrm{X}$ & & & $\mathrm{X}$ & & & & $\mathrm{X}$ & & & $\mathrm{X}$ & 4 \\
\hline & Vulnerability & & & & & $\mathrm{X}$ & & & $\mathrm{X}$ & & & $X$ & 3 \\
\hline
\end{tabular}




\section{Study area}

The EU MWD Preselection Protocol (Stanley et al. 2011, Annex 1) was applied on 145 ore mine sites as test cases in Hungary (Fig.8) in order to perform a simple risk-based ranking of the waste sites. The EEA Preliminary Risk Assessment (PRAMS) risk assessment Model (EEA, 2005c) was applied to the 145 test sites. The results of the EU MWD Pre-selection Protocol were compared to those of the PRAMS RA Model in order to provide a further means of parameter sensitivity analysis.

For the waste rock geochemical characterization and risk mapping in this study, 93 field samples (including alginite, coal (lignite and black coal), peat, algninite, clay, bauxite, limestones, rhyolite tuffs and andesite) from 30 mine-quarry waste sites in Hungary (Fig.9). A breif description of the most common rock formations that producing waste in Hungary was discussed as follows;

The alginite mined in Pula site (NW Hungary, Fig.1) originated from biomass of fossil algae during several millions of years in volcanic craters. Its organic material content is about 5-50\% (Szabo, 2004). Gömöryová et al. (2009) reported that tests of alginite from the deposits in Pula and Gerce showed that it can be used in agriculture and forestry to improve soil quality, soil water dynamics and nutrient content, to increase organic matter content, colloid content and to protect soil against acidification, desiccation and leakage of nutrients (Vass et al. 2003).

In the power generation sector, coal is playing a dominant role in the EU with $25 \%$ share of the total installed capacity and almost one-third of the power generation (Kavouridis and Koukouzas, 2008). Coal resources in Hungary are in total 3,300 million tons (Mt) with annual production between 9-10 Mt (of which $8 \mathrm{Mt}$ is lignite) (Perger A. 2009). At this rate of use the reserves could last for centuries. Three types of coal in Hungary were sampled: 1) black coal in southern Mecsek Mountains (Lower Jurassic- Lias) is Hungary's only black coal reserve, calculated to be 198.8 Mt. Due to the complicated geological circumstances and the high cost of exploitation, production was stopped in 2004. 2) Brown coal was widely mined throughout recent decades through the Transdanubian Mountains with good quality Eocene and Oligocene coal, supplying a significant amount of Hungary's energy needs. Mining has virtually stopped due to economic reasons, with remaining reserves calculated to be $170 \mathrm{Mt}$. There is only one mine operating and supplying the Vértes Power Plant. Cretaceous coal exploitation in the region ended in 2004, after resources ran out. Poor quality Miocene reserves can be found in Northern Hungary.

While all underground mining were ceased, small open-pit mines are still operating and exploitation can be extended. 3) Lignite represents about $90 \%$ of the Hungarian coal reserves, which means that lignite is first on the Hungarian conventional energy sources. While some Miocene lignite reserves ran out in the Transdanubian Mountains in 1996, about 3000 Mt of Miocene-Pliocene lignite can be found in Visonta, Bükkábrány (Northern Hungary) and Torony (Western Hungary) (Fig.1). Recently, the Visonta and Bükkábrány sites were subject to vast 
open-pit mining supplying the Mátra Power Plant, while the Torony site remains practically untouched by any mining activity (Hamor-Vido, 2004).

Peat was used as a fuel from early times in Europe. It was exploited intensively in agriculture and currently there is a renewed interest in the material because of its potential as a general source of hydrocarbons and other more particular organic raw materials used industrially. Peat was invariably found with significant moisture content at the surface of the ground, within a depth of 2-15m (Spedding, 1988). Number of significant articles were published on different aspects of peat and its use (e.g. Del-Rio et al. 1992; Steinmann and Shotyk, 1997; Charman 2002).

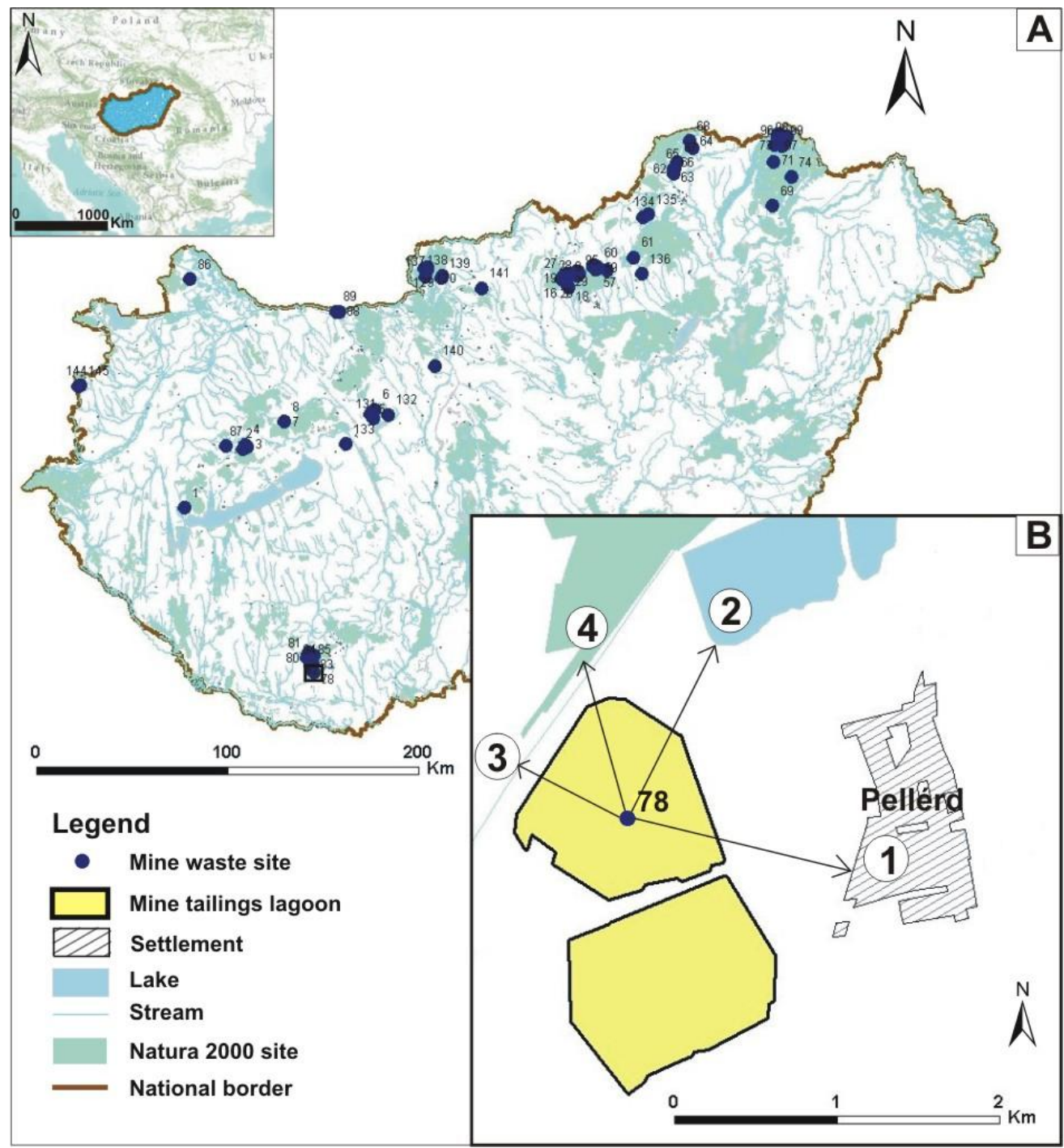

Figure 8. A. Mine waste sites in Hungary considered in this study. Solid box shows location of Figure 8B.

B. Distance measurement from the waste sites (polygon centroid) to the nearest settlement (1), surface water lake (2), stream (3) and to the nearest Natura 2000 protected area (4). 


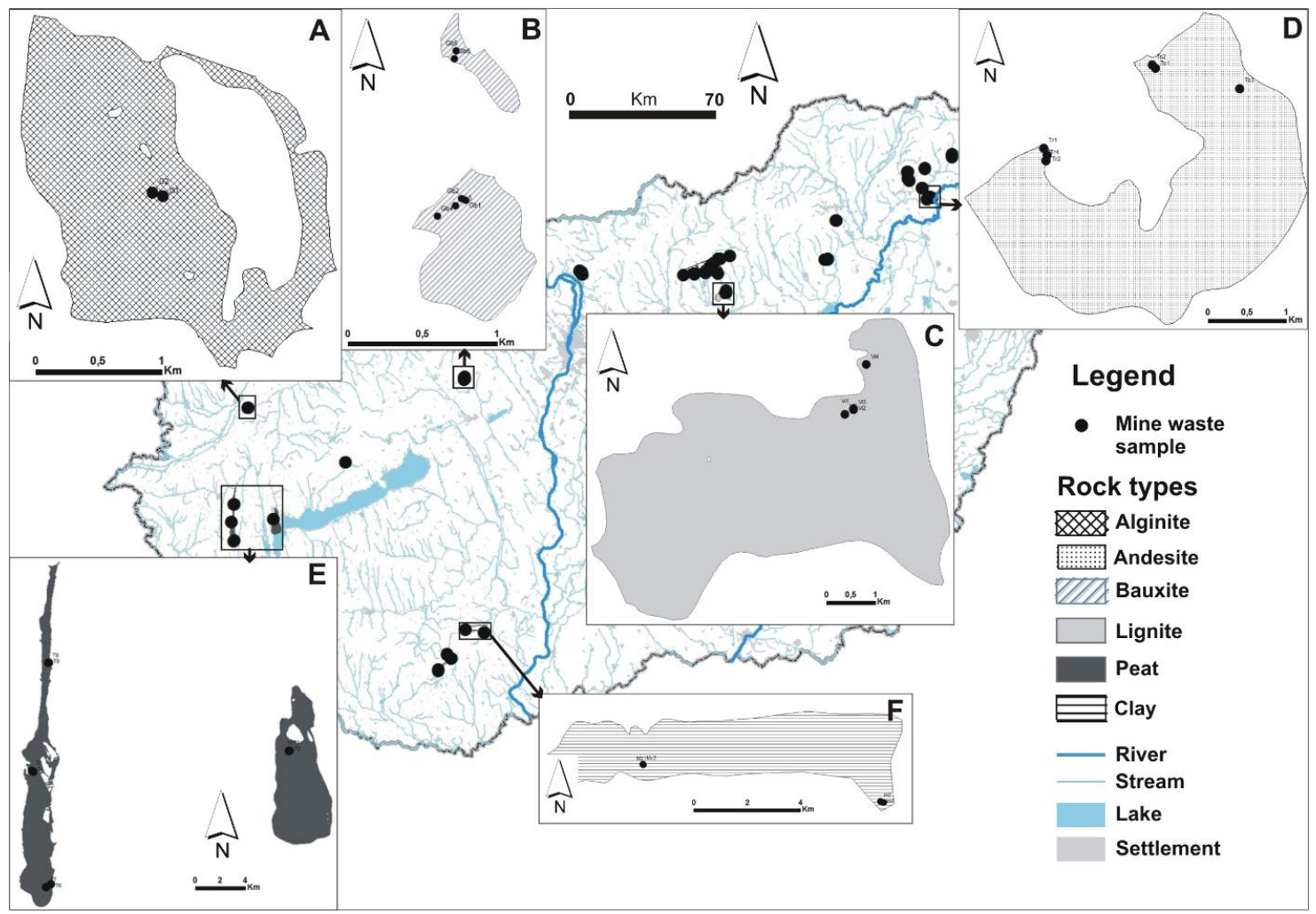

Figure 9. Examples of rock formations (as polygons) and locations of field sampling from abandoned mines and active quarries in Hungary. A) Pula Alginite Formation, B) Gant Bauxite Formation, C) Lignite Formation at Visonta, D) Andesite Formation in the TokajMts., E) Peat formation at Pölöske, F) Clay Formation at Maza. 


\section{Data}

Two types of data wre used in this study. Waste site data includes (1) location of mine waste sites as points, (2) composition of mine waste including sulphides, toxic metals, and dangerous processing substances (Q2 - Q4 of the EU Pre-selection Protocol (Annex 1), (3) geometry of the waste heap (height and area) and slope of foundation (Q6 - Q10), and (4) other data such as presence of a high permeable layer beneath the waste site (Q12), and if the facility is uncovered and thus the waste is exposed to wind or direct contact (Q13-Q14). Information on the mine waste facility engineering design was obtained from mine archives, aerial photos and field studies. Spatial data include topographic data of location of settlements as polygons, surface water courses (streams and lakes), and the slope data calculated from the Hungarian national contour based military DEM 50m grid using the ILWIS ${ }^{\circledR} 3.7$ open source raster GIS software were used in this study. Census data for Hungary (census 2009) obtained from the Hungarian Central Statistical Office.

Data on the national protected areas such as Natura 2000 protected ares was available from the Hungarian Central Directorate of Water and Environment (VKKI). Location and status classification of groundwater bodies in Hungary under the Water Framework Directive (WFD) obtained from VKKI, and from EEA website (Waterbase-Groundwater datatests). Land use/land cover data (LULC) maps at 1:100,000 scale are obtained from the European CORINE Land Cover website. The type, scale and source of each map used in this study are illustrated in Table 2.

Table 2. Type, scale and source of all maps and databases used in this study.

\begin{tabular}{|l|l|l|l|l|}
\hline \multicolumn{1}{|c|}{ Map type } & Format & Location & \multicolumn{1}{c|}{ Scale } & \multicolumn{1}{c|}{ Source } \\
\hline CORINE CLC2000 land cover map & SHP & Hungary & 1.100 .000 & EEA database \\
\hline CORINE CLC2006 land cover map & SHP & Hungary & 1.100 .000 & EEA database \\
\hline Natura 2000 protected ares in Hungary & SHP & Hungary & 1.100 .000 & VKKI \\
\hline Surface water bodeis in Hungary (streams \& lakes) & SHP & Hungary & 1.100 .000 & VKKI \\
\hline Official Mining map & SHP & Hungary & 1.100 .000 & MFGI \\
\hline Major waste dumps & SHP & Hungary & 1.100 .000 & MFGI \\
\hline Landscape wounds map 'quarries' open surface mining & SHP & Hungary & 1.100 .000 & MFGI \\
\hline Ground water depth map 2006 & SHP & Hungary & 1.100 .000 & MFGI \\
\hline Water polygons & SHP & Hungary & 1.50 .000 & MFGI \\
\hline Water lines & SHP & Hungary & 1.50 .000 & MFGI \\
\hline Settlements & SHP & Hungary & 1.50 .000 & MFGI \\
\hline Roads \& Railways & SHP & Hungary & 1.50 .000 & MFGI \\
\hline Border lines & SHP & Hungary & 1.50 .000 & MFGI \\
\hline Lithology polygons (Geologic map of Hungary) & SHP & Hungary & 1.100 .000 & MFGI \\
\hline DEM 50m & GRD & Hungary & 1.50 .000 & MFGI \\
\hline groundwater bodies (GWB) with outcrop & SHP & Hungary & 1.100 .000 & MFGI \\
\hline Surface permeability rock map of Hungary & SHP & Hungary & 1.100 .000 & this study \\
\hline Hungarian Inventory mining database-Ore mine sites & XLS & Hungary & & MFGI \\
\hline $\begin{array}{l}\text { Hungarian Inventory mining database-Coal and quarry } \\
\text { sites }\end{array}$ & XLS & Hungary & & MFGI \\
\hline
\end{tabular}




\section{Methods}

\subsection{Contamination Risk Assessment Methods in landscapes}

Two major methods of risk assessment of contamination at mining sites are used in this study as described below.

\subsubsection{EU MWD Pre-selection Protocol}

The EU MWD Pre-selection Protocol (Stanley et al. 2011) based on a 'YES-or-NO' questionnaire (Annex 1) created from a strong basic logic (Annex 2) and consists of 18 questions using simple criteria available in existing databases readily enabling the preliminary screening of the mine waste sites for environmental risk. This screening should result in the elimination of those sites which do not cause or have the potential to cause a serious threat to human health and the environment from the inventory of closed waste sites. Note that even if a waste facility passes the pre-selection protocol and it is classified as EXAMINE FURTHER, it does not mean that the closed waste facility will necessarily be included in the final inventory. In Annex III of the MWD criteria for determining the classification of waste facilities, idents 2 and 3 specifically refer to hazardous and dangerous substances being above a certain threshold. These thresholds have been fixed by Commission Decision 2009/337/EC. Since the pre-selection protocol is meant not to involve field sampling or laboratory analysis, any level will be sufficient to pass the test and select the site for further investigation as a precautionary measure. In case of lack of knowledge or information, i.e. in the presence of uncertainty, an 'UNKNOWN' response (Annex 1) is entered for the particular parameter which is the same as a YES response and the site is selected for further examination which is a precautionary position.

The EU MWD Pre-selection Protocol, as shown in its flowchart (Annex 1), consists of four sections: 1) Known serious impact, 2) Source, 3) Pathways and 4) Receptors. Section 1 seeks to determine if a site has had a documented incident with a serious impact on human health or the environment (Q1). For example, 850 million cubic meters of toxic red mud spilled through the failed dam of the Ajka alumina depository in Kolontar, Hungary, in 2010, resulting in a serious impact on human health and the agricultural lands (Jordan et al. 2011). The site would directly be assigned to the EXAMINE FURTHER category. Otherwise, if there is no known serious documented impact then the site is led to the next section of the questionnaire on source characterization. Section 2 addresses the chemical composition and physical stability of the mine waste site acting as potential contamination source (source questions Q2-Q10). Three questions address the content of the waste site, if the waste contains sulphide minerals (Q2), heavy metals (Q3) or the mine uses dangerous chemicals (Q4). This is followed by six questions that address the stability of the facility (see Annex 1). Q5 asks if the type of the facility is either a tailings lagoon or a waste heap. If the site is a tailings lagoon there are two further questions: if the area of tailings lagoon site is $>10.000 \mathrm{~m}^{2}$ (Q6) and the height is $>4 \mathrm{~m}$ (Q7). If the site is a waste rock heap there are three further questions: if the waste heap area is $>10.000 \mathrm{~m}^{2}(\mathrm{Q} 7)$, the height is $>20 \mathrm{~m}(\mathrm{Q} 8)$ and the topographic slope under the waste heap site is $>=5^{\circ}(\mathrm{Q} 10)$. Section 3 
considers the potential pathways by which receptors could be impacted by the mine waste source. Four pathway questions cover the four potential contamination transport routes: if a surface water course is within $1 \mathrm{~km}$ of a mine waste site (Q11), if there is a high permeability layer beneath the mine waste site (groundwater pathway; Q12), if the waste material is exposed to air (Q13), and if the waste site is uncovered allowing direct contact (Q14). Section 4 seeks to identify four major sensitive human and ecosystem receptors. Question Q15 examines if a human settlement with $>100$ people is located within $1 \mathrm{~km}$ of a waste site, Q16 asks if the waste site is located within $1 \mathrm{~km}$ distance of groundwater body in 'poor status', Q17 asks if a Natura 2000 site is located within $1 \mathrm{~km}$ distance of a waste site, and Q18 inquires if a waste site is within $1 \mathrm{~km}$ distance of an agricultural area. The possible responses to each question are YES, NO or UNKNOWN. The YES answer means the presence of a risk factor, such as a toxic metal in the waste, the potential of transport by groundwater or a nearby located settlement as a receptor. The UNKNOWN response indicates uncertainty in information and uncertainty implies risk. Thus, UNKNOWN follows the same route as the YES response pointing towards further examination, according to the precautionary principle. If there is at least one YES or UNKNOWN response in each of the three Sections of source, pathway and receptor then the assessor is directed to the EXAMINE FURTHER endpoint. This case means that there possibly exists a contamination source, at least one possible pathway and a sensitive receptor. If the answers to all questions in at least one Section are NO then the source-pathway-receptor chain is broken, no risk exists for the site, and the assessor is directed to NO NEED TO EXAMINE FURTHER endpoint (Annex 1). For example, the waste site no. 69 in our case study in Hungary passed the protocol with 6 YES responses to the questionnaire questions (4 questions in the source and 2 questions in the receptor sections). But there is no pathway existing in this site by which receptors could be impacted by the toxic mine waste source, therefore the site will not be included in the final inventory and reaches the NO NEED TO EXAMINE FURTHER risk class.

Threshold values such as distance to pathways or sensitive receptors, topographic slope and census data are defined for some of the key parameters in the Protocol. For example, if there is a stream or protected ecosystem with $1 \mathrm{~km}$ of the site or there is a nearby settlement with more than 100 inhabitants the site potentially bears high risk. The EU MWD Pre-selection Protocol sets a $1 \mathrm{~km}$ threshold for the distance to the nearest surface water course (Q11), settlement (Q15), groundwater body (Q16), Natura 2000 site (Q17), and agricultural area (Q18). The Protocol also sets 100 inhabitants as a limiting value for the nearest settlement (Q15) and a 5 degree threshold for facility stability in question 10 (Q10). The Protocol thresholds are based on the Irish regulation for the operation of ponds with respect to quarries (Safe Quarry, 2008). In the present study a detailed statistical analysis is carried using the 145 ore mines test cases and the original 1 $\mathrm{km}$ threshold value is modified to the values identified as natural breaks in the distance histograms (see Fig.17). The lowermost break in the histogram identifies sites that are located within the closest distance and therefore these have the highest risk. In this way, the distance threshold is adopted to, for example, the settlement and stream course density conditions in Hungary. Also, the median of the calculated 145 distances is calculated for all threshold limited 
parameters allowing a threshold estimation representing a $50 \%$ probability of the site falling within the risk limiting distance (Median-based threshold). The same calculations are performed for the census and slope data. Therefore, each Member State can choose a different threshold which can meet their particular topographic and census conditions.

In order to identify if there is a high permeable layer beneath the mine waste site (Q12), a surface permeability map for the geological formations of the 1:100,000 surface geological map of Hungary has been constructed using $\operatorname{ArcINFO}^{\circledR} 10$, on the basis of the physical and geochemical characteristics of the uppermost rock units. Three groups have been distinguished (Fig.10). Lowpermeability formations (clay and other impermeable rocks), formations with mediumpermeability (loess, sand-gravel and fractured metamorphic and volcanic rocks) and with highpermeability (karstified limestones and dolomites belong to this group).

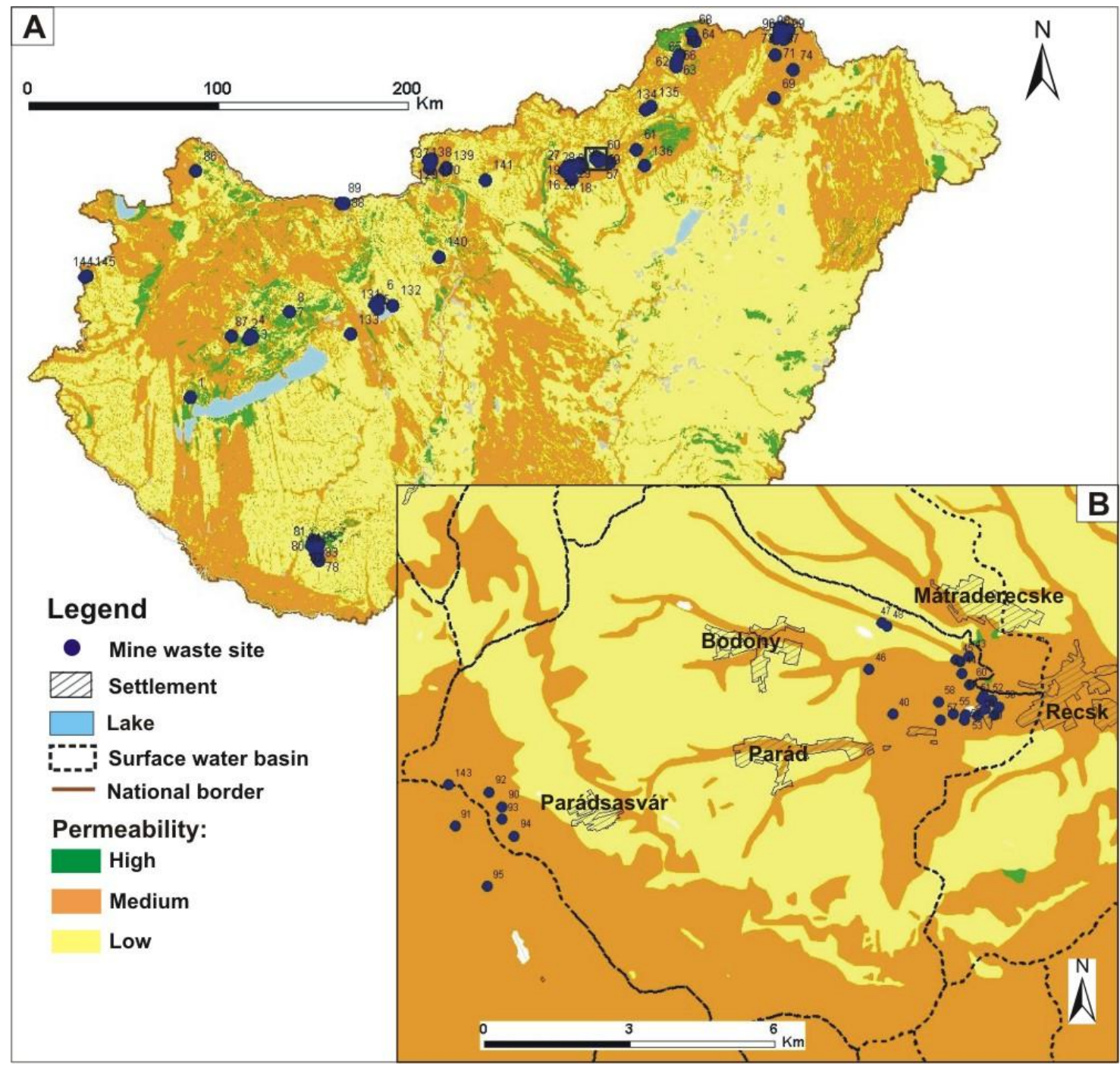

Fig.10 Surface permeability map developed to answer question Q12 of the EU Pre-selection Protocol (A). Surface permeability map for Hungary. Solid box shows location of Figure 10B. B. An example for the Recsk Mining Area in the Parádi-Tarna Creek catchment. 
Polygons of the mine waste sites derived from the CORINE land cover 1:50,000 map (2000) are overlaid by the most recent Google Earth ${ }^{\circledR}$ aerial photographs, in order to identify if the material within the mine waste sites is exposed to wind or not (Q13) or covered or not (Q14), (Fig.11).

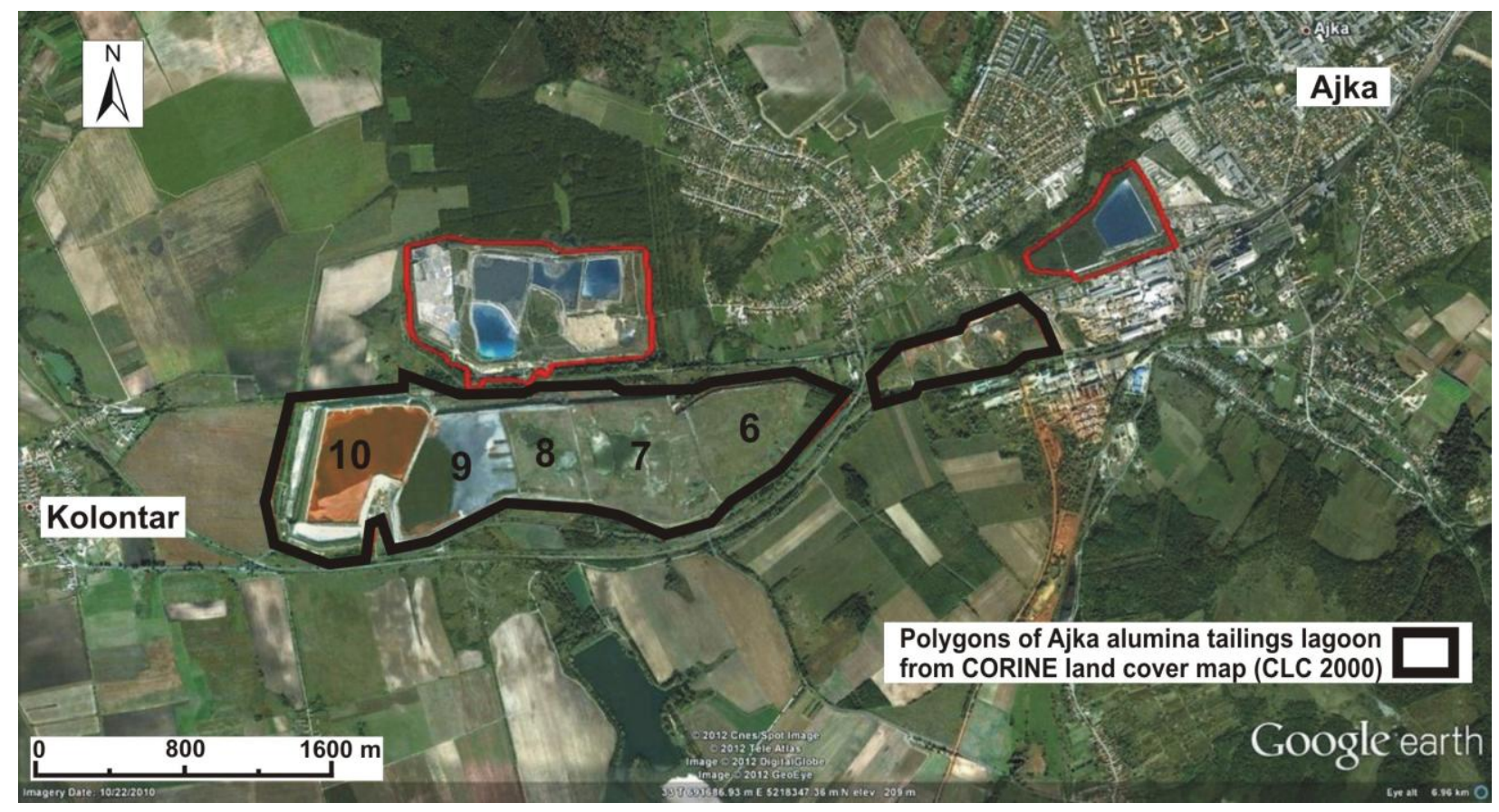

Fig.11 Polygons of the mine waste sites defined from the CORINE land cover map (CLC 2000) overlaid by Google Earth ${ }^{\circledR}$ aerial photographs (2010-2011) to answer EU Pre-selection Protocol questions Q13-14 on the air and direct contact pathways related to the cover of tailings. Example shows the Ajka alumina plant tailings lagoon. Note that cells 9 and 10 are not covered while cells 1-8 have been rehabilitated with soil and plant cover.

The topographic slope data calculated from the Hungarian national contour based military DDM $50 \mathrm{~m}$ grid using ArcGIS $10^{\circledR}$ software (Fig.12). Census data of Hungary for 2009 obtained from the Hungarian Central Statistical Office. Data on the national protected areas (Natura 2000 sites) and the location and status classification of groundwater bodies in Hungary under the Water Framework Directive (WFD, Directive 2006/118/EC; Fig.13) were obtained from the Hungarian Central Directorate of Water and Environment (VKKI) and from EEA website (WaterbaseGroundwater datasets). Land use/land cover data maps at 1:100,000 scale used the CORINE database.

Altogether 145 ore mine waste sites (Fig.8) are tested using the EU MWD Pre-selection Protocol as a case study from Hungary. Then, by running the protocol, the number of YES, NO and UNKNOWN responses are registered for each site. 


\subsubsection{EEA Preliminary Risk Assessment Model}

The Pre-screening procedure (Tier 0) of the EEA Preliminary Risk Assessment Model (PRAMS, EEA, 2005c), another international standard was applied to the 145 test sites. The results of the EU MWD Pre-selection Protocol are compared to those of PRAMS in order to provide a further means of parameter sensitivity analysis. In the PRAMS model the potentially contaminated areas of EU interest are preliminarily identified according to two sets of criteria as follows. The " $\mathrm{A}$ " criteria address sites with available knowledge on impact extent and the " $\mathrm{B}$ " criteria inquire about sites where this knowledge is not sufficiently available and surrogate information is used. " $\mathrm{A}$ " criteria include a YES/NO answer to one or more EU relevant policy questions. While " $\mathrm{B}$ " criteria include a set of questions on size in terms of surface area, waste or stored toxic materials volumes, and complexity in terms of number of sites, requiring simple information more likely to be readily available in data archives.

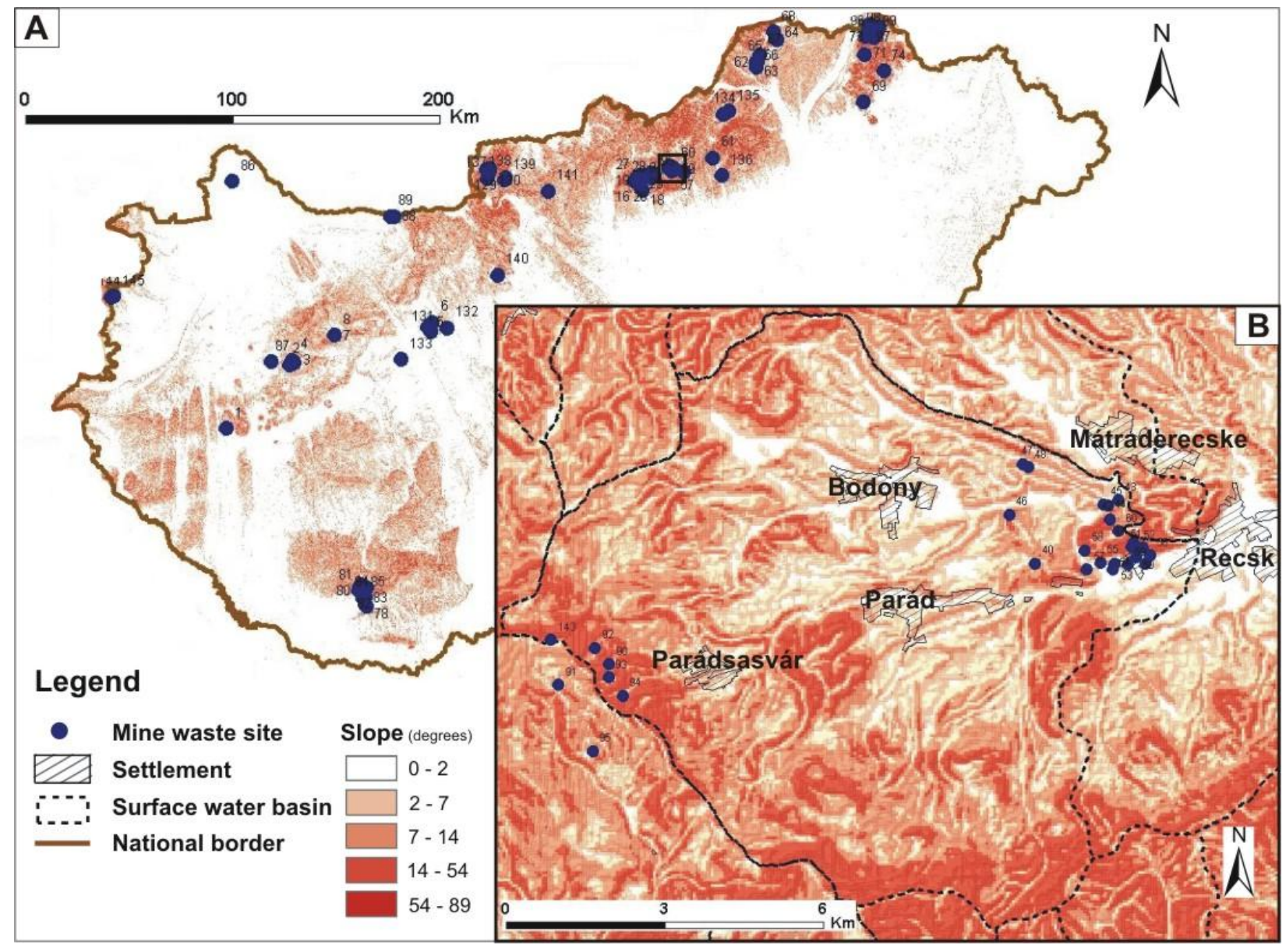

Figure 12. Topographic slope map calculated from the national contour-based spline-interpolated military 50m grid DEM, used for question Q10 in the EU Pre-selection protocol. A. Topographic slope map for Hungary. Solid box shows location of Figure 12B. B. An example for the Recsk Mining Area, in the Parádi-Tarna Creek catchment. 


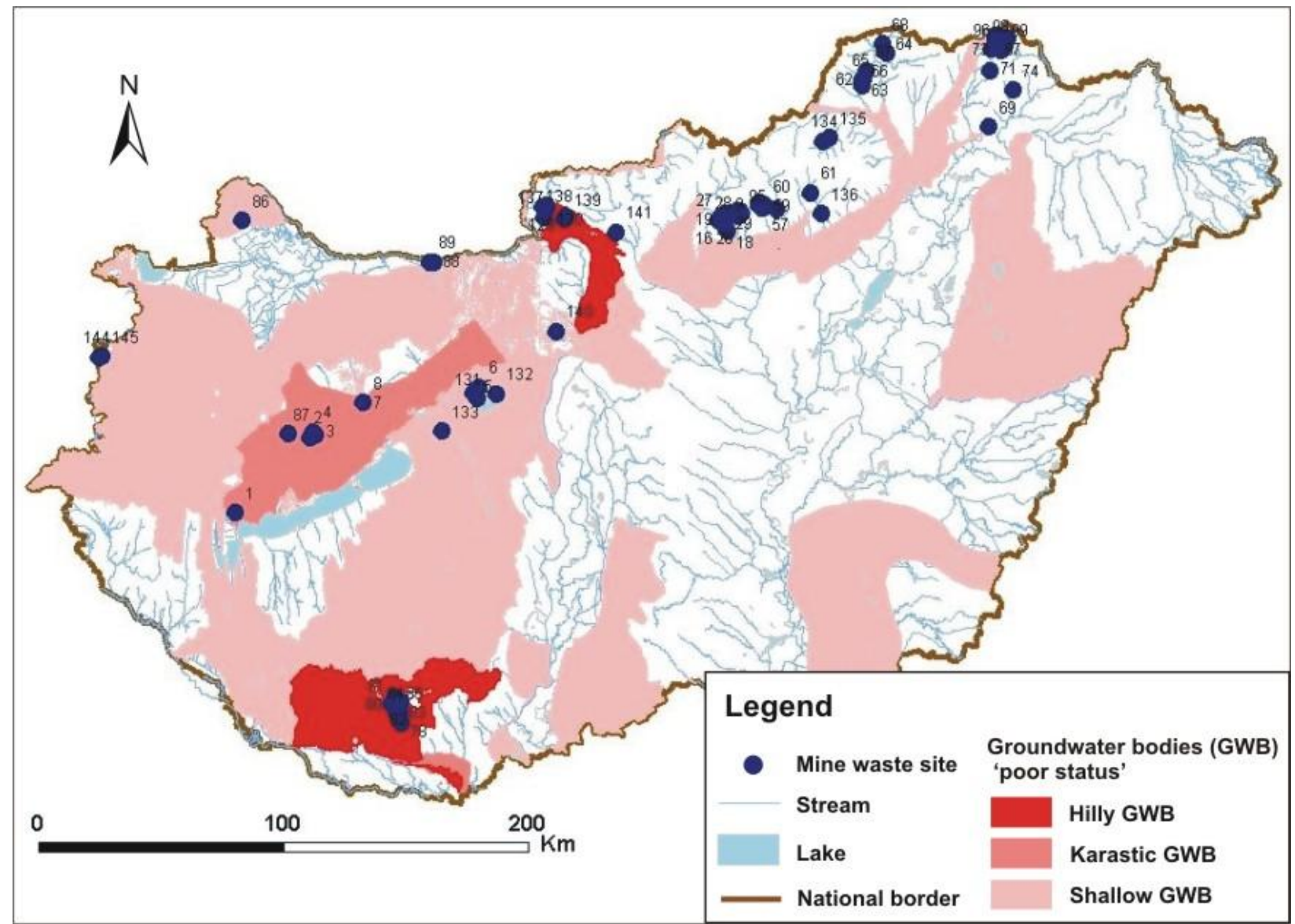

Figure 13. Groundwater bodies (GWB) with 'poor status' in Hungary according to the Water Frame Directive (WFD), used for question Q16 in the EU Pre-selection protocol. 


\subsubsection{Risk Assessment sensitivity analysis: numerical comparison of methods}

The proportion of the certain to uncertain responses for a site and for the total number of sites may give an insight of specific and overall uncertainty in the data we use. The distance from mine waste sites to the nearest receptors such as human settlements (Q15) was measured using proximity analysis tools (Point Distance and Generate Near Table) in ArcINFO ${ }^{\circledR} 10$ (Fig.8).

Statistical analyses were carried out using STATGRAPHICS Centurion XV.II ${ }^{\circledR}$ software, such as the topographic slope $(\mathrm{Q} 10)$ and the measured distance to the nearest surface water courses (Q11), settlements (Q15), ground water bodies (poor status) (Q16), protected areas (Natura 2000 sites, Q17) and agricultural areas (Q18).

The data derived for the implementation of the MWD Protocol such as the distance to the nearest stream or the size of the contamination source mine waste site is compared to those resulted from the PRAMS model in order to assess the sensitivity of mine waste site risk assessment in response to various methods.

\subsection{Waste rock geochemical characterization and risk mapping}

The EU MWD Pre-selection Protocol was applied on 30 abandoned and active quarries in Hungary in order to study the geochemical characteristics of the potentially generated mine wastes, in accordance with the EU MWD legislation. The mine-quarry waste sites were included inside the rock formations and delineated as polygons using ArcGIS $10^{\circledR}$ software (Fig.9). Altogether 30 mine waste sites both abandoned mines and active quarries, were selected for scientific testing using the EU MWD Pre-selection Protocol (Stanley et al. 2011, Annex 1). Then, by running the protocol, the number of YES, NO and UNKNOWN responses are registered for each site.

\subsubsection{Sampling}

The procedure applied in this study used a multi-level decision support scheme including a representative field sampling and laboratory analysis of formations listed in the Inert Mining Waste List and requesting available laboratory analysis data from selected operating mines. Altogether 93 samples have been collected according to the EuroGeoSurveys Geochemistry Expert Group Sampling Protocol from 30 mine-quarry waste sites in Hungary (Fig.9). Rock types and locations of samples as follow: coal (10 lignite samples from Visonta and Bükkábrány sites and 7 black coal samples from Pécs-Vasas mine sites); 9 peat samples from Pölöske, Hahót and Alsopatak sites; 5 alginite samples from Pula and Gérce sites; 6 bauxite samples from Gánt site; 8 clay samples from Máza, Miskolc and Vác sites and one bentonite clay sample from Mád site; 37

andesite samples from Recsk, Tokaj, Komló, Tállya, Sárospatak and Tarcal mine sites; 6 rhyolite tuffs samples from Gyöngyöslymos, Bedrog and Felsoabasár sites and 4 limestone samples from 
Vác mine site.(Fig.9, Table 3). The collected two kilograms of samples were always composed of three sub-samples located at a minimum of $10 \mathrm{~m}$ distance from each other (Fig.15).

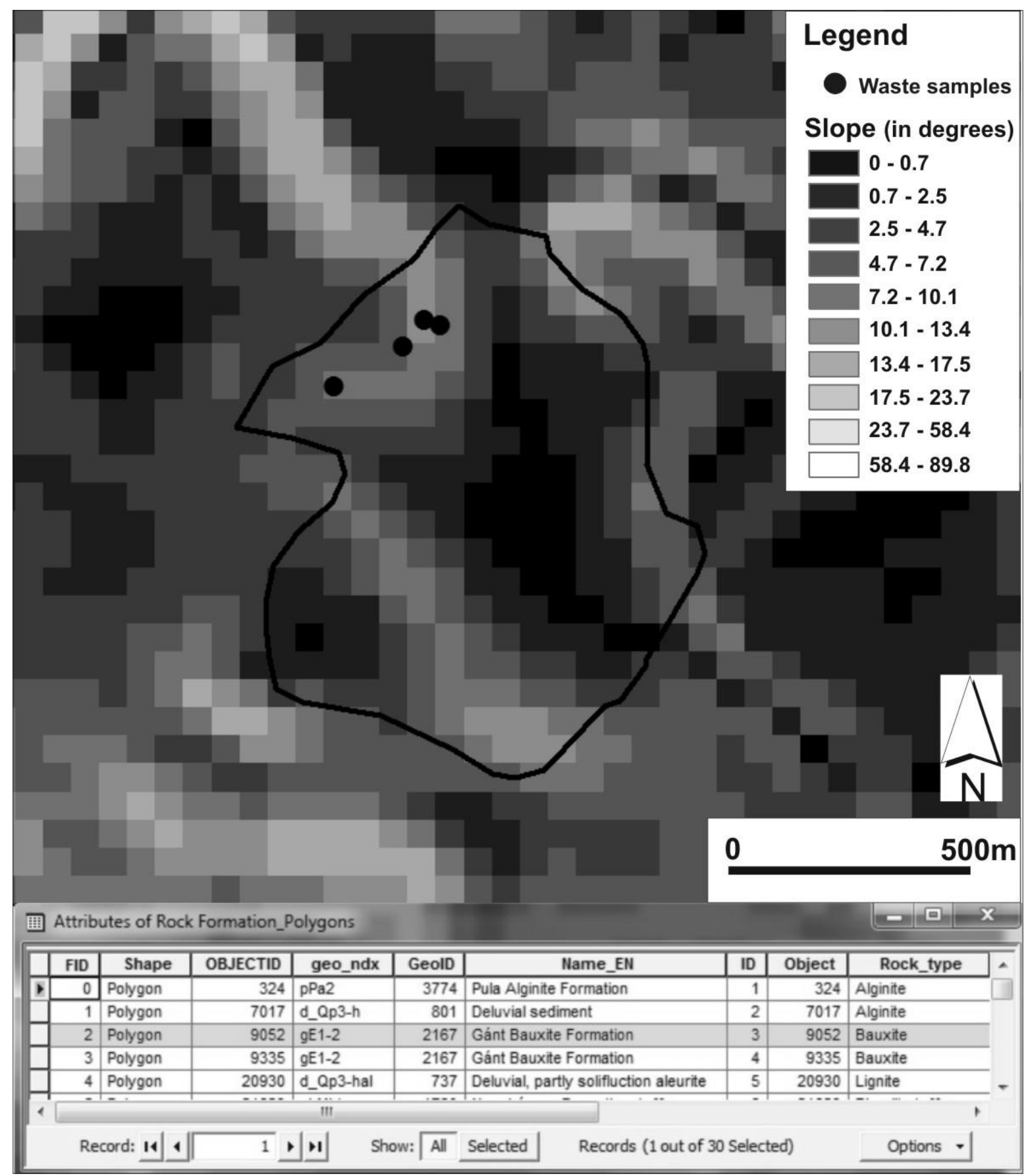

Figure 14. Calculation of the topographic slope for the sampled rock formations (as polygons) using the national contour-based spline-interpolated military 50m grid DEM. The same DEM is used for question Q10 of the EU Pre-selection protocol on the topographic slope below the mine waste site. Polygon highlighted is this example delineates the Gant Bauxite Formation including Bauxite samples from Gant bauxite mine. 
Selection of the samples at the site depends on the location of each sample, (e.g. lignite includes wall, overburden and waste samples), and on the rock type (mineral composition), (e.g. oxiandesite and pyrite andesite samples are collected). The collected two kilograms of samples are always composed of three subsamples located at a minimum of $10 \mathrm{~m}$ distance and at any sudden change in the color of waste rock, a new sample was collected (Fig.15).

Table 3. Showing the inert-not inert classification of the listed rock formations based on preliminary expert judgment. A: inert B: probably inert, but has to be checked $\mathrm{C}$ : probably not inert, has to be examined. Number of waste sites and field samples for each rock group are shown.

\begin{tabular}{|l|l|c|c|c|}
\hline Rock group & Rock type & $\begin{array}{c}\text { Number of } \\
\text { waste sites }\end{array}$ & Number of samples & $\begin{array}{c}\text { Inert-Not Inert } \\
\text { ranking }\end{array}$ \\
\hline \multirow{2}{*}{ Coal } & Lignite & 2 & 10 & C \\
\cline { 2 - 5 } & Black Coal & 2 & 7 & C \\
\hline Peat & 4 & 9 & C \\
\hline Alginite & 2 & 5 & B \\
\hline \multicolumn{2}{|l|}{ Bauxite } & 2 & 6 & B \\
\hline \multicolumn{2}{|l|}{ Rhyolite tuffs } & 2 & 6 & A-B \\
\hline \multirow{2}{*}{ Clay } & Clay & 4 & 8 & A \\
\cline { 2 - 5 } & $\begin{array}{l}\text { Bentonite } \\
\text { clay }\end{array}$ & 1 & 1 & B \\
\hline Andesite & 14 & 37 & A \\
\hline Limestone & 1 & 4 & \\
\hline
\end{tabular}

\subsubsection{Laboratory analysis}

Laboratory analyses of the total toxic element content (aqua regia extraction) and the mobile toxic element content (deionized water leaching) were carried out with ICP-OES according to the Hungarian national standards (GKM Decree No. 14/2008. (IV.3) concerning mining waste management. Altogether 70 samples were analyzed for different forms of sulfur (sulfuric acid potential) using HORIBA EMIA element analysis method. Calibration for this method is made according to the Hungarian AVKL-01-SPO-01-03 description procedure. In this way, the sampled rock types could be characterized for toxic element content that can be extended to the whole spatial extent (polygon) of the rock type in the geological map. Thus, not only the mine waste sites as point sources can be used for the contamination risk assessment but the whole area occupied by the mined rock type acts as a spatially extent contamination source. This data, the geochemically characterised rock formation polygon, is then input into the risk assessment model. Accordingly, two types of risk assessment were then carried out: (1) a point source assessment for each mine site as shown above and (2) a spatially extended source assessment for the mined rock type polygons.

For the point source assessment for each mine site, locations of the mine waste sites derived from the CORINE land cover 1:50,000 map (CLC 2000) were overlaid by the most recent Google Earth $^{\circledR}$ aerial photographs, in order to identify if the material within the mine waste sites is exposed to wind or not (Q13) or covered or not (Q14) (Fig.16). 
The median slope value for each rock formation polygon (in degrees) was calculated from all pixels inside the polygon using Spatial Analysis tool in ArcGIS $10^{\circledR}$. The distance from each rock formation polygon (as centroid point) to the nearest pathways (such surface water courses (Q11) and receptors (such as human settlements (Q15) and Natura 2000 protected areas (Q17)) was measured using Proximity Analysis tools (Point Distance and Generate Near Table) in ArcINFO ${ }^{\circledR}$ 10. Polygon highlighted is ana example for the Gant Bauxite Formation including Bauxite samples from Gant mine site (Fig.8).

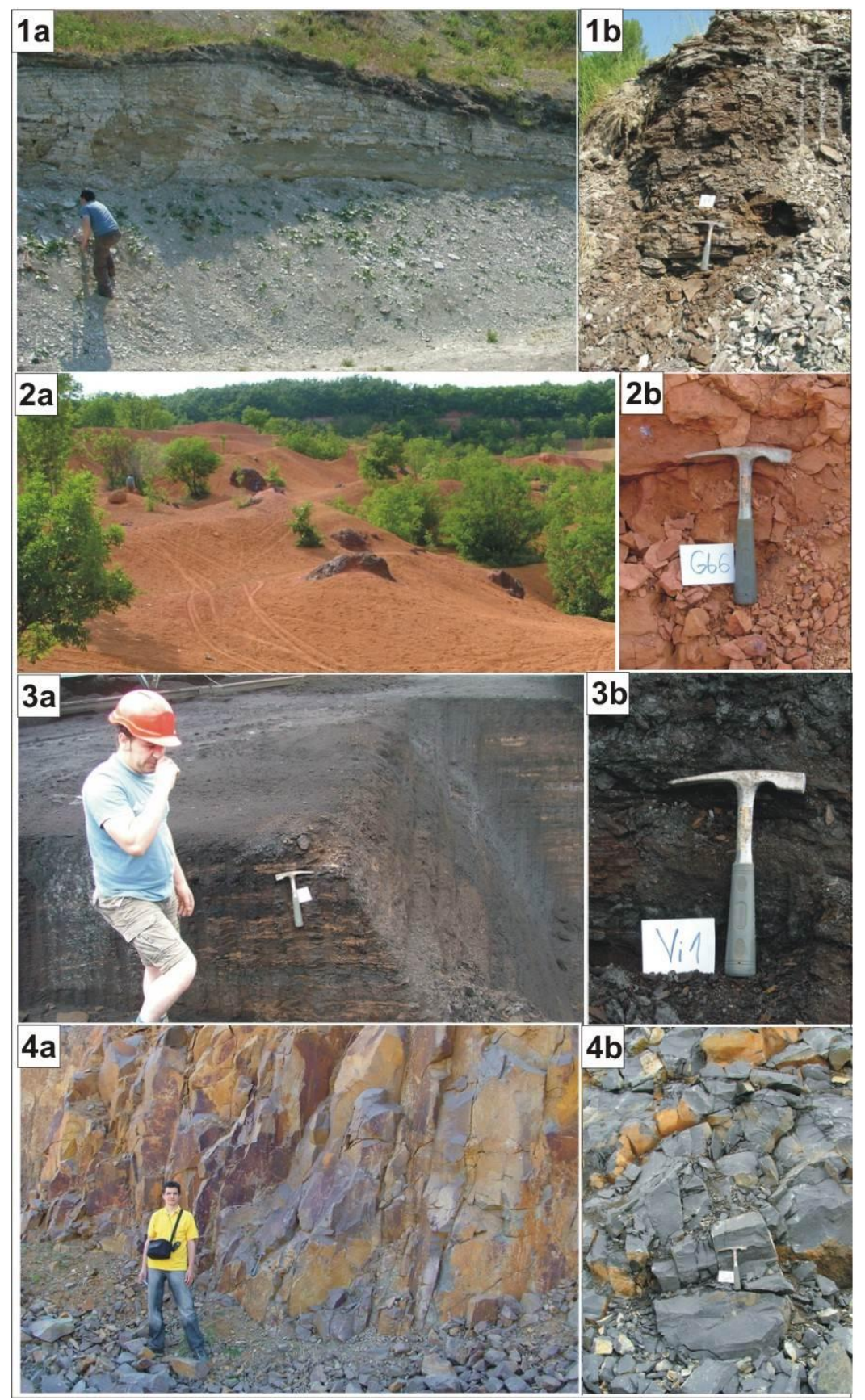

Figure 15. Field sampling for the EU Mine Waste Directive Inert waste testing and characterization in Hungary. $1 \mathrm{a}$ and $\mathrm{b}$. Alginite sampling in Pulla; $2 \mathrm{a}$ and $\mathrm{b}$. Bauxite sampling in Gant; $3 \mathrm{a}$ and $\mathrm{b}$. Lignite sampling in Visonta; $4 \mathrm{a}$ and b. Andesite sampling in Tokaj. See Figure 9 for sampling locations. 


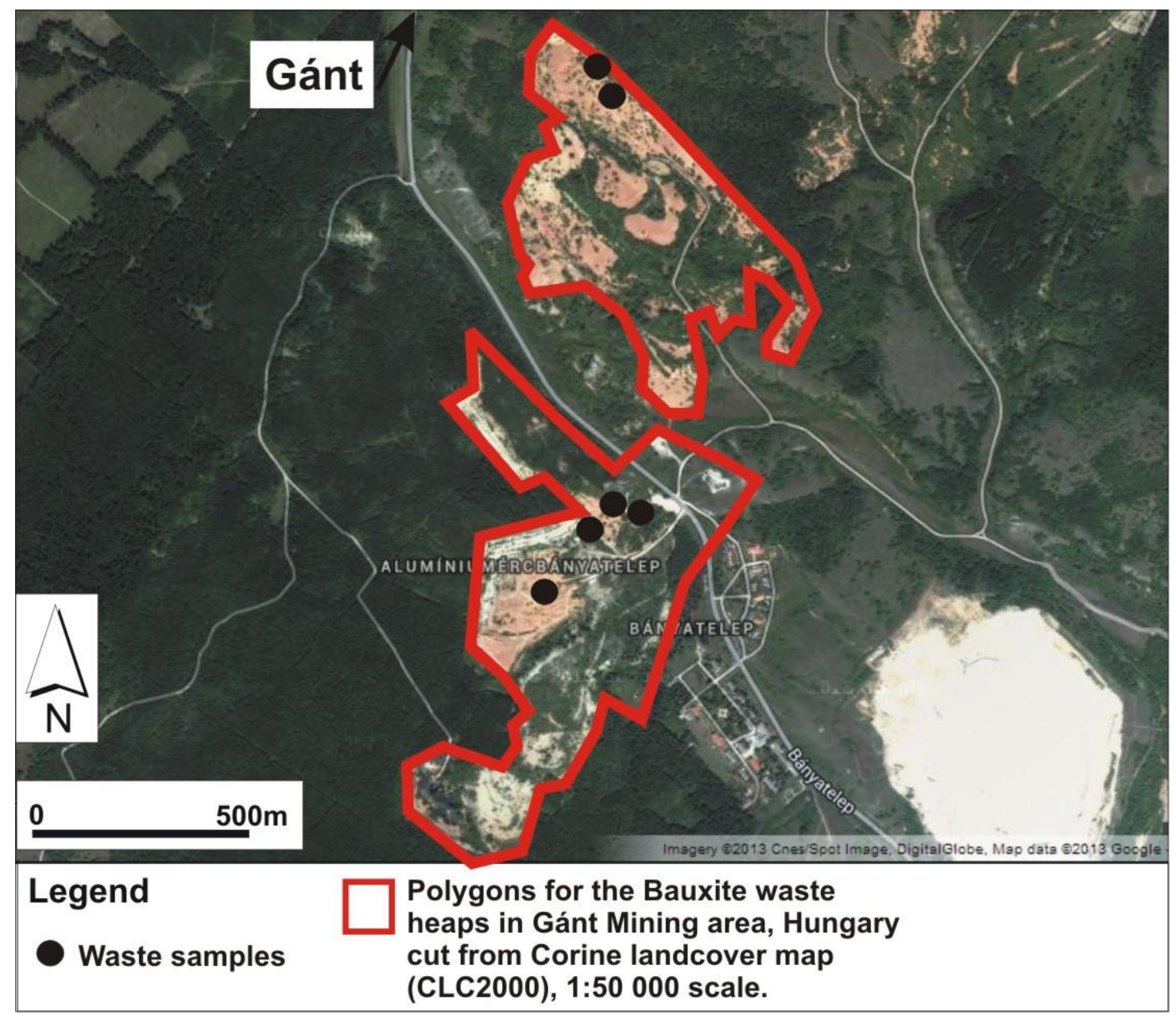

Figure 16. Polygons of the mine waste sites defined from the CORINE land cover map (CLC 2000) overlaid by Google Earth ${ }^{\circledR}$ aerial photographs (2013) to answer EU Pre-selection Protocol questions Q13 and Q14 on the air and direct contact pathways related to the cover of waste heaps, respectively. An example shows the Bauxite waste heap in Gánt Mining Area, Hungary. 


\section{Results}

\subsection{EU MWD Pre-selection Protocol Risk assesment using the EU thresholds}

The contamination RA according to the EU MWD Pre-selection Protocol is carried out in two runs. The first run uses the original EU thresholds (slope $\leq 5^{\circ}, 1 \mathrm{~km}$ distance and number of people in the nearest settlement $\geq 100$ ) (Tables 4 and 5). The second run uses local thresholds defined by (1) the highest natural break in the parameter (slope (Q10) and the lowest natural break for the nearest distance (Q11, Q15-18)) cumulative distribution curves (corresponding to local minima in the frequency histogram; see Fig.17) (Local threshold), and by (2) the median value of these parameters (Median-based threshold, Table 6). The highest break value threshold represents the precautionary principle and tries to include the largest number of sites for further examination while adjusting to the local physiographic conditions (Hungary in this study). The Median-based threshold takes a neutral position by giving a 50\% chance of relative risk. This test results altogether in three final selection of sites according to the three different thresholds (EU threshold, Local threshold and Median-based threshold).

Table 4. Questions with threshold values (Q10, Q11, and Q15-18) of the EU MWD Pre-selection Protocol, and the rationale behind each local threshold value. Note that the median distance value of all sites in Q17 is 0m to the nearest Natura 2000 sites, therefore the median value of the next larger group $(470 \mathrm{~m})$ is chosen as a median-based local threshold in this question (see Table 3 ).

\begin{tabular}{|c|c|c|c|c|}
\hline Question & Issue & $\begin{array}{l}\text { EU thresholds } \\
\text { (Irish Quarry } \\
\text { regulations) }\end{array}$ & $\begin{array}{c}\text { Local } \\
\text { thresholds } \\
\text { (Median-based) }\end{array}$ & Basis \\
\hline Q10 & $\begin{array}{l}\text { Is the heap foundation greater than a } \\
\text { specified slope? }\end{array}$ & $1: 12\left(5^{\circ}\right)$ & $10^{\circ}$ & Median of slope data \\
\hline Q11 & $\begin{array}{l}\text { Is there a water body within a } \\
\text { specified distance of the facility? }\end{array}$ & $1 \mathrm{~km}$ & $760 \mathrm{~m}$ & Median of distance data \\
\hline \multirow{2}{*}{ Q15 } & \multirow{2}{*}{$\begin{array}{l}\text { Is there a settlement with more than } \\
\text { a specified number of people within } \\
\text { a specified distance of the facility? }\end{array}$} & 100 & 820 & $\begin{array}{l}\text { Median of population } \\
\text { data }\end{array}$ \\
\hline & & $1 \mathrm{~km}$ & $1,722 \mathrm{~m}$ & Median of distance data \\
\hline \multirow[b]{2}{*}{ Q16 } & \multirow{2}{*}{$\begin{array}{l}\text { Is the facility within a specified } \\
\text { distance from a water body which is } \\
\text { at least at a specified quality status? }\end{array}$} & $1 \mathrm{~km}$ & $6,044 \mathrm{~m}$ & Median of distance data \\
\hline & & $\begin{array}{l}\text { less than Good } \\
\text { status }\end{array}$ & $\begin{array}{l}\text { less than Good } \\
\text { status }\end{array}$ & $\begin{array}{l}\text { Groundwater Directive } \\
(2006 / 118 / \mathrm{EC})\end{array}$ \\
\hline Q17 & $\begin{array}{l}\text { Is the facility within a specified } \\
\text { distance of a Natura } 2000 \text { site? }\end{array}$ & $1 \mathrm{~km}$ & $470 \mathrm{~m}$ & Median of distance data \\
\hline Q18 & $\begin{array}{l}\text { Is the facility within a specified } \\
\text { distance of agricultural land? }\end{array}$ & $1 \mathrm{~km}$ & $612 \mathrm{~m}$ & Median of distance data \\
\hline
\end{tabular}

The YES, NO and UNKNOWN responses of the EU MWD Pre-selection Protocol (Annex 1) are registered and calculated for each question in Table 5. Out of 145 mine waste sites, only 19 sites have a documented incident (Q1), and among these is the toxic red mud spilled through the failed dam of the Ajka alumina depository in Kolontár, Hungary, in 2010, killing 10 persons, injuring more than 150 and polluting agricultural land areas. These 19 sites are immediately directed to further examination in the EU MWD Pre-selection Protocol. 
Table 5. Summary statistics of the EU Pre-selection Protocol responses of questions Q1-18, showing the number of YES and NO responses based on the EU Pre-selection Protocol thresholds, and the local median-based thresholds and on the local highest group-based thresholds. The number (U) and percentage of certain to uncertain (U\%) responses for each question, based on the number of UNKNOWN responses. Bold indicates questions and statistics depending on thresholds.

\begin{tabular}{|c|c|c|c|c|c|c|c|c|c|c|}
\hline \multirow{2}{*}{\multicolumn{2}{|c|}{$\begin{array}{l}\text { Pre-selection } \\
\text { Protocol }\end{array}$}} & \multirow{3}{*}{$\begin{array}{c}\begin{array}{c}\text { Number } \\
\text { of Sites }\end{array} \\
145\end{array}$} & \multicolumn{2}{|c|}{ EU thresholds } & \multicolumn{2}{|c|}{$\begin{array}{l}\text { Local thresholds } \\
\text { (Median-based) }\end{array}$} & \multicolumn{2}{|c|}{$\begin{array}{l}\text { Local thresholds } \\
\text { (Highest group) }\end{array}$} & \multirow[t]{2}{*}{$\mathrm{U}$} & \multirow[t]{2}{*}{$\mathrm{U} \%$} \\
\hline & & & YES & NO & YES & NO & YES & $\mathrm{NO}$ & & \\
\hline Impact & Q1 & & 19 & 126 & 19 & 126 & 19 & 126 & 0 & 0 \\
\hline \multirow{9}{*}{$\begin{array}{l}\stackrel{0}{0} \\
\stackrel{\Xi}{0} \\
\mathscr{n}\end{array}$} & Q2 & 145 & 101 & 40 & 101 & 40 & 101 & 40 & 4 & 3 \\
\hline & Q3 & 145 & 126 & 15 & 126 & 15 & 126 & 15 & 4 & 3 \\
\hline & Q4 & 145 & 7 & 138 & 7 & 138 & 7 & 138 & 0 & 0 \\
\hline & Q5 & 145 & 9 & 136 & 9 & 136 & 9 & 136 & 0 & 0 \\
\hline & Q6 & 9 & 9 & 0 & 9 & 0 & 9 & 0 & 0 & 0 \\
\hline & Q7 & 9 & 4 & 2 & 4 & 2 & 4 & 2 & 3 & 33 \\
\hline & Q8 & 136 & 34 & 92 & 34 & 92 & 34 & 92 & 10 & 7 \\
\hline & Q9 & 136 & 9 & 115 & 9 & 115 & 9 & 115 & 12 & 9 \\
\hline & Q10 & 136 & 110 & 26 & 74 & 62 & 2 & 134 & 0 & 0 \\
\hline \multirow{4}{*}{ 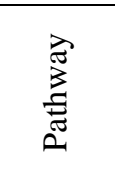 } & Q11 & 145 & 64 & 81 & 73 & 72 & 144 & 1 & 0 & 0 \\
\hline & Q12 & 145 & 120 & 25 & 120 & 25 & 120 & 25 & 0 & 0 \\
\hline & Q13 & 145 & 17 & 128 & 17 & 128 & 17 & 128 & 0 & 0 \\
\hline & Q14 & 145 & 17 & 128 & 17 & 128 & 17 & 128 & 0 & 0 \\
\hline \multirow{4}{*}{ 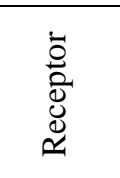 } & Q15 & 145 & 45 & 100 & 73 & 72 & 141 & 4 & 0 & 0 \\
\hline & Q16 & 145 & 28 & 117 & 73 & 72 & 142 & 3 & 0 & 0 \\
\hline & Q17 & 145 & 131 & 14 & 112 & 33 & 142 & 3 & 0 & 0 \\
\hline & Q18 & 145 & 84 & 61 & 73 & 72 & 142 & 3 & 0 & 0 \\
\hline
\end{tabular}

In Q2, 101 sites with YES responses were producing waste with sulphide minerals, 40 sites have NO responses, and the other 4 sites (3\% of the studied sites) with UNKNOWN response. While in Q3, 126 sites were producing minerals with toxic heavy metals, 15 sites have NO responses, and 4 sites (3\% of the total number of sites) have UNKNOWN response. In Q4, seven sites with YES responses have documented use of dangerous chemicals for the mineral processing, the other 138 sites have NO responses. In Q5, nine sites are tailings lagoon sites in Hungary and 136 sites are waste heaps. Still, the tailings lagoons represent a higher risk due to the fluid nature of the stored material and to the large size of these facilities. In Q6, the area of each of the 9 tailings lagoons is greater than the $10,000 \mathrm{~m}^{2}$ threshold. In Q7, only four tailings lagoons with YES responses are $>4 \mathrm{~m}$ in height of the waste site, while two sites with NO responses are $<4 \mathrm{~m}$ and the other three sites (33\% of the 9 tailings lagoons) have UNKNOWN responses. In Q8, 34 waste heap sites with YES responses are greater than $10,000 \mathrm{~m}^{2}$ in surface area and 10 waste heaps area extent ( $7 \%$ of the 136 waste heaps) is unknown. It is interesting to have lack of information and thus uncertainty in the simple engineering properties of abandoned mine waste facilities. One would expect that mine archives of former active mines shall contain readily this information. In Q9, nine waste heap sites are $>20 \mathrm{~m}$ in height and 12 sites (9\%) have unknown heights. The height of the waste rock heap is hard to determine due to the irregular geometry of the rock mass over a sloping terrain. The slope of the foundation upon which the waste heap rests is of concern with respect to stability. 
Table 6. Class boundaries of the EU Pre-selection Protocol parameters based on the natural-breaks found in the parameter distribution plots (see Fig. 17). Class boundaries are used to define thresholds adapted to local conditions (in Hungary in this case). The highest class boundary and the median of all sites value local thresholds are discussed in this study. Number of sites falling within each natural class helps guiding the selection of the proper threshold. See text for details.

\begin{tabular}{|c|c|c|c|c|c|}
\hline Question & $\begin{array}{l}\text { Class boundaries } \\
\text { (local thresholds) }\end{array}$ & $\begin{array}{l}\text { Topographic slope below } \\
\text { waste site (degree) }\end{array}$ & Median_of class & $\begin{array}{c}\text { Median_of all } \\
\text { sites } \\
\text { (local thresholds) }\end{array}$ & $\begin{array}{l}\text { Numb } \\
\text { er of } \\
\text { sites }\end{array}$ \\
\hline Q10 & $\begin{array}{c}>25 \\
20-25 \\
9-20 \\
<9\end{array}$ & $\begin{array}{c}25-29 \\
20-24 \\
9-19 \\
0-9\end{array}$ & $\begin{array}{c}29 \\
22 \\
14 \\
5\end{array}$ & $10^{\circ}$ & $\begin{array}{c}3 \\
8 \\
64 \\
70\end{array}$ \\
\hline Q11 & $\begin{array}{c}<500 \\
500-2000 \\
2000-3604 \\
>3604\end{array}$ & $\begin{array}{c}\begin{array}{c}\text { Distance to the nearest } \\
\text { surface water course (m) }\end{array} \\
11-481 \\
531-1997 \\
2029-3014 \\
3604-4021\end{array}$ & $\begin{array}{c}270 \\
1089 \\
2457 \\
3643\end{array}$ & 760 & $\begin{array}{c}57 \\
66 \\
19 \\
3\end{array}$ \\
\hline Q15 & $\begin{array}{c}<686 \\
686-1478 \\
1478-3604 \\
>3604\end{array}$ & $\begin{array}{c}\begin{array}{c}\text { Distance to the nearest } \\
\text { settlement (m) }\end{array} \\
0-582 \\
686-1462 \\
1478-3305 \\
3604-4367\end{array}$ & $\begin{array}{c}319 \\
1119 \\
2618 \\
4083\end{array}$ & 1,722 & $\begin{array}{c}33 \\
37 \\
66 \\
9\end{array}$ \\
\hline Q16 & $\begin{array}{c}0 \\
14-9541 \\
9541-11692 \\
>11692\end{array}$ & $\begin{array}{c}\begin{array}{c}\text { Distance to the } \\
\text { groundwater } \\
\text { bodies of 'poor status' (m) }\end{array} \\
0 \\
14-9541 \\
9545-11055 \\
11692-23771 \\
\end{array}$ & $\begin{array}{c}0 \\
5687 \\
10005 \\
13635\end{array}$ & 6,044 & $\begin{array}{c}25 \\
85 \\
28 \\
7\end{array}$ \\
\hline Q17 & $\begin{array}{c}0 \\
13-1299 \\
1480-1725 \\
>2294\end{array}$ & 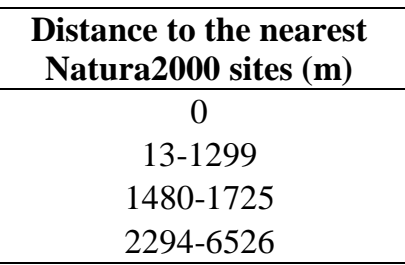 & $\begin{array}{c}0 \\
470 \\
1612 \\
2732 \\
\end{array}$ & 470 & $\begin{array}{c}91 \\
42 \\
6 \\
6 \\
\end{array}$ \\
\hline Q18 & $\begin{array}{c}<1064 \\
1064-2585 \\
2585-3688 \\
>3688\end{array}$ & $\begin{array}{c}\begin{array}{c}\text { Distance to the nearest } \\
\text { agricultural areas (m) }\end{array} \\
0-861 \\
1064-2272 \\
2585-3402 \\
3688-3976\end{array}$ & $\begin{array}{c}167 \\
1515 \\
3128 \\
3956\end{array}$ & 612 & $\begin{array}{c}81 \\
28 \\
31 \\
4\end{array}$ \\
\hline
\end{tabular}

The greater the slope angle the greater the risk of waste heap failure. The EU threshold chosen is $1: 12$ which equates to $8.3 \%$ or a slope angle of almost $5^{\circ}$. Based on the slope values derived from the 50m DEM (Fig.12), 110 waste heap sites with YES responses are greater than or equal 1:12 $\left(5^{\circ}\right)$ in slope and 26 sites with NO responses are less than $5^{\circ}(\mathrm{Q} 10)$. This shows that most of the sites are located in hilly areas. It is interesting that the failed Ajka red mud tailings facility is in fact located in a flat area below the slope threshold value. 

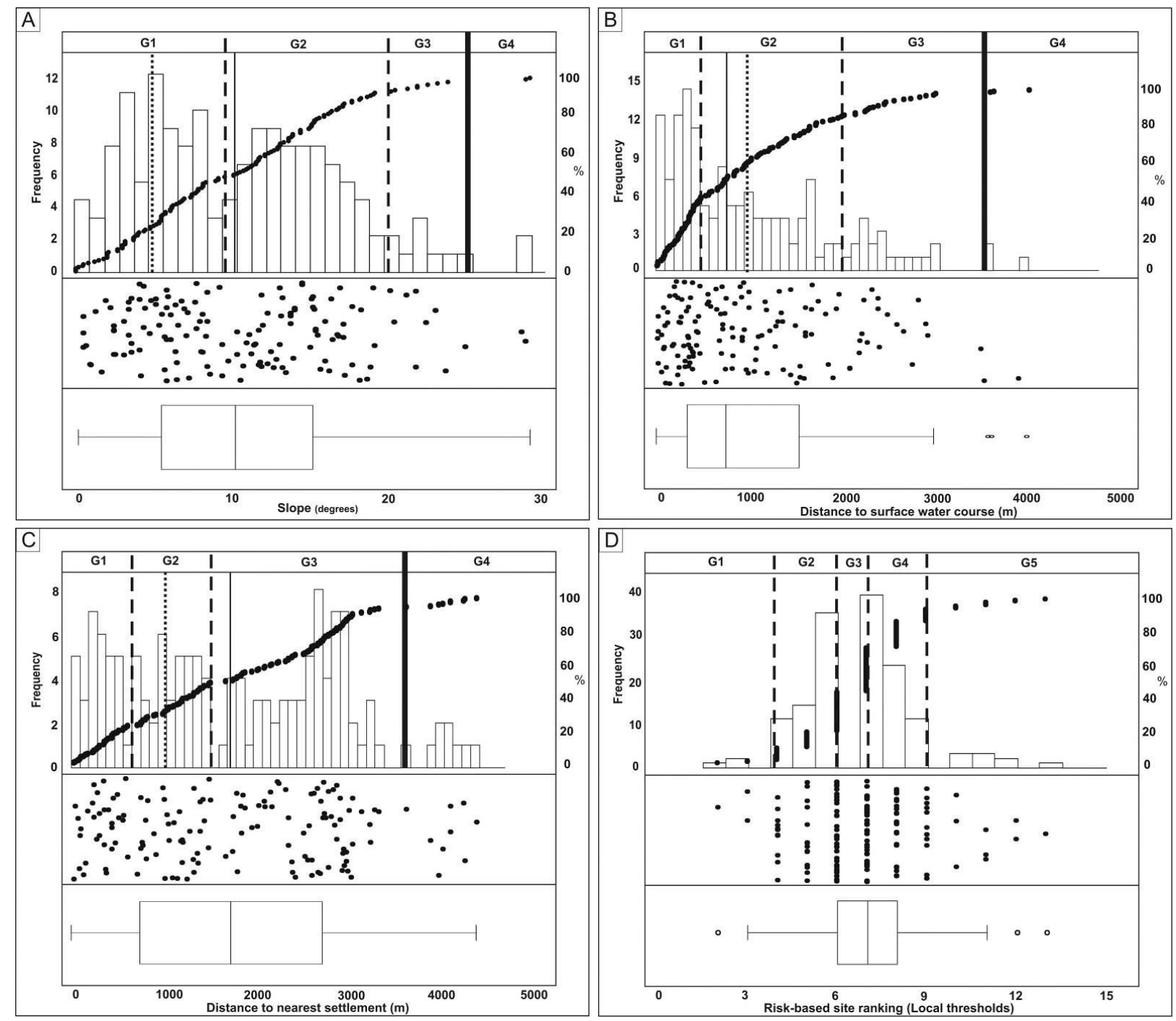

Figure 17. Distribution analyses for the EU Pre-selection Protocol parameters with histograms, scatterplots, box-whisker and cumulative probability plots. Vertical lines show sub-groups $(\mathrm{G} 1, \mathrm{G} 2, \ldots)$ identified by the natural-breaks found in the cumulative probability plots, corresponding to local minima

in the frequency histograms. Dotted line shows the EU Pre-selection Protocol threshold, dashed line shows the median, thin solid line shows the median in all sites and thick solid line indicates the highest group boundary, both used for defining thresholds for the questions in the protocol. See text for details. A. Distribution analysis for slope (question Q10). B. Distribution analysis for distance to the nearest surface water course (question Q11). C. Distribution analysis for distance to the nearest settlement (question Q15). D. Distribution analysis for the total site ranking classes based on the number of YES responses and using median-based local threshold.

The use of the surface permeability map (Fig.10) developed to generate answers for Q12, resulted in 120 sites with YES responses (three sites underlain by high permeable layers and 117 sites underlain by medium permeable layers), while 25 sites underlain by low permeable layers. When 
the mine waste site is covered and the original material is not accessible this means there is no direct contact with receptors. In Q13, 17 sites are exposed to the wind and 128 sites are not due to engineered or natural re- vegetation. While in Q14, 17 sites are uncovered and 128 sites are covered with water, vegetation, soil and forest (Fig.11). For example cells 9, 10 and 10a in the Ajka alumina tailings lagoon are not covered while cells 1-8 have been rehabilitated with soil and plant cover (Fig.11). The recent shift from wet to dry deposition decreased the risk of catastrophic spill but it has increased dusting as confirmed by field observation.

For Q11, 64 sites are within $1 \mathrm{~km}$ distance to the nearest surface water bodies (streams and lakes). In Q15, 45 mine waste sites are within $1 \mathrm{~km}$ distance to nearest human settlements with >100 people. 28 sites are within $1 \mathrm{~km}$ distance to the groundwater bodies of less than good status (poor status). For Q17, 131 mine waste sites are within $1 \mathrm{~km}$ to the national protected 'Natura 2000' sites (91 waste sites are completely inside the Natura 2000' sites), and 14 sites are within distance $>1 \mathrm{~km}$. Moreover, in Q18, 84 sites are within $1 \mathrm{~km}$ distance to the agricultural areas including arable lands, pastures, heterogeneous and permanent crops.

A preliminary risk-based site ranking is possible based on the EU thresholds (slope of almost $5^{\circ}$ and $1 \mathrm{~km}$ distance) by counting and ranking the YES responses of the Pre-selection Protocol, and ranging in scores from 3 to 12 in each site (Table 7). Obviously, if there is more than one dangerous substance at the source or there are multiple contamination pathways and receptors the site has a higher risk. A simple risk ranking based on classes derived from the histogram natural break method yielded break values 5, 6, 8, and 10 resulting in five classes (Fig.18) as follows: 3-4 YES (class V, 13 sites), 5 YES (class IV, 41 sites), 6-7 YES (class III, 48 sites), 8-9 YES (class II, 28 sites), and 10-12 YES (class I, 15 sites).

Table 7. Site ranking classification based on the number of YES responses of the EU Pre-selection Protocol using the original EU thresholds and the local median-based thresholds with risk classes, according to Figure 17D. The number of waste sites in each class is also shown.

\begin{tabular}{|c|c|c|c|c|}
\hline Class & $\begin{array}{c}\text { EU } \\
\text { thresholds }\end{array}$ & $\begin{array}{c}\text { Number of } \\
\text { sites }\end{array}$ & $\begin{array}{c}\text { local thresholds } \\
\text { (Median-based) }\end{array}$ & $\begin{array}{c}\text { Number of } \\
\text { sites }\end{array}$ \\
\hline 5 & $3-4$ & 13 & $2-3$ & 3 \\
\hline 4 & 5 & 41 & $4-5$ & 25 \\
\hline 3 & $6-7$ & 48 & 6 & 35 \\
\hline 2 & $8-9$ & 28 & $7-8$ & 62 \\
\hline 1 & $10-12$ & 15 & $9-13$ & 20 \\
\hline No Pathway & \multicolumn{2}{|c|}{18} & \multicolumn{2}{c|}{16} \\
\hline Examine further & \multicolumn{2}{|c|}{} \\
\hline
\end{tabular}




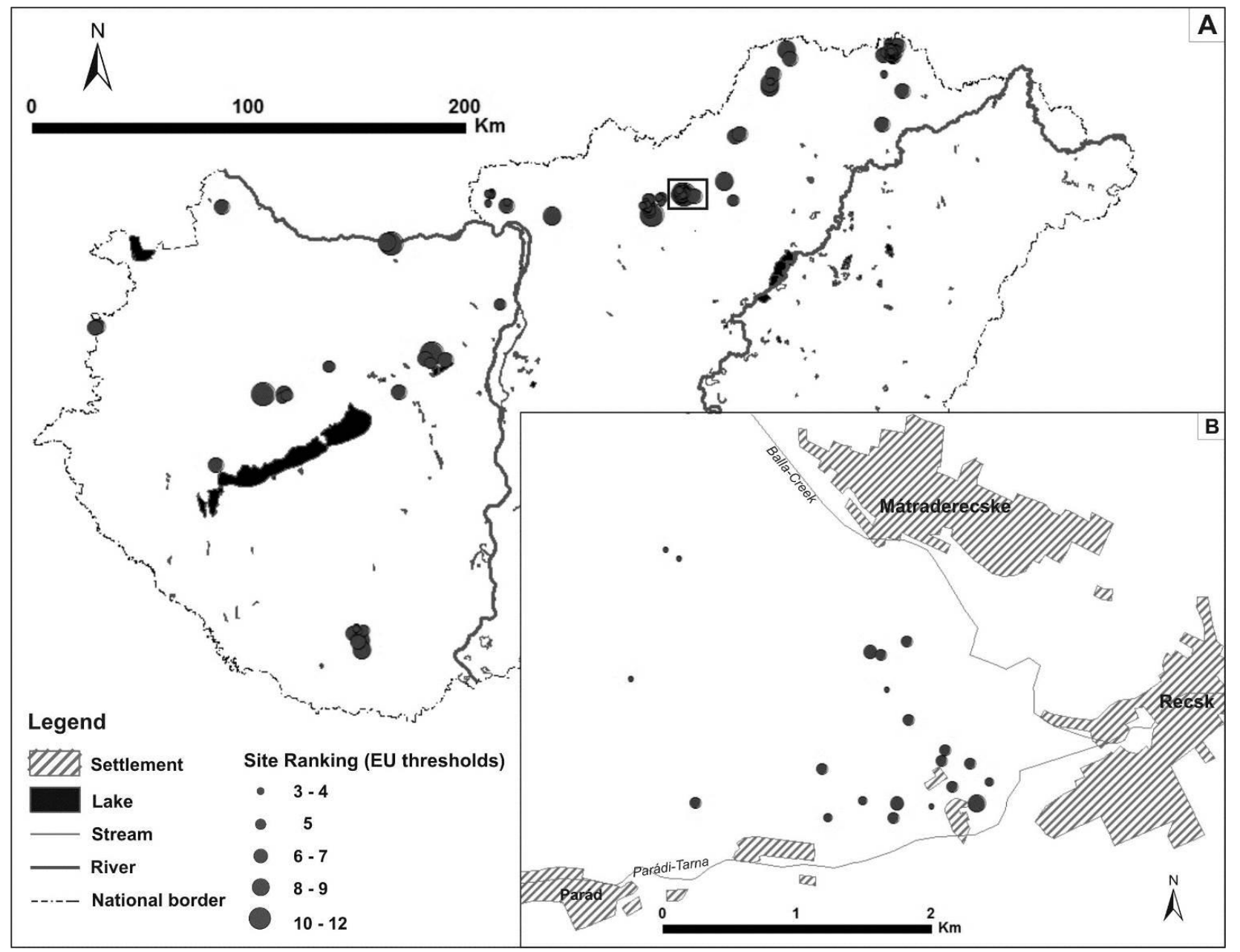

Figure 18. Total risk ranking of the mine waste sites using the EU Pre-selection Protocol thresholds, based on the number of YES responses A. Total risk ranking of the mine waste sites for Hungary. Solid box shows location of Figure 18B. B. An example of the site ranking classes in the Recsk Mining Area in the Parádi-Tarna Creek catchment. 


\subsection{EU MWD Pre-selection Protocol Risk assessment using the local thresholds}

Distribution analysis identified various sub-groups in the studied parameter thresholds (topographic slope, distance and census data) (Table 6, Fig.17). For example, in Q10 (Fig.17A), 3 sites have a topographic slope greater than $25^{\circ}, 8$ sites with slope $20-25^{\circ}$, 64 sites with slope 9$20^{\circ}$ and 70 sites with slope less than $9^{\circ}$. This result suggests the $9^{\circ}$ slope as a natural threshold reflecting the local (Hungarian) conditions, instead of the original $5^{\circ}$ slope threshold. Also, there are $11(8+3)$ sites located on very steep slopes above $20^{\circ}$ which may single out these sites for specific attention in terms of slope movement and facility stability. According to Figure 17B (Q11), 57 sites are within distance less than 500m to the nearest surface water bodies, 66 sites are within distance 531-1,997m, 19 sites within 2,029-3,014m and three sites are within distance $3,014-4,021 \mathrm{~m}$. This shows that almost half of the mine waste sites are significantly (at the $90 \%$ confidence) closer $(\leq 500 \mathrm{~m})$ to receiving streams than the other sites, highlighting these sites for more detailed surface transport modeling if identified for 'further examination' in the EU MWD Pre-selection Protocol. Moreover, the second group of 531-1,997m distance contains the original $1 \mathrm{~km}$ threshold and thus the $2 \mathrm{~km}(1,997 \mathrm{~m})$ threshold may better reflect the local topographic conditions for this question. In Q15 (Fig.17C), 33 sites with population more than 820 inhabitants are within distance less than $680 \mathrm{~m}$ to the nearest settlement, indicating that these sites require prime attention if settlement protection is the concern. It is interesting that 25 sites lie directly above the groundwater bodies with 'poor status' (Q16) and 91 sites are located inside the protected Natura 2000 sites (Q17). The amazing high portion (63\%) of mine waste sites lying directly in protected ecosystems calls for immediate special attention if landscape protection is a priority. While in Q18, 81 sites are within distance less than or equal to $861 \mathrm{~m}$ to the nearest agricultural areas.

The neutral local thresholds based on median values (Median-based threshold; Table 6), selecting half of the sites for YES response, yields $10^{\circ}$ for the slope below the waste site (Q10), $760 \mathrm{~m}$ for the distance to surface water bodies (Q11) and 1,722 $\mathrm{m}$ for the distance to settlements with 820 inhabitants (median-based) (Q15). This is all consistent with the fact that mining areas lie in forested hilly areas with high density drainage network and sparse population: sites are located on steep $10^{\circ}>5^{\circ}$ slopes, close $(760 \mathrm{~m}<1 \mathrm{~km})$ to abundant stream network and with settlements remote $(1,722 \mathrm{~m}>>1 \mathrm{~km})$ from mine sites. The settlement population cut off value is much higher than the original EU value $(820>100$ inhabitants), since people live in villages in Hungary unlike farm areas in Ireland. This calls for stringent catastrophe response in case of civil protection and rescue. The 6,044 $\mathrm{m}$ distance to the nearest groundwater bodies with 'poor status' (Q16) is however reassuring, unlike the median distances of $470 \mathrm{~m}$ to Natura 2000 sites (Q17) and $612 \mathrm{~m}$ agricultural areas (Q18).

Distribution analysis was performed on the population census data of Hungary (census 2009), to develop a population threshold number for Q15 of the EU MWD Pre-selection Protocol, resulting in 53 classes ranging from $<45$ to $>45,000$ persons bounding the two extreme groups. The analysis indicates that 1,670 of the total 3,157 settlements with less than or equal to 820 persons 
are representing $53 \%$ of the total number of settlements in Hungary. Therefore this number, 820 persons, is a reasonably representative choice as a local threshold (Median-based) for the population in Q15. By running the EU MWD Pre-selection Protocol using these local thresholds (Median-based), the YES, NO and UNKNOWN responses are compared to those of EU thresholds as depicted in Table 5. Table 5 shows that the number of waste sites with YES responses of the EU MWD Pre-selection Protocol varies from using the EU thresholds to local thresholds (Median-based). For example, in Q10 on underlying terrain slope, sites with YES responses are decreased from 110 (EU thresholds) to 74 (local thresholds (Median-based) and to two sites with the highest threshold group, whilst in Q11 on the distance to the nearest surface water course, the sites with YES responses are increased from 64 (EU thresholds) to 73 (Medianbased local threshold) and 144 (the highest group).

The local threshold of the highest distance group boundary (Table 6) represents the worst case scenario by selecting the possible largest number of sites for YES response and therefore for further examination based on the reasonable level of risk, depicted by solid lines in Fig.17A, B and $\mathrm{C}$. Thus, this threshold selection follows the precautionary principle.

In summary, after the existing pre-screening risk assessment of the mine waste sites in Hungary, 127 mine waste sites are directed to EXAMINE FURTHER based on the EU thresholds (Table 4), 18 sites with no risk (these sites have no pathway). While, 129 sites are directed to EXAMINE FURTHER based on the local thresholds (Median-based), 16 mine waste sites with no risk (these sites have no pathway). In the case of using the local threshold (lowest group boundary) (Table 3) in Q10 (5 $)$, Q11 (270m), Q15 (319m), Q16 (0m), Q17 (0m) and Q18 (167m), 118 sites are directed to EXAMINE FURTHER and 27 sites have no risk (19 sites with no Pathway and 8 sites with no Receptor). While by using the local threshold (highest group boundary) (Table 3) in Q10 (29 $)$, Q11 (3,643m), Q15 (4,083m), Q16 (13,635m), Q17 (2,732m) and Q18 (3,956m), all the 145 mine waste sites are directed to EXAMINE FURTHER. It is obvious that this threshold selection represents the worst case scenario and follows the precautionary principle.

\subsection{Pre-screening (Tier 0) EEA PRAMS Risk Assessment Model}

Table 8 illustrates the summary statistics of YES, NO and UNKNOWN responses of ' $A$ ' and 'B' criteria of the pre-screening of problem areas, according to the EEA PRAMS model. " $\mathrm{A}$ " criteria include six EU relevant policy questions with YES/NO answer. While "B" criteria include a set of questions on size in terms of surface area, waste or stored toxic materials volumes, and complexity in terms of number of sites, requiring simple information more likely to be available.

In question A1, 19 mine waste sites have YES responses with natural ecosystems of EU concern affected (Table 8). In A2, 19 sites have NO responses with contamination impact on surface water course which is not prevented according to the EU Water Frame Directive (WFD), while 126 sites with UNKNOWN responses that represent $87 \%$ of the total 145 sites. This shows that there is little harmonization among EU directives (MWD and WFD) and there are no linked 
environmental database yet. In A3, the overwhelming majority of sites (122 sites) has YES responses and have contamination in the groundwater body, so 'good status', as defined by the Groundwater (Directive 2006/118/EC), cannot be reached. In A4, none of the 145 mine waste sites have proven effect on food products brought on EU markets. According to question A5, there are no waste sites with contamination impacts on human and/or environmental health leading to use restrictions blocking regional social and economic development. In A6, 19 sites with YES responses are classified as problem areas of EU interest upon meeting at least one of the 'A' criteria questions and 126 sites with NO responses are classified as no problem areas.

Table 8. Summary statistics of 'A' and 'B' criteria of the Pre-screening of problem areas of PRAMS (Tier $0)$ model, showing the number of YES, NO and UNKNOWN (U) responses and the percentage of uncertain to certain (U\%) responses for each question.

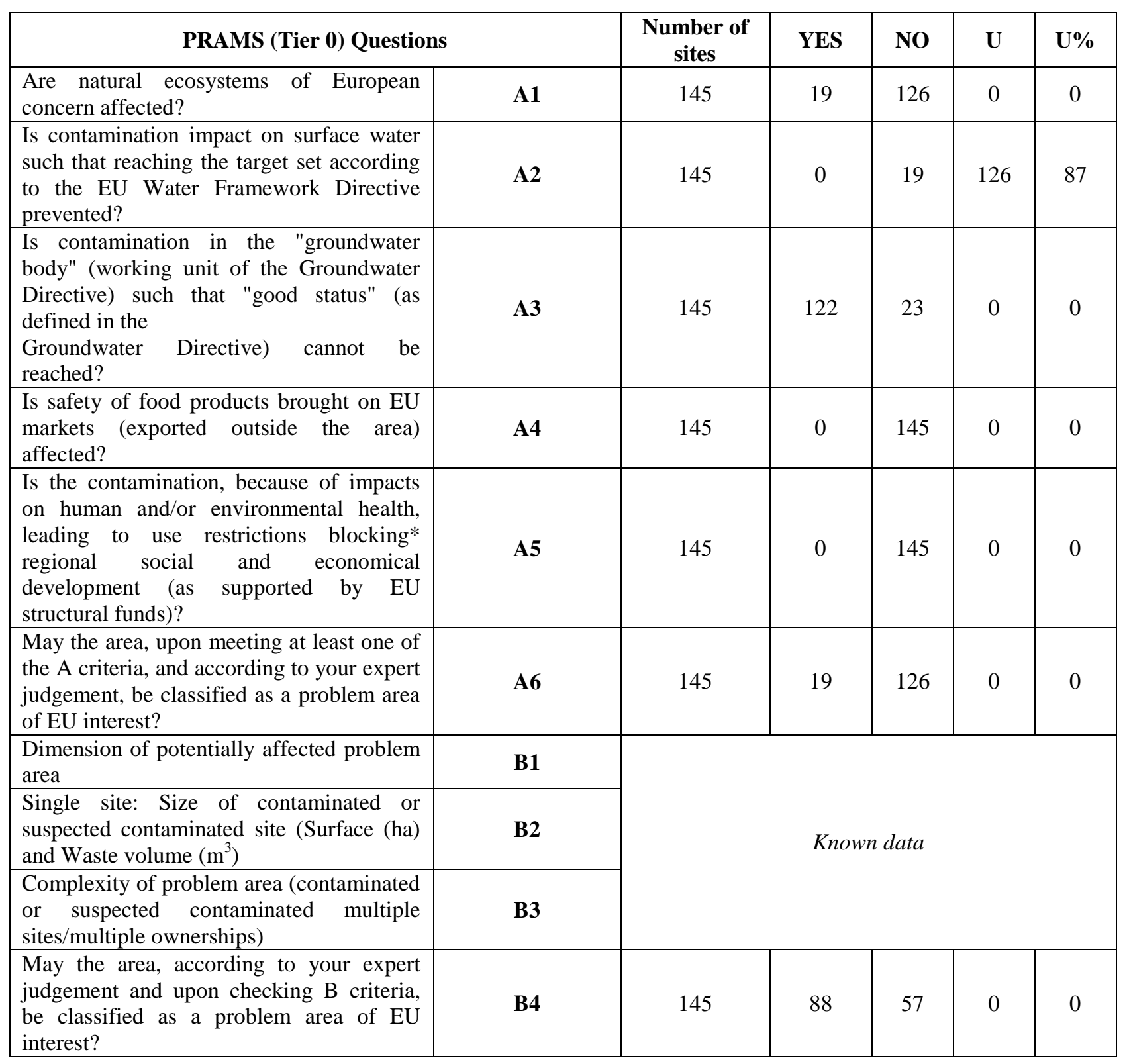


After checking ' $\mathrm{B}$ ' criteria with available known data of the 145 mine waste sites. This archive data is available from the Geological Institute of Hungary such as dimension of the area affected (ha) (question B1), size of the contaminated site (ha), waste or stored toxic materials volume in cubic meters (B2) and complexity of problem area (the number of contaminated or suspected as contaminated multiple sites/multiple ownerships) (B3). In question B4, 88 sites have YES responses and classified as a problem area of EU interest and 57 sites have NO responses and classified as no problem areas (Table 8).

The results of the pre-screening of problem areas by the EEA PRAMS model show that 88 sites are classified as a problem sites for further examination. It is obvious that the number of mine waste site that classified as a potential problem areas of EU interest and directed to further examination, increased from 19 (in question A6) to 88 sites in question B4 (Table 8). This decision is based on the availability of known data to answer the questions of ' $\mathrm{B}$ ' criteria.

\subsection{Sensitivity and uncertainty analysis of the EU MWD Pre-selection Protocol}

Uncertainty is inescapable in the assessment of environmental hazard, exposure and the consequent risks to human health, and it arises at every stage in these assessments (Ramesy 2009). It causes an increased risk of incorrect decisions being made in the assessment, particularly if the uncertainty is ignored in a deterministic approach, or just underestimated in a probabilistic approach. In this study, uncertainty assessment is limited to the UNKNOWN responses (U) in each question of the EU MWD Pre-selection Protocol due to missing of site specific data. The number of uncertain responses is simply counted for each site. The higher number of uncertain responses for a site exists, the higher risk the site bears due to lack of information and it requires more detailed further examination in the follow-up Tier 1 RA. Similarly, the number of uncertain responses can be lumped for each question which provides an overall indicator of parameter uncertainty. For example, if a question receives the response UNKNOWN for 10 sites it represents a more uncertain parameter than a question for which all sites have reliable data available for a solid YES/NO answer. For comparison, the same exercise is performed on the EEA PRAMS Pre-screening method. Since this method has a different set of parameters, results delivered an indication for the overall uncertainty that each RA method bears.

According to a preliminary site ranking performed within STATIGRAPHICS ${ }^{\circledR}$ and based on number of UNKNOWN responses (U) which is ranging in the sites from 0 to $2 \mathrm{U}$ responses and resulting in, 125 sites have no uncertain responses $(U=0), 7$ sites have one $(U=1)$ and 13 sites have two $(U=2)$ using the EU threshold and local Median-based threshold within the EU Preselection Protocol. While in case of using the Pre-screening PRAMS model, 19 sites have no uncertain responses $(U=0), 123$ sites have one $(U=1)$ and 3 sites have two $(U=2)$. Table 2 indicates that UNKNOWN (U) responses are located only in the source questions in the EU MWD Pre-selection Protocol, ranging from 3\% in Q2 (presence of sulphide minerals in waste) and Q3 (toxic element potential in waste) and 7\% in Q8 (size of the waste heap) to 33\% in Q7 (height of dam wall of the tailings lagoon). Thus, relaxing the source questions, the percentage of 
uncertain responses (U\%) reduces to zero. This is the most unexpected outcome of this study, because high certainty about the source, i.e. the mine waste facilities, was expected due to the assumed mine industry engineering archive documentation. An explanation is that mining flourished in the centrally directed economy period in the 50-80s when waste treatment and environmental issues were not among the priorities leading to poor documentation of related facilities. This is confirmed by the amazing fact that the overwhelming majority of mine sites have no environmental monitoring data whatsoever available.

In order to identify the key parameters and to check the sensitivity (in terms of final selection for further examination) by removal of parameters (questions of the MWD Pre-selection Protocol) from Q2 to Q18, the number of YES responses are recalculated in the other questions for all sites using the EU and local Median-based thresholds. By removal of question Q1 (if site has a known impact with documented incident) there is no change to the total source-pathway-receptor site ranking because the 19 sites with known impact are directed to 'Examine Further' in one step. For the Source Q2 to Q10, by removal of Q2, 125 sites are directed to 'Examine Further' using EU thresholds while 141 sites with 'Examine Further' using local Median-based thresholds. In Q3, 126 sites with 'Examine Further' using EU thresholds while 136 sites with 'Examine Further' using local thresholds. In Q4, Q5, Q6, Q7 and Q9, 126 sites with 'Examine Further' using EU thresholds while 142 sites with 'Examine Further' using local thresholds. In Q8, 125 sites with 'Examine Further' using EU thresholds while 141 sites with 'Examine Further' using local thresholds. In Q10, 120 sites with 'Examine Further' using EU thresholds while 139 sites with 'Examine Further' using local thresholds. For the Pathway Q11 to Q14, by removal of Q11, 127 sites with 'Examine Further' using EU thresholds while 139 sites with 'Examine Further' using local thresholds. In Q12, 69 sites with 'Examine Further' using EU thresholds while 92 sites with 'Examine Further' using local thresholds. In Q13 and Q14, 127 sites with 'Examine Further' using EU thresholds while 142 sites with 'Examine Further' using local thresholds. For the Receptor Q15-Q18, by removal of Q15 and Q16, 127 sites with 'Examine Further' using EU thresholds while 142 sites with 'Examine Further' using local thresholds. In Q17, 74 sites with 'Examine Further' using EU thresholds while 140 sites with 'Examine Further' using local thresholds. In Q18, 124 sites are directed to 'Examine Further' using EU thresholds while 128 sites with 'Examine Further' using local Median-based thresholds.

The key parameters as depicted from above are Q3 (if sites are producing minerals with toxic heavy metals) and Q10 (slope) for source questions, Q12 (presence of higher permeable layer beneath the waste site) for pathway and Q17 (distance to the nearest surface water course) and Q18 (distance to the nearest agricultural areas) for receptor questions. The final selection of sites to further examination will be sensitive to and depends most heavily on these parameters.

For the pre-screening (Tier 0) PRAMS model, by removal of questions A1 and A2, 69 sites are directed to 'Examine Further' (Table 8). By removal of A3, 23 sites are directed to 'Examine Further'. By removal of questions A4 and A5, nothing will change because all of these questions 
have only NO responses. By removal of question A6, 69 sites are directed to 'Examine Further' and by removal of question B4 (presence of known data), 19 sites are directed to 'Examine Further' (Table 8).

In order to estimate the spatial uncertainty in distance measurements, buffer distances 100, 200, 500, 1000, 1500 and 2000m are delineated to pathway Q11 and the receptor Q15-18 and the number of waste sites are counted within each buffer distance. Resulting in distance to the nearest surface water course (Q11), 6 sites are within 100m, 9 sites within 200m, 20 sites within $500 \mathrm{~m}$, 30 sites within $1000 \mathrm{~m}, 32$ sites within $1500 \mathrm{~m}$ and 34 sites within $2000 \mathrm{~m}$. In distance to the nearest settlements (Q15), 4 sites within 100-200m, 10 sites within $500 \mathrm{~m}, 18$ sites within $1000 \mathrm{~m}$, 34 sites within $1500 \mathrm{~m}$ and 42 sites within $2000 \mathrm{~m}$. In distance to the nearest Groundwater bodies (Q16), 24 sites within 100-200m, 25 sites within 500m, 26 sites within $1000 \mathrm{~m}, 30$ sites within 1500-2000m. In distance to the nearest Natura 2000 sites (Q17), 9 sites within $100 \mathrm{~m}, 12$ sites within $200 \mathrm{~m}, 20$ sites within 500-1000m, 24 sites within $1500 \mathrm{~m}$ and 26 sites within $2000 \mathrm{~m}$. In distance to the nearest agricultural areas (Q18), 22 sites within $100-200 \mathrm{~m}, 37$ sites within $500 \mathrm{~m}$, 47 sites within $1000 \mathrm{~m}, 55$ sites within $1500 \mathrm{~m}$ and 63 sites within $2000 \mathrm{~m}$. It is obvious from above that there is no change in number of sites from $100-200 \mathrm{~m}$ buffer distance. There is no big change in Q16 from 100-2000m. For Q11, the number of sites is increased from 100-1000m after only 4 sites increased till $2000 \mathrm{~m}$. In Q18 there is a continuous increase in the number of sites from 200-2000m. Moreover, most of the digital topographic maps used in this study have $1: 100,000$ scale therefore $\pm 100 \mathrm{~m}$ will be reasonably accepted as spatial uncertainty in the distance measurements.

For the topographic slope (Q10), by increasing the slope from 1 to 5 degrees (EU threshold) the number of sites decreases from 138 to 111 sites, respectively. At $9^{\circ} 78$ sites will be risky while at $10^{\circ} 74$ sites are in risk position and at $11^{\circ} 69$ sites will be risky. And so on, the number of risky sites is decreasing to 39 at $15^{\circ}$, to 11 sites at $20^{\circ}$ and to 3 sites at $25^{\circ}$.

\subsection{A preliminary risk-based ranking based on the EU MWD Pre-selection Protocol}

Although risk-based site ranking is a subject for Tier $1 \mathrm{RA}$ for the sites selected for further examination by any pre-selection (Tier 0 ) procedure, a simple preliminary ranking is already enabled by the numeric evaluation of responses to the questions. The number of YES responses using the local Median-based threshold is counted for each site from the possible 0 to 13 (Table 7). Obviously, since a YES response means presence of risk, the higher number of YES responses exist for a site, the higher the risk is. The number of YES responses was also analysed

for distribution by the natural breaks and the Jenks Natural breaks analysis within ArcINFO ${ }^{\circledR} 10$ as shown in Fig.17D. The resulting five risk classes are shown in Fig.19, according to the number of YES responses for each site: 2-3 YES (class V, 3 sites), 4-5 YES (class IV, 25 sites), 6 YES (class III, 35 sites), 7-8 YES (class II, 62 sites), and 9-13 YES (class I, 20 sites). It is noted that in this exercise only the YES responses are calculated supported by solid data. Although UNKNOWN is identical with a YES response in RA, in this part of the investigation sites with 
UNKNOWN responses are separately studied and ranked in order to have a clear and transparent picture of site ranking related to responses to the questions.

Based on number of YES responses for ' $A$ ' and 'B' criteria, a preliminary site ranking is enabled in case of the Pre-screening (Tier 0) PRAMS model, resulting in two classes, 0-2 YES (class II, 126 sites) and 3-4 YES (class I, 19 sites).

The site ranking is based on the number of YES responses of the local Median-based threshold is more adapted to Hungary rather than that based on the EU thresholds $\left(5^{\circ}\right.$ slope and $1 \mathrm{~km}$ distance, 100 inhabitants). Therefore, this ranking is the most appropriate and logic to guide the final site pre-selection of mine waste sites in this study (Fig.19).

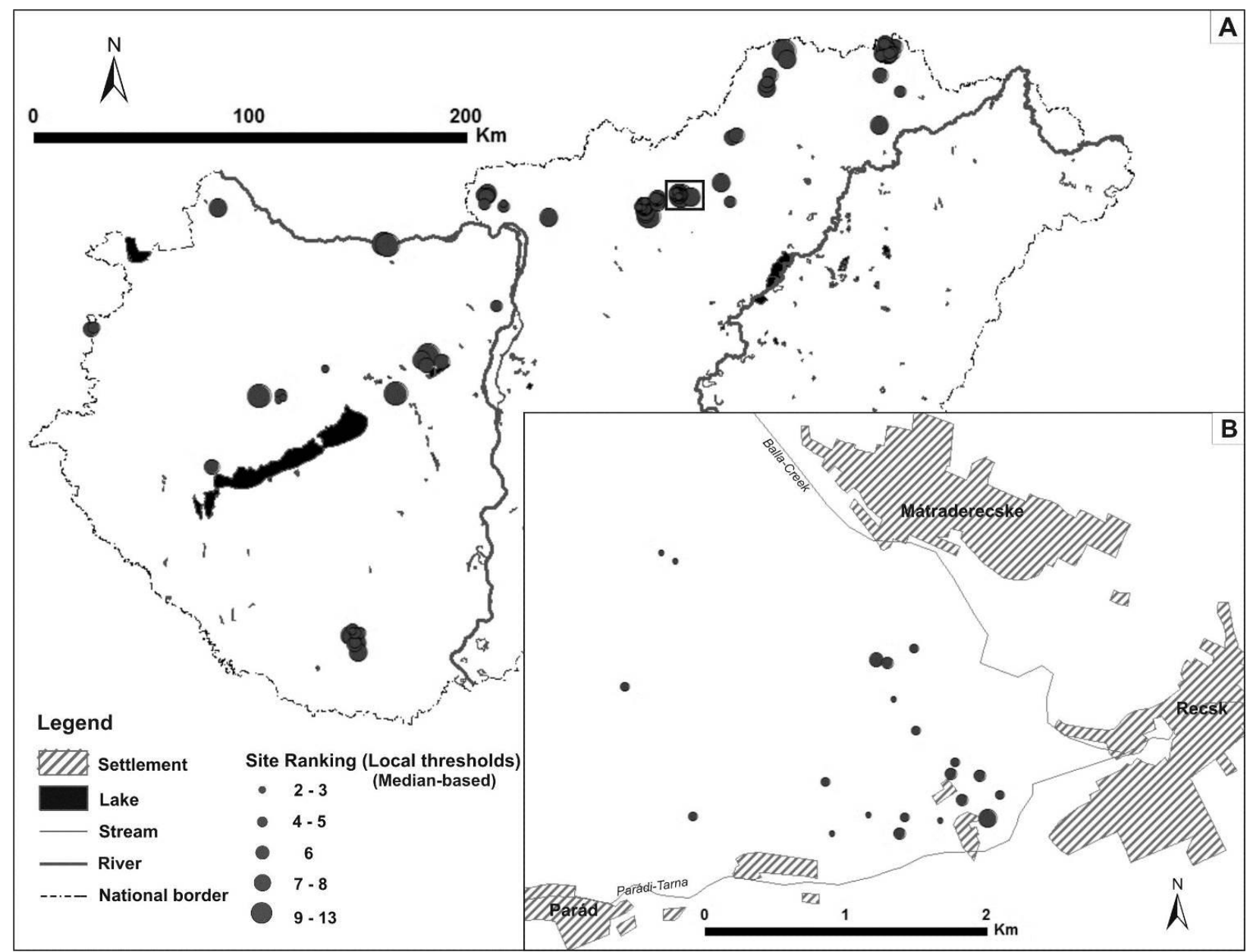

Fig.19 Total risk ranking of the mine waste sites using the median-based local thresholds (see Fig. 17), based on the number of YES responses A. Total risk ranking of the mine waste sites for Hungary. Solid box shows location of Figure 19B. B. An example of the site ranking classes in the Recsk Mining Area in the Parádi-Tarna Creek catchment.

For sake of completeness, the results of the risk-based site ranking system of the EU MWD Preselection Protocol outlined in this study are compared to those results of the Hungarian 
Prioritization method published as a final report on the national programme at the Geological and Geophysical Institute of Hungary (MFGI, Kiss and Jordan 2012). In their method they divided the waste sites into two major risk classes of tailings lagoon and waste heaps (similar to Q5 in the Pre-selection Protocol), then each class was divided into remediated or none remediated site subclasses (similar to Q14 in the Pre-selection Protocol). Each of the remediated or none remediated sites was further classified on basis of the area into large ( $>1$ ha) and small (<1ha), and subsequently by slope into steep $\left(>5^{\circ}\right)$ and flat $\left(<5^{\circ}\right)$ (similar to Q10 in the Pre-selection Protocol). This stratified risk classification also shows the prioritization of key parameters for risk ranking. For example, the type of waste site is considered the most important parameter, while size and underlying slope less important. The final results are, for tailings lagoon sites 20 sites are remediated and one site is not. For waste heaps, 50 sites are remediated and 35 sites are not. In general, for the Hungarian Prioritization method, out of 101 sites, 70 sites have been remediated. In the present study (Q14 of the Pre-selection Protocol), out of 145 sites, 128 sites are covered/remediated with water, vegetation and forest (Table 5, Fig.11).

\subsection{Pre-selection Risk Assessment of the selected 30 mine-quarry waste sites}

The contamination RA according to the EU MWD Pre-selection Protocol is carried out using the EU thresholds (slope $\leq 5^{\circ}$ and $1 \mathrm{~km}$ distance and number of people in the nearest settlement $\geq$ 100). The YES, NO and UNKNOWN responses of the EU MWD Pre-selection Protocol (Annex 1) were registered and calculated for each question in Table 2. In this study each rock formation was treated as a waste site and projected in the map as one or more polygons (Fig.9). Questions describe if the mine uses any dangerous chemicals in processing minerals (Q4), the geometry of the tailings lagoon height and area (Q6-Q7) and for the waste heap height (Q9) of the Preselection Protocol are not fit to the rock waste sites and were skipped in this study (Table 9). Out of 30 mine waste sites, none of sites have a documented incident (Q1, Jordan et al. 2011). In Q2, 12 sites with YES responses were producing waste with sulphide minerals, 18 sites have NO responses. While in Q3, 14 sites were producing minerals with toxic heavy metals. In Q5, all sites are waste heaps and none of sites are tailings lagoon. In Q8, all 30 waste heap sites with YES responses are greater than $10,000 \mathrm{~m}^{2}$ in surface area. The slope of the foundation upon which the waste heap rests is of concern with respect to stability. The greater the slope angle the greater the risk of waste heap failure. The EU threshold chosen is 1:12 which equates to $8.3 \%$ or a slope angle of almost $5^{\circ}$. Based on the slope values derived from the 50m DEM, 16 waste heap sites with YES responses are greater than or equal 1:12 $\left(5^{\circ}\right)$ in slope $(\mathrm{Q} 10)$. This shows that most of the sites were located in hilly areas. The use of the surface permeability map (Fig.4) developed to generate answers for Q12, resulted in 21 waste sites with YES responses and underlain by medium and high permeable layer, while 9 sites underlain by low permeable layers. When the mine waste site is covered and the original material is not accessible this means there is no direct contact with receptors. In Q13, 18 sites were exposed to the wind and 12 sites were not. While in Q14, 18 sites were uncovered and 12 sites were covered with water, vegetation, soil and forest (Fig.5). 
Table 9. Summary statistics of the EU Pre-selection Protocol responses of questions Q1-Q18, showing the number of YES, NO and UNKNOWN responses (U) based on the EU thresholds.

\begin{tabular}{|c|c|c|c|c|c|}
\hline \multirow{2}{*}{\multicolumn{2}{|c|}{ EU Pre-selection Protocol }} & \multirow{3}{*}{$\begin{array}{c}\text { Number of sampled sites } \\
30 \\
\end{array}$} & \multicolumn{3}{|c|}{ EU thresholds } \\
\hline & & & \multirow{2}{*}{$\begin{array}{c}\text { YES } \\
0 \\
\end{array}$} & \multirow{2}{*}{$\frac{\mathrm{NO}}{30}$} & \multirow{2}{*}{$\begin{array}{ll}\mathrm{U} \\
0 \\
\end{array}$} \\
\hline Impact & Q1 & & & & \\
\hline \multirow{5}{*}{ 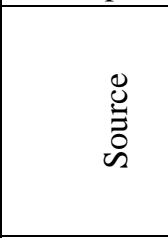 } & Q2 & 30 & 12 & 18 & 0 \\
\hline & Q3 & 30 & 14 & 16 & 0 \\
\hline & Q5 & 30 & 0 & 30 & 0 \\
\hline & Q8 & 30 & 30 & 0 & 0 \\
\hline & Q10 & 30 & 21 & 9 & 0 \\
\hline \multirow{4}{*}{ 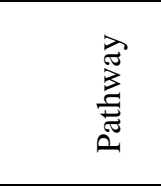 } & Q11 & 30 & 16 & 14 & 0 \\
\hline & Q12 & 30 & 21 & 9 & 0 \\
\hline & Q13 & 30 & 18 & 12 & 0 \\
\hline & Q14 & 30 & 18 & 12 & 0 \\
\hline \multirow{4}{*}{ 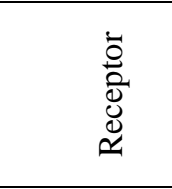 } & Q15 & 30 & 26 & 4 & 0 \\
\hline & Q16 & 30 & 22 & 8 & 0 \\
\hline & Q17 & 30 & 19 & 11 & 0 \\
\hline & Q18 & 30 & 28 & 2 & 0 \\
\hline
\end{tabular}

For Q11, 16 sites are within $1 \mathrm{~km}$ distance to the nearest surface water bodies (streams and lakes). In Q15, 26 mine waste sites are within $1 \mathrm{~km}$ distance to nearest human settlements with $>100$ people, indicating that these sites require prime attention if settlement protection is the concern. In Q16, 22 sites are within $1 \mathrm{~km}$ distance to the groundwater bodies of less than good status. For Q17, 19 waste sites are within $1 \mathrm{~km}$ distance to the national protected Natura 2000 sites. 12 waste sites were located completely inside the Natura 2000 sites), this calls for immediate special attention if landscape protection is a priority. Moreover, in Q18, 28 waste sites are within $1 \mathrm{~km}$ distance to the agricultural areas including arable lands, pastures, heterogeneous and permanent crops, 24 sites are completely located inside the agricultural lands (Table 10).

Distribution analysis performed on the 30 mie-quarry waste sites (Table 10) identified various sub-groups in the parameter thresholds of the EU Pre-selection Protocol. For example, in Q10, all the 30 waste sites have one class of topographic slope ranges from $1-20^{\circ}$. This result suggests the median slope value of all waste sites $10^{\circ}$ as a natural threshold reflecting the local Hungarian conditions, instead of the original $5^{\circ}$ slope threshold. In Q11, 22 waste sites were located within distance $0-1280 \mathrm{~m}$ to the nearest surface water bodies and 8 sites are within distance 2,219$5,376 \mathrm{~m}$. This shows that almost $73 \%$ of the mine waste sites are significantly (at the $90 \%$ confidence) closer $(\leq 1280 \mathrm{~m})$ to receiving streams than the other sites, thus the $631 \mathrm{~m}$ (medial value of all sites) threshold may better reflect the local topographic conditions for this question. In Q15, 14 waste sites were located directly inside the nearest settlement (distance=0), indicating that these sites require prime attention if settlement protection is the concern, 12 sites are within distance $82-838 \mathrm{~m}$ to the nearest settlement and 2 sites are within distance 1,585-3,319m to the nearest settlement. This result suggests the distance $150 \mathrm{~m}$ (medial value of all sites) as a local threshold for this question in Hungary. It is interesting that 18 waste sites lie directly above the 
groundwater bodies with 'poor status' (Q16) and 12 sites are located inside the protected Natura 2000 sites (Q17). While in Q18, 24 waste sites are located inside the agricultural areas (Table $10)$.

Table 10. Class boundaries of the EU MWD Pre-selection Protocol parameters based on the naturalbreaks found in the corresponding cummulative histograms. Class boundaries are used to define thresholds adapted to local conditions in Hungary.

\begin{tabular}{|c|c|c|c|c|c|}
\hline Question & $\begin{array}{c}\text { Class } \\
\text { boundaries }\end{array}$ & Class-Range & Median of class & Median of all sites & Number of sites \\
\hline Q10 & $1 .-20$ & $\begin{array}{c}\text { Topographic slope below waste } \\
\text { site (degree) } \\
1 .-20\end{array}$ & 10 & 10 & 30 \\
\hline Q11 & $\begin{array}{l}<1300 \\
>1300\end{array}$ & $\begin{array}{c}\text { Distance to the nearest surface } \\
\text { water course }(\mathrm{m}) \\
0-1280 \\
2219-5376\end{array}$ & $\begin{array}{c}188 \\
2861\end{array}$ & 631 & $\begin{array}{c}22 \\
8\end{array}$ \\
\hline Q15 & $\begin{array}{c}0 \\
>0<=1000 \\
>1000\end{array}$ & $\begin{array}{c}\text { Distance to the nearest } \\
\text { settlement (m) } \\
0 \\
82-838 \\
1585-3319 \\
\end{array}$ & $\begin{array}{c}0 \\
548 \\
2350 \\
\end{array}$ & 150 & $\begin{array}{c}14 \\
12 \\
4\end{array}$ \\
\hline Q16 & $\begin{array}{c}0 \\
>=36\end{array}$ & $\begin{array}{c}\text { Distance to the groundwater } \\
\text { bodies of 'poor status' (m) } \\
0 \\
36-14717\end{array}$ & $\begin{array}{c}0 \\
5229\end{array}$ & 0 & $\begin{array}{l}18 \\
12\end{array}$ \\
\hline Q17 & $\begin{array}{c}0 \\
>0<=1000 \\
>1000\end{array}$ & $\begin{array}{c}\text { Distance to the nearest Natura } \\
2000 \text { sites }(\mathrm{m}) \\
0 \\
158-713 \\
1072-5548\end{array}$ & $\begin{array}{c}0 \\
286 \\
2416 \\
\end{array}$ & 224 & $\begin{array}{c}12 \\
6 \\
11\end{array}$ \\
\hline Q18 & $\begin{array}{c}0 \\
59-2092\end{array}$ & $\begin{array}{c}\text { Distance to the nearest } \\
\text { agricultural areas (m) } \\
0-861 \\
3688-3976\end{array}$ & $\begin{array}{c}0 \\
359\end{array}$ & 0 & $\begin{array}{c}24 \\
6\end{array}$ \\
\hline
\end{tabular}

A preliminary risk-based site ranking is possible based on the EU thresholds (slope of almost $5^{\circ}$ and $1 \mathrm{~km}$ distance) by counting and ranking the YES responses of the Pre-selection Protocol, and ranging in scores from 5 to 10 . Obviously, if there is more than one hazardous material at the source or there are multiple contamination pathways and receptors the site has a higher risk. A simple risk ranking of the rock formations based on the YES responses in descending order as follows: black coal and peat (10 YES), alginite (9 YES), lignite and clay (8 YES), bauxite (7 YES), bentonite-clay (6 YES) and andesite and rhyolite tuffs (5 YES). In summary, after the existing pre-screening risk assessment of the mine waste sites in Hungary, 28 sites were directed to EXAMINE FURTHER based on the EU thresholds and two sites with no risk (one Bauxite site has no pathway and one Andesite site has no sensitive receptor).

Table 11 summarizes the estimated heavy metal concentrations from the mine waste sites (aqua regia extraction) with respect to the environmental limit values in Hungary and Europe. In case of central tendency expressed by the Median, the analyzed heavy metals are in descending order; 
$\mathrm{Zn}>\mathrm{V}>\mathrm{Cu}>\mathrm{Cr}>\mathrm{Pb}>\mathrm{Co}>\mathrm{Ni}>\mathrm{As}>\mathrm{Mo}>\mathrm{Cd}$. This result shows that $\mathrm{Zn}$ has the highest median (24.6 $\mathrm{mg} / \mathrm{kg}$ ) and $\mathrm{Cd}$ has the lowest Median $(0.11 \mathrm{mg} / \mathrm{kg})$. In case of spread expressed by IQR/Med (Interquartile range/Median), the heavy metals are in descending order; $\mathrm{Ni}>\mathrm{As}>\mathrm{Cr}>\mathrm{V}>\mathrm{Pb}>\mathrm{Co}>\mathrm{Cd}>\mathrm{Zn}>\mathrm{Cu}$. It is obvious that Ni has the highest spread (5.11) and $\mathrm{Cu}$ has the lowest (1.11). While spread expressed by Range/Median, the heavy metals are in descending order; $\mathrm{Ni}>\mathrm{Cr}>\mathrm{Mo}>\mathrm{Co}>\mathrm{Zn}>\mathrm{Pb}>\mathrm{As}>\mathrm{Cd}>\mathrm{Cu}>\mathrm{V}$. Ni still has the highest spread (327.6) but in this case $\mathrm{V}$ has the lowest spread (8.42).

Table 11. Summary statistics of heavy metal concentrations from the mine waste sites (aqua regia extraction in $\mathrm{mg} / \mathrm{kg}$ ) in respect to the environmental limit values in Hungary and the European Top Soil Baseline Values. Minimum (MIN), maximum (MAX), median (MED) and spread expressed as median absolute deviation (MAD), lower quartile (LQ), upper quartile (UQ), Interquartile range (IQR), Standard deviation (SD). Bold figures show those heavy metal concentrations higher than the environmental standard limits (i.e. the tolerated limit in Hungarian soils or EU FOREGS Geochemical Atlas baseline value for top soils).

\begin{tabular}{|c|c|c|c|c|c|c|c|c|c|c|c|}
\hline & & As & $\mathrm{Cd}$ & Co & $\mathrm{Cr}$ & $\mathrm{Cu}$ & Mo & $\mathrm{Ni}$ & $\mathrm{Pb}$ & $\mathrm{V}$ & $\mathrm{Zn}$ \\
\hline \multicolumn{2}{|c|}{ Min } & 0.6 & 0.06 & 0.018 & 0.537 & 0.766 & 0.2 & 0.4 & 1.15 & 3 & 0.1 \\
\hline \multicolumn{2}{|c|}{ LQ } & 1.54 & 0.073 & 2.92 & 2.58 & 6.8 & 0.2 & 1.88 & 4.56 & 5.48 & 14.4 \\
\hline \multicolumn{2}{|c|}{ Med } & 3.93 & 0.117 & 5.12 & 8.11 & 12.3 & 0.2 & 4.79 & 7.08 & 18.4 & 24.6 \\
\hline \multicolumn{2}{|c|}{ UQ } & 14.3 & 0.22 & 9.98 & 21 & 20.5 & 0.2 & 26.4 & 14.3 & 38 & 46.1 \\
\hline \multicolumn{2}{|c|}{ IQR } & 12.76 & 0.152 & 7.06 & 18.42 & 13.7 & 0 & 24.52 & 9.74 & 32.52 & 31.7 \\
\hline \multicolumn{2}{|c|}{ Max } & 247 & 6.07 & 416 & 1185 & 573 & 24.3 & 1570 & 468 & 158 & 1690 \\
\hline \multicolumn{2}{|c|}{ Mean } & 18.17 & 0.33 & 19.92 & 56.24 & 34.16 & 1.08 & 60.89 & 23.4 & 28.91 & 84.28 \\
\hline \multicolumn{2}{|c|}{ Range } & 246.4 & 6.01 & 415.9 & 1184.4 & 572.2 & 24.1 & 1569.6 & 466.8 & 155 & 1689.9 \\
\hline \multicolumn{2}{|c|}{ SD } & 43.31 & 0.87 & 63.67 & 170.09 & 92.44 & 2.96 & 223.3 & 68.72 & 31.64 & 255.83 \\
\hline \multicolumn{2}{|c|}{ MAD } & 3.07 & 0.057 & 3.52 & 6.34 & 5.7 & 0 & 4.25 & 3.84 & 13.94 & 15.8 \\
\hline \multicolumn{2}{|c|}{ Mode } & 0.6 & 0.06 & 11.5 & & 13.9 & 0.2 & 0.4 & & 3 & 0.1 \\
\hline \multicolumn{2}{|c|}{ Range/Med } & 62.69 & 51.36 & 81.24 & 146.04 & 46.52 & 120.5 & 327.68 & 65.93 & 8.42 & 68.69 \\
\hline \multicolumn{2}{|c|}{ IQR/Med } & 3.24 & 1.29 & 1.37 & 2.27 & 1.11 & 0 & 5.119 & 1.37 & 1.76 & 1.28 \\
\hline \multicolumn{2}{|c|}{ MAD/Med } & 0.78 & 0.48 & 0.68 & 0.78 & 0.46 & 0 & 0.88 & 0.54 & 0.75 & 0.64 \\
\hline \multicolumn{12}{|c|}{ Environmental standard values in Hungary and the European Top Soil Baseline Values (FOREGS Atlas) } \\
\hline \multicolumn{2}{|c|}{$\begin{array}{l}\text { Tolerated limit } \\
\text { in Soils, } \\
\text { Hungary }\end{array}$} & 15 & 1 & 30 & 75 & 75 & 7 & 40 & 100 & & 200 \\
\hline \multirow{4}{*}{ 四 } & Min & $<0.5$ & $<0.01$ & $<1$ & 1 & 1 & $<0.1$ & $<2$ & $<3$ & & 4 \\
\hline & Max & 220 & 14.1 & 255 & 2340 & 239 & 21.3 & 2560 & 886 & & 2270 \\
\hline & Med & 6 & 0.145 & 7 & 22 & 12 & 0.62 & 14 & 15 & & 48 \\
\hline & Mean & 9.88 & 0.28 & 8.91 & 32.6 & 16.4 & 0.94 & 30.7 & 23.9 & & 60.9 \\
\hline
\end{tabular}

Total concentrations of the heavy metals defined by aqua regia extraction were compared to the environmental limit values in Hungary and to the European environmental geochemical background values based on the FOREGS European Geochemical Atlas (Table 11). Results show that the median value of $\mathrm{Cu}(12.3 \mathrm{mg} / \mathrm{kg})$ is less than the Hungarian environmental limit $(75$ $\mathrm{mg} / \mathrm{kg}$ ) and exceeds the median of EU FOREGS (12 mg/kg). In case of central tendency 
expressed by the Median, the analyzed total heavy metal concentrations are in the descending order of $\mathrm{Zn}>\mathrm{V}>\mathrm{Cu}>\mathrm{Cr}>\mathrm{Pb}>\mathrm{Co}>\mathrm{Ni}>\mathrm{As}>\mathrm{Mo}>\mathrm{Cd}$. This result shows that $\mathrm{Zn}$ has the highest median $(24.6 \mathrm{mg} / \mathrm{kg})$ and $\mathrm{Cd}$ has the lowest Median $(0.11 \mathrm{mg} / \mathrm{kg})$. In case of relative variability (spread) expressed by IQR/Med (Inter-quartile range/Median), the total heavy metal concentrations follow the order: $\mathrm{Ni}>\mathrm{As}>\mathrm{Cr}>\mathrm{V}>\mathrm{Pb}>\mathrm{Co}>\mathrm{Cd}>\mathrm{Zn}>\mathrm{Cu}$. It is obvious that $\mathrm{Ni}$ has the highest variability (5.11) and $\mathrm{Cu}$ has the lowest (1.11). In case of the $\mathrm{S}_{\text {sulphide, }}$, the median (0.02\%) is less than the Hungarian environmental limit $(0.1 \%)$ and $\mathrm{S}_{\text {sulphide }}$ has a range from $0.003 \%$ to $3.82 \%$. The Spearman correlation coefficients (Tables 12 and 13) shows significant $(\mathrm{p}<0.05)$ relationship for the aqua regia extraction in the cases of $\mathrm{As}$ and $\mathrm{Ni}(\mathrm{r}=0.57), \mathrm{Cd}$ and $\mathrm{Pb}(\mathrm{r}=0.58)$, $\mathrm{Co}$ and $\mathrm{Zn}(\mathrm{r}=0.86), \mathrm{Co}$ and $\mathrm{Cu}(\mathrm{r}=0.77), \mathrm{Cr}$ and $\mathrm{Ni}(\mathrm{r}=0.81), \mathrm{Cu}$ and $\mathrm{Zn}(\mathrm{r}=0.71), \mathrm{Ni}$ and $\mathrm{Pb}$ $(\mathrm{r}=0.71)$ and $\mathrm{Pb}$ and $\mathrm{Zn}(\mathrm{r}=0.63)$. For the deionized water leaching the elemental pair $\mathrm{Co}$ and $\mathrm{Ni}$ $(\mathrm{r}=0.8)$ is significantly correlated at $\mathrm{p}<0.05$ level.

Table 12. The Spearman's rank correlation coefficients between concentrations of heavy metals from the waste sites (aqua regia extraction). Significant correlation coefficients are in bold; $\rho<0.05$.

\begin{tabular}{cccccccccc}
\hline & $\mathrm{As}$ & $\mathrm{Cd}$ & $\mathrm{Co}$ & $\mathrm{Cr}$ & $\mathrm{Cu}$ & $\mathrm{Mo}$ & $\mathrm{Ni}$ & $\mathrm{Pb}$ & $\mathrm{Zn}$ \\
\hline $\mathrm{As}$ & & & & & & & & & \\
$\mathrm{Cd}$ & $\mathbf{0 . 4 5}$ & & & & & & & & \\
$\mathrm{Co}$ & $\mathbf{0 . 4 1}$ & $\mathbf{0 . 3 4}$ & & & & & & \\
$\mathrm{Cr}$ & $\mathbf{0 . 3 7}$ & $\mathbf{0 . 3 9}$ & $\mathbf{0 . 7 2}$ & & & & & \\
$\mathrm{Cu}$ & $\mathbf{0 . 4 2}$ & $\mathbf{0 . 4 2}$ & $\mathbf{0 . 7 7}$ & $\mathbf{0 . 6 6}$ & & & & \\
$\mathrm{Mo}$ & $\mathbf{0 . 3 5}$ & $\mathbf{0 . 2 2}$ & -0.13 & -0.12 & 0.06 & & & \\
$\mathrm{Ni}$ & $\mathbf{0 . 5 7}$ & $\mathbf{0 . 5}$ & $\mathbf{0 . 7 2}$ & $\mathbf{0 . 8 1}$ & $\mathbf{0 . 7}$ & 0.19 & & \\
$\mathrm{~Pb}$ & $\mathbf{0 . 5}$ & $\mathbf{0 . 5 8}$ & $\mathbf{0 . 6 1}$ & $\mathbf{0 . 5 7}$ & $\mathbf{0 . 6}$ & 0.09 & $\mathbf{0 . 7 1}$ & \\
$\mathrm{Zn}$ & $\mathbf{0 . 3 1}$ & $\mathbf{0 . 3 9}$ & $\mathbf{0 . 8 6}$ & $\mathbf{0 . 6 1}$ & $\mathbf{0 . 7 1}$ & -0.17 & $\mathbf{0 . 5 7}$ & $\mathbf{0 . 6 3}$ & \\
\hline
\end{tabular}

Table 13. The Spearman's rank correlation coefficients between concentrations of heavy metals from the waste sites (deionized water leaching). Significant correlation coefficients are in bold; $\rho<0.05$.

\begin{tabular}{cccccccccc}
\hline & $\mathrm{As}$ & $\mathrm{Cd}$ & $\mathrm{Co}$ & $\mathrm{Cr}$ & $\mathrm{Cu}$ & $\mathrm{Mo}$ & $\mathrm{Ni}$ & $\mathrm{Pb}$ & $\mathrm{Zn}$ \\
\hline $\mathrm{As}$ & & & & & & & & & \\
$\mathrm{Cd}$ & 0.12 & & & & & & & & \\
$\mathrm{Co}$ & $\mathbf{0 . 2 2}$ & $\mathbf{0 . 2 7}$ & & & & & & \\
$\mathrm{Cr}$ & 0.03 & $\mathbf{0 . 2 5}$ & $\mathbf{0 . 2 6}$ & & & & & \\
$\mathrm{Cu}$ & 0.17 & 0.16 & $\mathbf{0 . 3 5}$ & 0.18 & & & & \\
$\mathrm{Mo}$ & $\mathbf{0 . 2 8}$ & 0.08 & -0.04 & 0.1 & $\mathbf{0 . 2 7}$ & & & \\
$\mathrm{Ni}$ & $\mathbf{0 . 2 1}$ & $\mathbf{0 . 3}$ & $\mathbf{0 . 8}$ & $\mathbf{0 . 2 8}$ & $\mathbf{0 . 4 7}$ & 0.16 & & \\
$\mathrm{~Pb}$ & -0.04 & 0.14 & $\mathbf{0 . 3 1}$ & $\mathbf{0 . 2 4}$ & 0.14 & 0.01 & $\mathbf{0 . 2 6}$ & \\
$\mathrm{Zn}$ & 0.14 & 0.02 & $\mathbf{0 . 2 7}$ & -0.04 & $\mathbf{0 . 4 7}$ & 0.11 & $\mathbf{0 . 3 5}$ & 0.12 \\
\hline
\end{tabular}

The relative mobility of heavy metals in the various sampled rock formations was calculated as the percentage of the mobile element content (deionized water leaching) to the total element content (Aqua regia extraction) for the 93 samples. Then the median value of these mobility percentages was calculated for each rock type (Fig.20). Results show in Black Coal samples, the relative mobility of the heavy metals reduced in the following order: $\mathrm{Zn}(30.7)>\mathrm{Co}(29.5)>\mathrm{Ni}$ 
(26) $>\mathrm{V}(11.2)>\mathrm{Cd}(4.6)>\mathrm{Cu}(2.3)>\mathrm{Pb}(0.3)>\mathrm{As}(0.27)>\mathrm{Mo}(0.26)$. In Lignite samples, Mo (5) $>\mathrm{V}(4.6)>\mathrm{As}(1.4)>\mathrm{Cd}(1.2)>\mathrm{Zn}(0.8)>\mathrm{Pb}(0.5)>\mathrm{Co}(0.3)>\mathrm{Ni}(0.2)>\mathrm{Cu}(0.16)>\mathrm{Cr}$ (0.1). In Peat samples, $\mathrm{Zn} \mathrm{(31)} \mathrm{>} \mathrm{V} \mathrm{(16)} \mathrm{>} \mathrm{Mo} \mathrm{(6)}>\mathrm{Cd}(3)>\mathrm{As}(2.5)>\mathrm{Co}(1.3)>\mathrm{Pb}(0.8)>\mathrm{Cu}$ $(0.7)>\mathrm{Cr}(0.4)>\mathrm{Ni}(0.3)$. In Bauxite samples, Mo (5) $>\mathrm{Cd}(0.7)>\mathrm{V}(0.4)>\mathrm{As}(0.3)>\mathrm{Co}$ $(0.11)>\mathrm{Pb}(0.1)>\mathrm{Zn}(0.06)>\mathrm{Cu}(0.05)>\mathrm{Ni}(0.03)>\mathrm{Cr}(0.01)$. In Alginite samples, Mo (175) $>\mathrm{V}(2.1)>\mathrm{Cd}(0.6)>\mathrm{As}(0.2)>\mathrm{Pb}(0.08)>\mathrm{Cu}(0.04)>\mathrm{Ni}(0.03)>\mathrm{Zn}(0.025)>\mathrm{Co}(0.02)>\mathrm{Cr}$ (0.01). In Clay samples, Mo (8.7) $>\mathrm{V}(2.3)>\mathrm{Cd}(1.8)>\mathrm{Zn}(0.5)>\mathrm{As}(0.4)>\mathrm{Pb}(0.2)>\mathrm{Co}(0.1)$ $>\mathrm{Ni}(0.07)>\mathrm{Cu}(0.05)>\mathrm{Cr}(0.04)$. In Andesite samples, $\mathrm{Mo} \mathrm{(5)}>\mathrm{Cd}(4)>\mathrm{As}(2.5)>\mathrm{V}(1.6)>$ $\mathrm{Ni}(0.7)>\mathrm{Pb}(0.6)>\mathrm{Zn}(0.4)>\mathrm{Co}(0.2)>\mathrm{Cu}(0.15)>\mathrm{Cr}(0.14)$. While in Rhyolite tuffs samples, V (16.6) > Mo (5) > Ni (4) > Cd (3) > As (2.3) > Co (2) > Zn (1.2) > Cr (0.8) > Cu (0.7) $>\mathrm{Pb}(0.2)$. It is obvious that Mo had the highest mobility in Lignite, Bauxite, Alginite, Clay and Andesite rock samples and $\mathrm{Zn}$ had the highest mobility in Black coal and Peat samples. While, $\mathrm{V}$ had the highest mobility in Rhyolite tuffs samples (Fig.20).

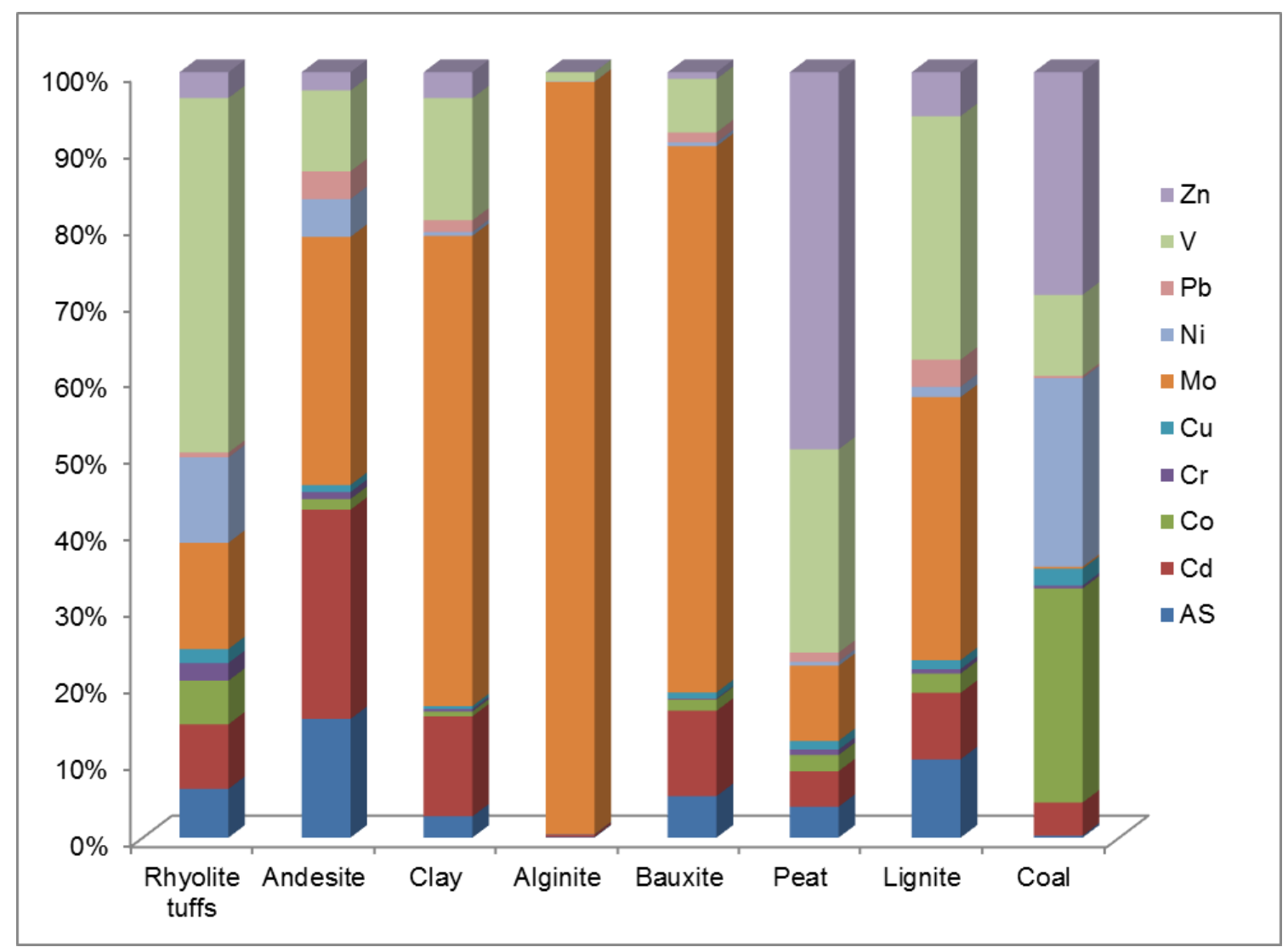

Figure 20. Distribution of the relative mobility (\%) of heavy metals in the various sampled rock formations

For the deionized water leaching, the Ficklin Diagram (Fig.21) showed that acid generation potential $(\mathrm{pH}<5.5)$ is for coal, lignite and peat rocks, in addition to a bauxite sample. Elevated mobile heavy metal content is associated with coal, andesite and some clay and a bauxite sample. 
Multivariate analysis such as CA and PCA using the analysed trace elements could not identify significant groups of samples. This is not unexpected due to the heterogeneity of the sampled rock types. It seems that specific rock formations with ore minerals content, including pyrite with acid generation potential, such as some andesites and coals are distinct from the non-mineralised as shown by the Ficklin Diagram (Fig.21).

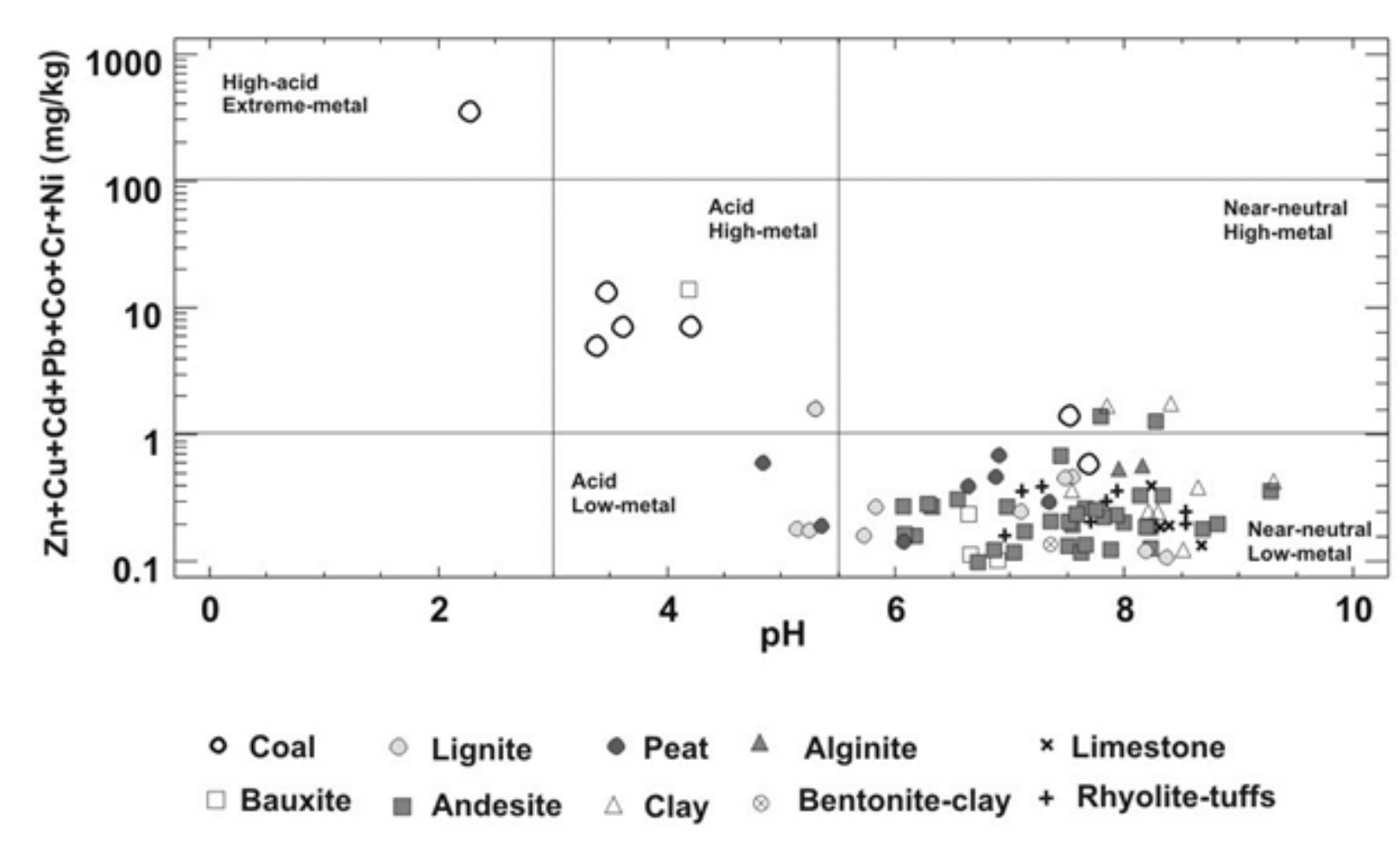

Figure 21. Ficklin Diagram showing the sum of heavy metals $\mathrm{Zn}, \mathrm{Cr}, \mathrm{Cd}, \mathrm{Pb}, \mathrm{Co}$ and $\mathrm{Ni}$ plotted against $\mathrm{pH}$ in the deionized water leaching (DW). Note that acid generation potential $(\mathrm{pH}<5.5)$ is for coal, lignite and peat rocks, in addition to a bauxite sample. Elevated mobile heavy metal content is associated with coal, andesite and some clay and a bauxite samples. See text for details.

Based on the expert judgment, the listed rock formations were classified into three preliminary categories. A: inert B: probably inert, but has to be checked $\mathrm{C}$ : probably not inert, has to be examined (Table 3). According to the geochemical analysis results in this study, coal (black coal and lignite) and peat samples are not inert and classified into group $\mathrm{C}$ which matches with the preliminary expert judgment. While alginite, bauxite, rhyolite tuffs and clay samples are probably inert and classified into B group which also matches with the preliminary expert judgment. Moreover limestone and clay samples are inert (A group). It is interesting to report that andesite samples are probably inert (B group) and according to our geochemical analyses, it was found that 5 andesite samples contain higher concentrations of the heavy metals $\mathrm{Ni}, \mathrm{Zn} \mathrm{Cu}, \mathrm{Cr}$ and $\mathrm{Co}$ than the minimum, median and mean values of the Hungarian standards. While As is even higher than the maximum values of the national environmental standards. These results may suggest that those 5 andesite samples with higher heavy metal concentrations could classify the andesite rock formation into the $\mathrm{B}$ or $\mathrm{C}$ groups 


\subsection{Linkage between heavy metal contamination RA and the Landscape metrics}

Landscape pattern of the watersheds has significant role on runoff/infiltration ratio of rainfall, and the sediment and contamination transport processes too. Some authors underlying that the landscape pattern has a big influence on the sediment delivery ratio (Jordan et al. 2005; Szilassi et al. 2006). Across these processes the landscape characteristics (mainly the land use and land cover) of catchments has a relevant impact on the surface and subsurface water quality (Xia et al. 2012).

To illustrate the role of the landscape pattern on the water quality, let's see two extreme examples: The forest patches at the bank of the rivers (thick but long linear land use patches parallel with the streams and rivers) would be strong barriers of the sediment and contamination transport. But if there is no any riparian forest near the river or stream, and the linear land cover/land use units without vegetation cover (such as arable land parcels in spring or autumn) are dominant, and these parcels direction is square of the rivers or streams, this kind of landscape pattern has an important role on the increasing level of the sediment and contamination transport processes. We can say that in this case the long arable land parcels on the slopes direction forward to the river or stream charnels, can be defined from the environmental risk assessment point of view as a "pathways" between point or non-point contamination sources and the receptors such as rivers, streams or settlements. In this situation almost every rainfall events the sediment and the contaminated soil grains can move almost directly into the nearest stream or river without any barriers (Jordan et. al. 2005 Szilassi et al. 2006).

It can be seen that the spatial characteristics of the landscapes (especially the land use/land cover pattern) has a big relevance for the environmental risk assessment, the recent widely used risk assessment methods makes low level attention for this question. Although the PRAMS and other methods are considering the landscape characteristics (for instance the spatial distances between the point sources, and receptors such as settlements and Natura 2000 areas), the spatial characteristics of the land use/land cover pattern has not been consider according to this method. Several research studies show a significant statistical relationship between the landscape indices of the watersheds, and the water quality datas (Xia et al. 2012). Some authors show the strongest statistical relationship between the landscape pattern and the water quality in case of the percentage cover of forests and the non-point source pollutions of water such as nitrate, nitrite contamination (e.g. Wu et al. 2012; Xiao and Ji 2007; Romic et al. 2007; Uuemaa et al. 2005; 2013). This is the reason for why, beside the landscape metric parameters, the percentage of the

main land cover classes (such as artificial surfaces (CLC1), agricultural areas (CLC2) and forest and semi-natural areas (CLC3)) was investigated in this study.

For the further extension of ERA methods, it is very important to find those landscape metric parameters that have a "key role" on the sediment and contamination transport processes. It can be said these parameters will be indicator of the landscape pattern, which shows the strongest statistical relationship with the surface water quality, after these indicators will be integrated into 
the ERA methods. The objective of this part of the thesis is to analuse that question, but the real integration of my results is not an aim of my dissertation, because it requires more investigations.

From the 1990's the landscape metric indices are widely used to describe the spatial characteristics of the landscapes. We can distinguish from each other, the patch level, class level, and the landscape level indices. In this chapter the statistical relationship was investigated between the landscape level landscape indices of the investigated 33 watersheds (Fig.22), and the heavy metals and conductivity water quality data of the main streams of the watersheds.

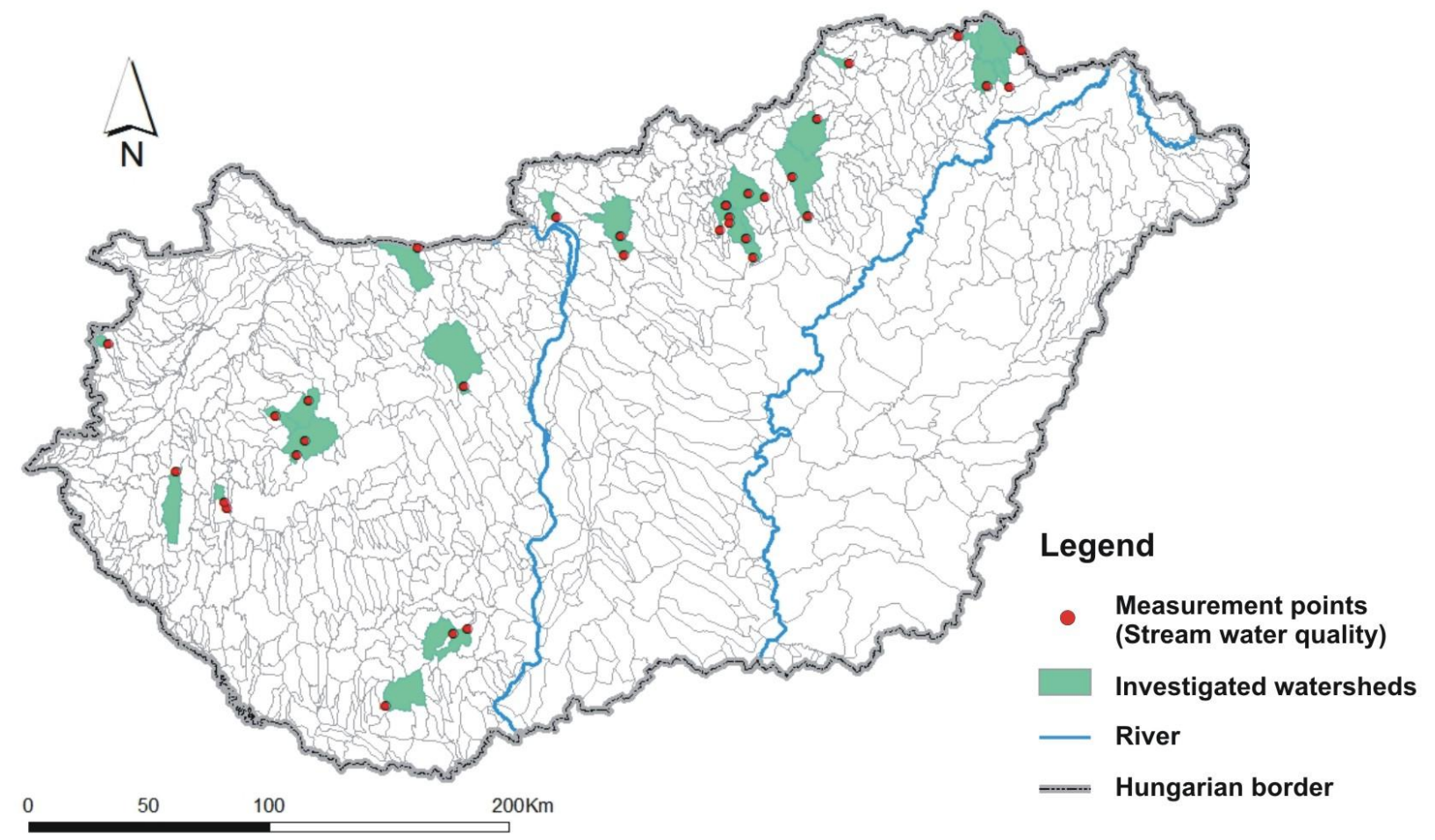

Fig. 22 Location map of the investigated 33 landscape watersheds enclosing the mine waste sites in Hungary.

The following landscape indices were considered for the watershed containing the selected 33 mine-quarries: Total Number of Patches (NP), Core Area (CA), length of Total Edge (TE) Splitting Index (SPLIT), Division Index (DIVISION), Effective Mesh Size (MESH), Main Patch Size (MPS), Patch Size Standard (PSSD), Deviation Mean Patch Ratio (MPE), Mean Shape Index (MSI) Mean Perimeter Area Ratio (MPAR) and Mean Fractal Dimension Index (MFRACT). The parameters were calculated for each of the 33 mining watersheds based on regional scale (1:100,000) CORINE land cover database from years 2000 and 2006. The percentage area of the main CORINE land cover classes was also calculated, and its role on the water quality was also investigated. The V-late (vector-based landscape analysis tools extension) within ArcGIS $10 \AA$ and the STATGRAPHICS ${ }^{\circledR}$ software were used for spatial and statistical analyses. 
Spearman correlation coefficients were calculated for all landscape metrics and the minimum, median, average and maximum values of stream water quality data pairs of years 2000 and 2006 (Tables 14 and 15). Results show that median dissolved Ni in stream water, minimum and maximum $\mathrm{Zn}$ and average stream water conductivity values were significantly correlated with MSI, while median Mn with MESH, average Mn with CA, TE, MPE and MPAR, maximum Mn with artificial surfaces (CLC1), minimum Conductivity with MPS, PSSD, MFRACT, agricultural areas (CLC2) and forest and semi-natural areas (CLC3) showed significant correlations. However, Cr showed no correlation with the landscape indices. For 2006 data, minimum and average Ni values were significantly correlated with DIVISION and SPLIT, minimum Mn with NP, PSSD, CA, TE, MPE and MESH, median Mn with CA and TE, minimum Conductivity with MFRACT, median Conductivity with MPAR, average Conductivity with MSI and MFRACT, maximum Conductivity with MSI, MPAR and MFRACT. In this case all $\mathrm{Cr}$ and $\mathrm{Zn}$ values showed no significant correlation with the landscape indices. However, no stream water quality variable had significant correlation with Main Patch Size (MPS), Artificial surfaces (CLC1), Agricultural areas (CLC2), and Forest and semi-natural areas (CLC3).

It is concluded that the Mean Shape Index (MSI) is the most important 'key' landscape index in 2000 and the Main Fractal Dimension Index (MFRACT) in 2006, in respect to the stream water quality heavy metal contamination in the studied mining watersheds. Based on the above results, in case of the further development of the RA methods, at least these two landscape indices should be taken into consideration.

It is important to note that the minimum Conductivity values are positively correlated (1.00) with the forest and semi-natural areas (CLC3) and negatively correlated (-1.00) with the arable lands (CLC2). This is unexpected result; however the higher percentage of arable lands shows a positive correlation with the conductivity which represents the total pollution of water. In my opinion the background of this "false" result refers to a mistake in the measurement process, because the minimum values are very low and very difficult to be measure punctually.

It is concluded that the Mean Shape Index (MSI) is the most important "key" landscape index in 2000, and the Main Fractal Dimension Index in 2006 (Table 14), from the surface water quality heavy metal contamination point of view. Based on our statistical analyses we can conclude that in case of the further modification of the RA methods, at least these two landscape indices should take under consideration, and integrate into the RA methods. The median $\mathrm{Ni}$, average $\mathrm{Mn}$, average $\mathrm{Zn}$ and minimum conductivity variables are the most significantly correlated with the landscape indices in 2000 . While the minimum \& average $\mathrm{Ni}$, the minimum \& median $\mathrm{Mn}$, the average \& maximum conductivity variables are the most significantly correlated with the landscape indices in 2006 (Table 15). 
Table 14. The Spearman's rank correlation between the water quality variables (heavy metals) and the landscape metrics data of 2000. Significant correlation coefficients are in bold; $p<0.05$.

\begin{tabular}{|c|c|c|c|c|c|c|c|c|c|c|c|c|c|c|c|c|c|c|c|c|}
\hline & \multicolumn{4}{|c|}{$\mathrm{Ni}$} & \multicolumn{4}{|c|}{$\mathrm{Mn}$} & \multicolumn{4}{|c|}{$\mathrm{Cr}$} & \multicolumn{4}{|c|}{$\mathrm{Zn}$} & \multicolumn{4}{|c|}{ Conductivity } \\
\hline & Min & Med & Avg & $\operatorname{Max}$ & Min & Med & Avg & $\operatorname{Max}$ & Min & Med & Avg & $\operatorname{Max}$ & Min & Med & Avg & Max & Min & Med & Avg & $\operatorname{Max}$ \\
\hline NP & 0.21 & 0.20 & 0.40 & 0.40 & 0.77 & 0.40 & -0.60 & -0.80 & -0.11 & -0.40 & -0.80 & -0.40 & 0.40 & -0.40 & 0.20 & 0.20 & 0.00 & 0.40 & -0.20 & -0.40 \\
\hline $\mathrm{CA}$ & -0.63 & -0.20 & 0.40 & 0.40 & 0.26 & -0.40 & -1.00 & -0.80 & -0.32 & -0.40 & -0.80 & -0.40 & 0.40 & -0.40 & -0.20 & -0.20 & 0.80 & 0.40 & 0.20 & -0.40 \\
\hline MPS & -0.95 & -0.40 & 0.20 & 0.20 & -0.26 & -0.80 & -0.80 & -0.40 & -0.32 & -0.20 & -0.40 & -0.20 & 0.20 & -0.20 & -0.40 & -0.40 & 1.00 & 0.20 & 0.40 & -0.20 \\
\hline PSSD & -0.95 & -0.40 & 0.20 & 0.20 & -0.26 & -0.80 & -0.80 & -0.40 & -0.32 & -0.20 & -0.40 & -0.20 & 0.20 & -0.20 & -0.40 & -0.40 & 1.00 & 0.20 & 0.40 & -0.20 \\
\hline $\mathrm{TE}$ & -0.63 & -0.20 & 0.40 & 0.40 & 0.26 & -0.40 & -1.00 & -0.80 & -0.32 & -0.40 & -0.80 & -0.40 & 0.40 & -0.40 & -0.20 & -0.20 & 0.80 & 0.40 & 0.20 & -0.40 \\
\hline MPE & -0.63 & -0.20 & 0.40 & 0.40 & 0.26 & -0.40 & -1.00 & -0.80 & -0.32 & -0.40 & -0.80 & -0.40 & 0.40 & -0.40 & -0.20 & -0.20 & 0.80 & 0.40 & 0.20 & -0.40 \\
\hline MSI & 0.21 & 1.00 & -0.80 & -0.80 & -0.26 & 0.00 & 0.20 & 0.40 & 0.95 & 0.80 & -0.40 & -0.80 & 0.80 & 0.80 & 1.00 & 1.00 & -0.40 & -0.80 & -1.00 & -0.80 \\
\hline MPAR & 0.63 & 0.20 & -0.40 & -0.40 & -0.26 & 0.40 & 1.00 & 0.80 & 0.32 & 0.40 & 0.80 & 0.40 & -0.40 & 0.40 & 0.20 & 0.20 & -0.80 & -0.40 & -0.20 & 0.40 \\
\hline MFRACT & 0.95 & 0.40 & -0.20 & -0.20 & 0.26 & 0.80 & 0.80 & 0.40 & 0.32 & 0.20 & 0.40 & 0.20 & -0.20 & 0.20 & 0.40 & 0.40 & -1.00 & -0.20 & -0.40 & 0.20 \\
\hline DIVISION & 0.63 & -0.60 & 0.80 & 0.80 & 0.77 & 0.80 & 0.20 & -0.40 & -0.74 & -0.80 & 0.40 & 0.80 & -0.80 & -0.80 & -0.60 & -0.60 & -0.40 & 0.80 & 0.60 & 0.80 \\
\hline SPLIT & 0.63 & -0.60 & 0.80 & 0.80 & 0.77 & 0.80 & 0.20 & -0.40 & -0.74 & -0.80 & 0.40 & 0.80 & -0.80 & -0.80 & -0.60 & -0.60 & -0.40 & 0.80 & 0.60 & 0.80 \\
\hline MESH & -0.95 & 0.00 & -0.40 & -0.40 & -0.77 & -1.00 & -0.40 & 0.20 & 0.21 & 0.40 & -0.20 & -0.40 & 0.40 & 0.40 & 0.00 & 0.00 & 0.80 & -0.40 & 0.00 & -0.40 \\
\hline CLC1\% & 0.11 & 0.40 & -0.80 & -0.80 & -0.77 & -0.20 & 0.80 & 1.00 & 0.63 & 0.80 & 0.60 & 0.00 & 0.00 & 0.80 & 0.40 & 0.40 & -0.40 & -0.80 & -0.40 & 0.00 \\
\hline CLC $2 \%$ & 0.95 & 0.40 & -0.20 & -0.20 & 0.26 & 0.80 & 0.80 & 0.40 & 0.32 & 0.20 & 0.40 & 0.20 & -0.20 & 0.20 & 0.40 & 0.40 & -1.00 & -0.20 & -0.40 & 0.20 \\
\hline CLC3\% & -0.95 & -0.40 & 0.20 & 0.20 & -0.26 & -0.80 & -0.80 & -0.40 & -0.32 & -0.20 & -0.40 & -0.20 & 0.20 & -0.20 & -0.40 & -0.40 & 1.00 & 0.20 & 0.40 & -0.20 \\
\hline
\end{tabular}


Table 15. The Spearman's rank correlation between the water quality variables (heavy metals) and the landscape metrics of 2006. Significant correlation coefficients are in bold; $\mathrm{p}<0.05$.

\begin{tabular}{|c|c|c|c|c|c|c|c|c|c|c|c|c|c|c|c|c|c|c|c|c|}
\hline & \multicolumn{4}{|c|}{$\mathrm{Ni}$} & \multicolumn{4}{|c|}{$\mathrm{Mn}$} & \multicolumn{4}{|c|}{$\mathrm{Cr}$} & \multicolumn{4}{|c|}{$\mathrm{Zn}$} & \multicolumn{4}{|c|}{ Conductivity } \\
\hline & Min & Med & Avg & Max & Min & Med & Avg & Max & Min & Med & Avg & Max & Min & Med & Avg & Max & Min & Med & Avg & Max \\
\hline $\mathrm{NP}$ & -0.42 & 0.31 & & 0.25 & -0.88 & -0.72 & -0.71 & -0.43 & -0.27 & -0.54 & & -0.01 & -0.26 & -0.07 & & 0.05 & 0.10 & 0.02 & 0.05 & -0.02 \\
\hline $\mathrm{CA}$ & -0.63 & 0.12 & -0.26 & -0.02 & -0.95 & -0.85 & -0.55 & -0.31 & -0.41 & -0.63 & -0.22 & 0.07 & -0.45 & -0.29 & -0.45 & -0.24 & 0.02 & -0.07 & -0.07 & -0.05 \\
\hline MPS & -0.49 & -0.24 & -0.19 & -0.13 & -0.68 & -0.52 & & -0.38 & -0.35 & -0.32 & -0.32 & -0.20 & -0.31 & -0.60 & -0.57 & -0.40 & 0.05 & -0.48 & -0.21 & -0.17 \\
\hline PSSD & -0.68 & -0.07 & -0.29 & -0.14 & -0.85 & -0.73 & -0.57 & -0.33 & -0.25 & -0.44 & -0.32 & -0.17 & -0.26 & -0.26 & -0.33 & -0.07 & 0.00 & -0.31 & -0.24 & -0.19 \\
\hline $\mathrm{TE}$ & -0.42 & 0.40 & -0.02 & 0.19 & -0.85 & -0.74 & -0.67 & -0.45 & -0.27 & -0.54 & -0.46 & -0.10 & -0.33 & -0.14 & -0.33 & -0.07 & 0.17 & 0.07 & 0.10 & 0.10 \\
\hline MPE & -0.54 & -0.14 & -0.26 & -0.07 & -0.85 & -0.66 & -0.62 & -0.45 & -0.41 & -0.41 & -0.29 & -0.01 & -0.38 & -0.43 & -0.48 & -0.24 & -0.02 & -0.33 & -0.17 & -0.10 \\
\hline MSI & -0.66 & -0.42 & -0.59 & -0.42 & -0.32 & -0.19 & & 0.54 & -0.63 & -0.66 & 0.29 & 0.54 & -0.50 & -0.24 & -0.28 & 0.11 & -0.90 & -0.52 & -0.85 & -0.84 \\
\hline MPAR & 0.08 & -0.68 & & 0.05 & & 0.54 & & 0.07 & & & & & 0.34 & -0.26 & & 0.25 & -0.36 & -0.85 & -0.56 & -0.79 \\
\hline & -0.38 & -0.57 & -0.45 & -0.47 & 0.17 & 0.28 & & 0.69 & -0.46 & -0.34 & 0.32 & 0.38 & -0.29 & -0.26 & -0.17 & 0.14 & -0.93 & -0.67 & -0.93 & -0.93 \\
\hline DIVISION & 0.92 & 0.50 & & 0.66 & & 0.54 & & & & 0.44 & & & & 0.17 & & -0.07 & 0.52 & 0.50 & 0.71 & 0.55 \\
\hline & 0.92 & 0.50 & & 0.66 & 0.56 & 0.54 & 0.05 & -0.24 & 0.30 & 0.44 & -0.17 & -0.14 & 0.33 & 0.17 & 0.19 & -0.07 & 0.52 & 0.50 & 0.71 & 0.55 \\
\hline MESH & -0.68 & -0.07 & -0.29 & -0.14 & -0.85 & -0.73 & -0.57 & -0.33 & -0.25 & -0.44 & -0.32 & -0.17 & -0.26 & -0.26 & -0.33 & -0.07 & 0.00 & -0.31 & -0.24 & -0.19 \\
\hline CLC1 $\%$ & 0.36 & 0.29 & 0.17 & 0.16 & 0.51 & 0.30 & 0.60 & 0.55 & 0.14 & 0.00 & 0.51 & 0.41 & 0.10 & 0.40 & 0.31 & 0.05 & -0.02 & 0.57 & 0.26 & 0.12 \\
\hline CLC2\% & 0.52 & 0.50 & 0.48 & 0.47 & 0.44 & 0.41 & 0.19 & 0.24 & 0.11 & 0.00 & 0.00 & 0.14 & 0.17 & 0.36 & 0.29 & 0.29 & 0.00 & 0.40 & 0.24 & 0.02 \\
\hline CLC3 $\%$ & -0.56 & -0.48 & -0.50 & -0.51 & -0.44 & -0.37 & -0.21 & -0.21 & -0.19 & -0.07 & -0.12 & -0.18 & -0.24 & -0.43 & -0.36 & -0.24 & -0.12 & -0.52 & -0.38 & -0.14 \\
\hline
\end{tabular}




\section{Conclusions}

In conclusion it can be said that some of the most important decision support methods were evaluated and compared that were developed and applied to mining-related contamination In Paper I of this thesis, Jordan and Abdaal (2013) compares the 'holistic' approaches including (1) landscape ecology (LE), (2) industrial ecology (IE), (3) landscape geochemistry (LG), (4) geoenvironmental models (GEM), (5) environmental impact assessment (EIA), (6) environmental risk assessment (RA), (7) material flow analysis (MFA), and (8) life cycle assessment (LCA) (Fig.2). This study, as a part of the PhD thesis, concluded that none of the methods alone can address all of the environmental problems of mining. Methods of LE, IE, LG and GEM put the emphasis on the study of natural systems in a landscape context while EIA, RA, MFA and LCA study more the decision making process within the human socio-economic systems. The common in all these methods is that they try to bridge the gap between socio-economic and natural sciences in order to support decisions on the management of the environment. Among natural science techniques an integrated use of the Landscape Geochemistry (LG) with MFA seems to be the most efficient for contamination studies in mining areas. Among socio-economic techniques, asset LCA may provide the broadest and the most 'holistic' framework to bring together EIA, RA and decision analysis, in general. In the European legislative context, the Strategic Environmental Assessment Directive (Directive 2001/42/EC) is the most holistic European directive that integrates many of the different methods considered in this study (Jordan and Abdaal 2013). In case of abandoned mines LCA and EIA have no application in making decisions on the necessary site remediation

In accordance with the EU environmental legislation contamination RA received a specific attention and a detailed comparison of the key parameters (such as heavy metal content of the mine waste dump or the slope beneath mine waste facility for the contamination source; distance to contamination transport routes of rivers, for example or the presence of high permeable layer beneath waste site for groundwater transport; and distance to sensitive receptors i.e. settlements and; and ecosystems) of 11 internationally recognized pre-screening RA methods of mine waste sites was developed. The Mine Waste Directive (2006/21/EC) requires the risk-based inventory of all mine waste sites in Europe. In order to address the problem a standard risk-based preselection protocol has been developed by the EU Commission consisting of 18 simple questions about contamination source, pathway and receptor such as (for the source, if mine waste contains heavy metals (Q3); for the pathway, if there is a high permeability layer beneath the mine waste site (Q12); for the receptor questions, if a settlement with $>100$ inhabitants is located within $1 \mathrm{~km}$ of a waste site (Q15) etc.). Beyond the comparison to the other international approaches, this method was studied and tested in detail in the thesis research.

The EU MWD Pre-selection Protocol provides a systematic methodology for pre-screening contamination risk associated with the mine waste sites. The method is based on a fundamental understanding of the key factors and parameters controlling the contamination fate along the source-pathway-receptor chain and the chemical behavior of wastes in the mine sites. The 
preliminary screening RA by the Protocol plays a key role in the initial stage decision-making. The data derived from the Protocol is compared with those resulted from the Pre-screening of problem areas of EEA PRAMS model in order to highlight the sensitivity and differences in each question in each site. It is an unexpected outcome of this study that so high unknown parameters are found for facility engineering. Similarly, the number of YES responses can be accumulated for each site for the source, pathway and receptor questions separately which may indicate the presence of multiple contamination source, multiple pathways or receptors.

According to the results, out of the 145 sites, 11 waste sites are the most risky with topographic slope $>20^{\circ}, 57$ sites are within distance less than $500 \mathrm{~m}$ to the nearest surface water bodies (streams and lakes), and 33 sites are within distance less than $680 \mathrm{~m}$ to the nearest settlements. Moreover, 25 sites are located directly above the groundwater bodies with 'poor status' and 91 sites are located inside the protected Natura 2000 sites. According to the number of YES responses to the Pre-selection Protocol questions, a risk-based site ranking was performed resulting in 127 and 129 sites are directed to 'Examine Further' using the EU and local Medianbased thresholds, respectively. Based on the local thresholds (Median-based), 16 waste sites have no risk (without pathway) and are directed to 'No Need to Examine Further' (Table 4). Results of the Pre-selection Protocol are consistent with those of the pre-screening (Tier 0) PRAMS model. Moreover, this further confirms that the Protocol delivers reliable selection results that are not particularly sensitive to the selected parameters. It is important to note that this study has no relationship to the reported national inventory by any means and the site data used for this scientific study is not based on the reported inventory.

The heavy metal contamination risk assessment (RA) for a number of selected mines in order to study the inert characteristics of the potentially generated mine wastes, in accordance with the EU MWD legislation. Altogether 30 waste sites (including abandoned mines and active quarries) were selected for scientific testing using the MWD Pre-selection Protocol. In addition to detailed geochemical study together with spatial analysis using ArcGIS was performed to derive a geochemically sound contamination RA of these mine waste sites. A detailed geochemical study together with spatial analysis using GIS has been performed to derive a geochemically sound contamination RA of the mine waste sites. Key parameters such as heavy metals, in addition to the landscape metric parameter, the distance to the nearest surface and ground water bodies, or to sensitive receptors such as settlements and protected areas were calculated and statistically evaluated using STATGRAPHICS ${ }^{\circledR}$ in order to calibrate the RA methods.

A simple risk ranking of the 30 quarry-mine waste sites based on the YES responses in descending order as follows: black coal and peat (10 YES), alginite (9 YES), lignite and clay (8 YES), bauxite (7 YES), bentonite-clay (6 YES) and andesite and rhyolite tuffs (5 YES). After the existing pre-screening risk assessment of the waste sites in Hungary, 28 sites are directed to EXAMINE FURTHER based on the EU thresholds and two sites with no risk (one Bauxite site has no pathway and one Andesite site has no receptor). 
Total concentrations of the heavy metals defined by aqua regia extraction were compared to the environmental limit values in Hungary and to the European environmental geochemical background values based on the FOREGS European Geochemical Atlas (Table 11). Results show that the median value of $\mathrm{Cu}(12.3 \mathrm{mg} / \mathrm{kg})$ is less than the Hungarian environmental limit $(75$ $\mathrm{mg} / \mathrm{kg}$ ) and exceeds the median of EU FOREGS $(12 \mathrm{mg} / \mathrm{kg})$. In case of central tendency expressed by the Median, the analyzed total heavy metal concentrations are in the descending order of $\mathrm{Zn}>\mathrm{V}>\mathrm{Cu}>\mathrm{Cr}>\mathrm{Pb}>\mathrm{Co}>\mathrm{Ni}>\mathrm{As}>\mathrm{Mo}>\mathrm{Cd}$. This result shows that $\mathrm{Zn}$ has the highest median $(24.6 \mathrm{mg} / \mathrm{kg})$ and $\mathrm{Cd}$ has the lowest Median $(0.11 \mathrm{mg} / \mathrm{kg})$. In case of relative variability (spread) expressed by IQR/Med (Inter-quartile range/Median), the total heavy metal concentrations follow the order: $\mathrm{Ni}>\mathrm{As}>\mathrm{Cr}>\mathrm{V}>\mathrm{Pb}>\mathrm{Co}>\mathrm{Cd}>\mathrm{Zn}>\mathrm{Cu}$. It is obvious that $\mathrm{Ni}$ has the highest variability (5.11) and $\mathrm{Cu}$ has the lowest (1.11). In case of the $\mathrm{S}^{\text {sulphide }}$, the mdian $(0.02 \%)$ is less than the Hungarian environmental limit $(0.1 \%)$ and $S^{\text {sulphide }}$ has a range from $0.003 \%$ to 3.82\%. Moreover Mo had the highest relative mobility in Lignite, Bauxite, Alginite, Clay and Andesite rock samples and $\mathrm{Zn}$ had the highest mobility in Black coal and Peat samples. While, V had the highest mobility in Rhyolite tuffs samples (Fig.20).

According to the geochemical analysis results in this study, coal (black coal and lignite) and peat samples are not inert and classified into group $\mathrm{C}$ which matches with the preliminary expert judgment. While alginite, bauxite, rhyolite tuffs and clay samples are probably inert and classified into B group which also matches with the preliminary expert judgment. Moreover limestone and clay samples are inert (A group). It is interesting to report that andesite samples are probably inert (B group) and according to our geochemical analyses, it was found that 5 andesite samples contain higher concentrations of the heavy metals $\mathrm{Ni}, \mathrm{Zn} \mathrm{Cu}, \mathrm{Cr}$ and $\mathrm{Co}$ than the minimum, median and mean values of the Hungarian standards. While As is even higher than the maximum values of the national environmental standards. These results may suggest that those 5 andesite samples with higher heavy metal concentrations could classify the andesite rock formation into the $\mathrm{B}$ or $\mathrm{C}$ groups

Multivariate analysis such as CA and PCA using the analysed trace elements could not identify significant groups of samples. This is not unexpected due to the heterogeneity of the sampled rock types. It seems that specific rock formations with ore minerals content, including pyrite with acid generation potential, such as some andesites and coals are distinct from the non-mineralised as shown by the Ficklin Diagram (Fig.21).

The linkage between selected water quality variables (e.g. $\mathrm{Ni}, \mathrm{Mn}, \mathrm{Cr}, \mathrm{Zn}$ and conductivity) in streams nearby the studied 33 mining waste sites and the landscape metrics of watersheds of these mining sites was investigated and analysed. The hypothesis is the landscape structure may have an influence on and thus a relationship with contamination transport from the mine sources to the receiving surface waters. The water quality variables were selected on the basis that 1) these point source chemical contamination variables are important in this study, and 2) other point source contamination variables were not measured by the Central Environmental Agency of 
Hungary, and 3) these are the most complete data series available for the stream water quality monitoring stations in Hungary concerning the studied watersheds. The annual minimum, median, average and maximum of $\mathrm{Ni}, \mathrm{Cr}, \mathrm{Mn}, \mathrm{Zn}$, and conductivity were calculated for years 2000 and 2006. The landscape indices such as Total Number of Patches (NP), length of Total Edge (TE) Mean Shape Index (MSI), Main Patch Size (MPS), Patch Size Standard (PSSD), Deviation Mean Patch Ratio (MPE), Mean Perimeter Area Ratio (MPAR) and were calculated for each of the 33 mining watersheds. The percentage area of the main CORINE land cover classes (such as artificial surfaces (CLC1), agricultural areas (CLC2) and forest and semi-natural areas (CLC3)) was calculated and its role on the water quality was also investigated.

It is concluded that the Mean Shape Index (MSI) is the most important "key" landscape index in 2000, and the Main Fractal Dimension Index in 2006 (Table 14), from the surface water quality heavy metal contamination point of view. Based on our statistical analyses we can conclude that in case of the further modification of the RA methods, at least these two landscape indices should take under consideration, and integrate into the RA methods. The median $\mathrm{Ni}$, average $\mathrm{Mn}$, average $\mathrm{Zn}$ and minimum conductivity variables are the most significantly correlated with the landscape indices in 2000 . While the minimum \& average $\mathrm{Ni}$, the minimum \& median $\mathrm{Mn}$, the average \& maximum conductivity variables are the most significantly correlated with the landscape indices in 2006 (Table 15). 


\section{Acknowledgements}

I wish to express my deepest gratitude to Dr. Gyozo Jordan and Dr. Peter Szialssi, my supervisors, whose invaluable guidance, support and encouragement have nourished this dissertation research from start to successful completion. I still feel that I should go one step further, not only due to the best research condition and environment at Szeged University but also because of the excellent supervision provided by both of them. Obviously, the above words are not sufficient to express my sincere appreciation.

I am grateful to the Department of Physical Geography and Geoinformatics at Szeged University for providing tools and assistantships for my $\mathrm{Ph}$. D. studies. I would like to express my deepest gratitude to Prof. Dr. Gábor Mezősi for his continuous encouragement and kind help, and my warmest thanks to all professors and fellow PhD students in the department (e.g. Theodora Bata, Zsuzsanna Ladanyi, and Kitti Balog and many others) for their kindness and invaluable assistance. Special thanks refer to Dr. Boudewijn van Leeuwen for his valuable suggestions and kind assistance in the practical work of this thesis.

I would like to thank Gyorgy Toth, Peter Scharek and Laszlo Orosz of the Geological and Geophysical Institute of Hungary (MFGI). I appreciate all precious time and kind help from Julianna Albert and Dóra Zacháry. Special thank is extended to Janos Kiss and Gergely Detzky co-authoring the Hungarian EU Mine Waste Inventory Report and the related fruitful discussions. The Hungarian Scholarship Board (MOB-Grant) is gratefully acknowledged.

All the time I spent with Dr. Gyozo Jordan and Dr. Peter Szilassi during my PhD studies is a priceless treasure for me, and I will take it as guidance for my future career.

My parents and my wife are appreciated for their love and understanding. 


\section{References}

Andrews, R. N. L. (1988). Environmental impact assessment and risk assessment: learning from each other. In: Wathern P. (Ed.), Environmental impact assessment. Theory and practice. Unwin Hyman, London.

Arquette, M., Cole, M., Cook, K., LaFrance, B., Peters, M., Ransom, J., Sargent, E., Smoke, V., Stairs, A. (2002). A Holistic risk-based environmental decision making: a Native perspective. Environmental Health Perspectives, 110 (Suppl 2):259-64.

Aspinall, R., \& Pearson, D. (2000). Integrated geographical assessment of environmental condition in water catchments: Linking landscape ecology, environmental modelling and GIS. Journal of Environmental Management, 59, 299-319.

Atkins, R. (1984). A comparative analysis of the utility of EIA methods. In: Clark B. D. \& Gilad A. (eds), Perspectives on environmental impact assessment. D. Reidel publishing Company, Dodrecht.

Ayres, R. U. \& Ayres, L.W. (Eds.), (2002). A Handbook of Industrial Ecology. Edward Elgar

Azapagic, A. (1999). Life cycle assessment and its application to process selection, design and optimization. Chemical Engineering Journal, 73, 1-21.

Bagur, M. G., Morales, S., López-Chicanoc, M. (2009). Evaluation of the environmental contamination at an abandoned mining site using multivariate statistical techniques-The Rodalquilar (Southern Spain) mining district. Talanta 80, 377-384.

Basson, L., \& Petrie, J. G. (2007). An integrated approach for the consideration of uncertainty in decision making supported by Life Cycle Assessment. Environmental Modelling \& Software, 22, 167-176.

BAT, (2003). Draft Reference Document on Best Available Techniques for Management of Tailings and Waste-Rock in Mining Activities, 2003. European IPPC Bureau, Joint Research Centre of the European Commission, Seville. http://www.aimme.es/archivosbd/ftp/BREF_Tratamiento_de_Superficies.pdf.

Baumann, H., \& Tillman, A. M. (2004). The Hitch Hiker's guide to LCA--An orientation in life cycle assessment methodology and application. Lund, Sweden: Student Literature; 2004.

Beanlands, G. (1988). Scoping methods and baseline studies in EIA. In: Wathern P. (ed.), Environmental impact assessment. Theory and practice. Unwin Hyman, London.

Bisset, R. (1980). Methods for environmental impact assessment: recent trends and future prospects. Journal of Environmental Management, 11, 27-43.

Bisset, R. (1984). Methods for assessing direct impacts. In: Clark B. D. \& Gilad A. (Eds), Perspectives on environmental impact assessment. D. Reidel publishing Company, Dodrecht.

Blengini, G. A., Garbarino, E., Solar, S., Shields, D. J., Hámor, T., Vinai, R., \& Agioutantis, Z. (2012). Life Cycle Assessment guidelines for the sustainable production and recycling of aggregates: the Sustainable Aggregates Resource Management project (SARMa). Journal of Cleaner Production, 27, 177-181.

Bouman, M., Heijungs, R., van der Voet, E., van den Bergh, J., \& Huppes, G. (2000). Material flows and economic models: an analytical comparison of SFA, LCA and partial equilibrium models. Ecological Economics, 32, 195-216.

Bradshaw P. M. D. (1975). Conceptual models in exploration geochemistry. Journal of Exploration Geochemistry, 4, 1-213. 
Broadhurst, J. L., Petrie, J. G.. (2010). Ranking and scoring potential environmental risks from solid mineral wastes. Minerals Engineering 23, 182-191.

Browne, D., O'Regan, B., \& Moles. R. 2011. Material flow accounting in an Irish city-region 1992-2002. Journal of Cleaner Production, 19, 967-976.

Butcher, S. S., Charlson, R. J., Orians, G. H. \& Wolfe, G. V. (eds.), (1992). Global Biogeochemical Cycles. Academic Press, San Diego.

CARACAS (Concerted Action on Risk Assessment for Contaminated Sites in the European Union), (1999). Risk Assessment for Contaminated Sites in Europe. Volume 1, Scientific Basis. LQM Press, Nottingham.

Charman, D. 2002. Peatlands and environmental change. J. Wiley \& Sons, London \& New York, $301 \mathrm{p}$.

Cleary, J. (2010). The incorporation of waste prevention activities into life cycle assessments of municipal solid waste management systems: methodological issues. International Journal of Life Cycle Assessment, 15, 579-589.

$\operatorname{COM}(2003) 319$ final. Proposal for a Directive of the European Parliament and of the Council on the Management of Waste from the Extractive Industries. COM(2003) 319 final, 2003/0107 (COD), Commission of the European Communities, Brussels. http://eurlex.europa.eu/LexUriServ/LexUriServ.do?uri=COM:2003:0319:FIN:EN:PDF.

$\operatorname{COM}(2005) 670$ final. Communication from the Commission to the Council, the European Parliament, the European Economic and Social Committee and the Committee of the Regions - Thematic Strategy on the sustainable use of natural resources. http://eurlex.europa.eu/LexUriServ/LexUriServ.do?uri=COM:2005:0670:FIN:EN:PDF.

Commission Decision 2009/337/EC on the Criteria for the classification of waste facilities in accordance with Annex III, of Directive 2006/21/EC of the European Parliament and of the Council concerning the management of waste from extractive industries. http://eurlex.europa.eu/LexUriServ/LexUriServ.do?uri=OJ:L:2009:102:0007:01:EN:HTML

Cox, D. P., \& Singer, D. A. (1986). Mineral deposit models. U.S. Geological Survey Bulletin 1693.

De Jong, P. (1988). Uncertainty in EIA. In: Wathern P. (Ed.), Environmental impact assessment. Theory and practice. Unwin Hyman, London.

deLemos, J. L., Brugge, D., Cajero, M., Downs, M., Durant, J. L., George, C. M., HenioAdeky, S., Nez, T., Manning, T., Rock, T., Seschillie, B., Shuey, C., Lewis, J. (2009). Development of risk maps to minimize uranium exposures in the Navajo Churchrock mining district. Environmental Health 8, 29.

Del-Rio, J.C., Gonzalez-Vila, F.J., Martin, F. 1992. Variation in the content and distribution of biomarkers in two closely situated peat and lignite deposits. Organic Geochemistry. Vol. 18(1), 67-78.

Despeisse, M., Ball, P. D., Evans, S., \& Levers, A. (2012). Industrial ecology at factory level - a conceptual model. Journal of Cleaner Production, 31, 30-39.

Di Sante, M., Mazzieri, F., Pasqualini, E. (2009). Assessment of the sanitary and environmental risks posed by a contaminated industrial site. Journal of Hazardous. Materials. 171, 524-534.

Directive 2001/42/EC of the European Parliament and of the Council of 27 June 2001 on the assessment of the effects of certain plans and programmes on the environment. http://eurlex.europa.eu/LexUriServ/LexUriServ.do?uri=CELEX:32001L0042:EN:HTML. 
Directive 2006/118/EC of The European Parliament and of the Council of 12 December 2006 on the protection of groundwater against pollution and deterioration. http://eurlex.europa.eu/LexUriServ/LexUriServ.do?uri=OJ:L:2006:372:0019:0031:EN:PDF

Directive 2006/21/EC the European Parliament and of the Council on the management of waste from extractive industries and amending Directive 2004/35/EC. http://eurlex.europa.eu/LexUriServ/LexUriServ.do?uri=CONSLEG:2006L0021:20090807:EN:PDF.

Directive 85/337/EEC Directive of 27 June 1985 on the assessment of the effects of certain public and private projects on the environment. Directive as last amended by Directive 2003/35/EC of the European Parliament and of the Council. http://eurlex.europa.eu/LexUriServ/LexUriServ.do?uri=CONSLEG:1985L0337:20090625:EN:PDF.

Duchin, F., \& Levine, S. H. (2008). Industrial Ecology. Encyclopedia of Ecology, 1968-1975. http://dx.doi.org/10.1016/B978-008045405-4.00627-3.

Eduljee, G. (1999). Environmental impact assessment and waste management. In: J. Petts (Ed.), Handbook of environmental impact assessment. Environmental impact assessment in practice: impact and limitations. Blackwell Science, London.

EEA, 2005. European Environmental Agency. http://org.eea.eu.int/documents/brochure/brochure_reason.html

EEA, European Environment Agency. (2005a). Towards an EEA Europe-wide assessment of areas under risk for soil contamination, Vol. 2. Review and analysis of existing methodologies for preliminary risk assessment. http://sia.eionet.europa.eu/activities/reportste/PRAMS2.

EEA, European Environment Agency. (2005b). Towards an EEA Europe-wide assessment of areas under risk for soil contamination Vol. 3. PRA.MS: scoring model and algorithm. http://sia.eionet.europa.eu/activities/reportste/PRAMS3.

EEA, European Environment Agency. (2005c). Towards an EEA Europe-wide assessment of areas under risk for soil contamination. Objectives and Methodology. Attachment 1: Prescreening of problem areas/Megasites. http://eea.eionet.europa.eu/Public/irc/eionetcircle/te/library?l=/collection_2006/prescreening 060703pdf/EN_1.0_\&a=d.

EEA, European Environment Agency. (2007). Progress in the management of contaminated sites (CSI 015) - assessment published in August 2007.

Ehrenfeld, J. R., \& Gertler, N. (1997). Industrial ecology in practice: the evolution of interdependence at Kalundborg. Journal of Industrial Ecology, 1(1), 67-79.

Erkman, S., \& Ramaswamy, R. (2001). Applied Industrial Ecology: Leveraging the Wealth of Societies. Case Studies on Resource Optimization in India. Geneva \& Bangalore, ICAST, 2001 (forthcoming).

Fan, C., Chen, Y. C., Ma, H. W., Wang, G. S. (2010). Comparative study of multimedia models applied to the risk assessment of soil and groundwater contamination sites in Taiwan. Journal of Hazardous Materials, 182(1-3), 778-786.

Fanga, Y., Cote, R. P., \& Qinc, R. (2007). Industrial sustainability in China: Practice and prospects for eco-industrial development. Journal of Environmental Management, 83, 315328.

Feoli, E. (2002). Industrial ecology and bioremediation. Theoretical framework and technological tools for sustainable development. In: Fabbri A. G., Gaal G. and McCammon R. B. (Eds), Deposit and Geoenvironmental Models for Resource Exploitation and Environmental Security, NATO Science Series, 2. Environmental Security, 80, pp. 291-302. Kluwer Academic Publishers, Dordrecht. 
Fergusson, C. (Ed.). (1998).Risk assessment for contaminated site in Europe. vol 1: scientific basis(p. 165). Nottingham: LQM Press.

Field, F. R., Isaacs, J. A., \& Clark, J. P. (1993). Life cycle analysis and its role in product and process development. International Journal of Environmentally Conscious Design and Manufacturing, 2, 13-20.

Forman, R.T.T, \& Godron, M. (1986). Landscape Ecology. Wiley, New York.

Forman, R.T.T. (1995). Land Mosaics. The ecology of landscapes and regions. Cambridge University Press, New York.

Fortescue, J.A.C. (1980). Environmental geochemistry: a holistic approach. Springer, New York.

Fortescue, J.A.C. (1992). Landscape geochemistry: retrospect and prospect - 1990. Applied Geochemistry, 7, 1-53.

Frank, A. (1986). In search of biomonitors for cadmium. Cadmium content of wild Swedish fauna during 1973-1976. The Science of the Total Environment, 57, 57-65.

French, S., \& Geldermann, J. (2005). The varied contexts of environmental decision problems and their implications for decision support. Environmental Science \& Policy, 8, 378-391.

Gazdag, E. R., Sipter, E. (2008). Geochemical background in heavy metal metals and human health risk assessment at an ore mine site, Gyöngyösoroszi (North Hungary). Carpathian Journal of Earth and Environmental Sciences, 3(2), 83-92.

Gerrard, J. (1992). Soil geomorphology. Chapman \& Hall, London.

Gild, A. (1984). The health component of the environmental impact assessment process. . In: Clark B. D. and Gilad A. (Eds), Perspectives on environmental impact assessment. D. Reidel publishing Company, Dodrecht.

Glazovskaya, M.A. (1963). On geochemical principles of the classification of natural landscapes. International Geological Reviews, 5, 1403-1430.

Goldhamber, M. B., Morrison, J. M., Holloway, J. M, Mills, C. T. \& Wanty, R. B. (2009). Geochemical landscape studies of geogenic trace elements in Northern California, USA. $\begin{array}{llll}\text { Goldschmidt } & \text { Conference } & \text { Abstracts } & \end{array}$ http://goldschmidt.info/2009/abstracts/finalPDFs/A447.pdf.

Gömöryová, E., Vass, D., Pichler, V., Gömöry, D. 2009. Effect of alginite amendment on microbial activity and soil water content in forest soils. Biologia, 64(3), 585-588.

González, V., García, I., del Moral, F., de Haro, S., Sánchez, J. A., Simón, M. (2011). Impact of unconfined sulphur-mine waste on a semi-arid environment (Almería, SE Spain). Journal of Environmental Management 92, 1509-1519.

Graedel, T. E., \& Howard-Grenville, J. A. (2005). Greening the Industrial Facility: Perspectives, Approaches, and Tools. Springer, New York.

Grennan, E. (1996). EPA Small Scale Study - EPA register of former mine sites. Sligo RTC, Ireland.

Gzyl, J. (1990). Ecological impact and remediation of contaminated sites around lead smelters in Poland. Journal of Geochemical Exploration, 52, 251-258.

Haines-Young R., Green D. R. \& Cousins S. H. (Eds), (1993). Landscape Ecology and GIS. Taylor \& Francis, London.

Hamor, T. (2002). Legislation on Mining and Mining Waste in Central and Eastern European Candidate Countries. Joint Research Centre of the European Commission, Ispra, EUR 20545 
EN.

http://publications.jrc.ec.europa.eu/repository/bitstream/111111111/10880/1/EUR\%2020545 \%20EN.pdf.

Hamor-Vido, M. 2004. Coal facies studies in Hungary: a historical review. International Journal of Coal Geology 58, 91-97.

Hansen, Y., Broadhurst, J. L., Petrie, J. G. (2008). Modelling leachate generation and mobility from copper sulphide tailings: an integrated approach to impact assessment. Minerals Engineering 21, 288-301.

Harp, D.R., \& Vesselinov, V.V. (2012). Contaminant remediation decision analysis using information gap theory. Stochastic Environmental Research and Risk Assessment, doi: 10.1007/s00477-012-0573-1.

Horvath, B., Gruiz, K. (1996). Impact of metalliferous ore mining activity on the environment in Gyongyosoroszi, Hungary. The Science of the Total Environment 184, 215-227.

Hu, C. Q., Zhang, C. X., Han, X. W. \& Yin, R. Y. (2008). Sulfur Flow Analysis for New Generation Steel Manufacturing Process. Journal of Iron and Steel Research, International, 15(4), 12-15, 37.

Hungarian GKM Decree No. 14/2008. (IV. 3) concerning mining waste management. http://www.mbfh.hu/gcpdocs/201107/gkm_ministry_of_economy_and_transport_decree_no_ 14_2008_iv_3_on_minig_waste_management.pdf.

Hunsaker, C. T., Graham, R. L., Suter II, G. W., O'Neill, R. V., Barnthouse, L. W., Gardner, R. H. (1990). Assessing ecological risk on a regional scale. Environmental Management; 14(3), 325-332.

ICPDR, (2006). Final report for the Danube Region Project Development of M2 Methodology / Checklist, prepared by Hermine Weber, Federal Environment Agency Ltd., Austria. http://www.icpdr.org/main/activities-projects/industry-and-municipal-activities.

International Organization for Standardization (1995). ISO 11466 International standard Soil quality -extraction of trace elements soluble in aqua regia. 03-01.

Irish EPA, Environmental Protection Agency, (2009). Historic Mine Sites - Inventory and Risk Classification (HMS-IRC) Volume 1. http://www.epa.ie/downloads/pubs/land/mines/.

Jordan, G. \& D'Alessandro, M. (Eds), 2004. Mining, Mining Waste and Related Environmental Issues: Problems and Solutions in the Central and Eastern European Candidate Countries. Joint Research Centre of the European Commission, Ispra. LB-NA-20868-EN-C.

Jordan, G. (2004a). Mining and mining waste: pressures, impacts and responses in the enlarged European Union. In: Jordan, G. \& M. D’Alessandro (Eds), 2004. Mining, Mining Waste and Related Environmental Issues: Problems and Solutions in the Central and Eastern European Candidate Countries. Joint Research Centre of the European Commission, Ispra. LB-NA-20868-EN-C.

Jordan, G. (2004b). Mining and mining waste: problems and solutions in the Central and Eastern European Candidate Countries. In: Jordan, G. \& M. D’Alessandro (Eds), 2004. Mining, Mining Waste and Related Environmental Issues: Problems and Solutions in the Central and Eastern European Candidate Countries. Joint Research Centre of the European Commission, Ispra. LB-NA-20868-EN-C.

Jordan, G., \& Szucs A. (1997). The role and future of geology in modern environmental research and decision support. Proceedings of the 30th IGC, Theory of Geology, Wang et al. (Eds), 26, pp. 237-249. 
Jordan, G., \& Szucs A. (2002). Environmental mapping of geochemical systems. In: P. T. Bobrowsky (Ed.), Geo-environmental Mapping: Theory, Methods and Applications, pp. 5774. A. A. Balkema, Lisse.A

Jordan, G., \& Szucs, A. (2011). Geochemical Landscape Analysis: Development and Application to the Risk Assessment of Acid Mine Drainage. A Case Study in Central Sweden. Landscape Research, 36, 231-261.

Jordan, G., Fügedi, U., Bartha, A., Vatai, J., Tóth, G., Murati, J., Szentpéteri, I., Konya, P., Gaburi, I., Tolmács, D., \& Müller, T. (2011). The red mud catastrophe in Kolontár Hungary: applying geology. European Geologist, 32, 9-13.

Jordan, G., Fügedi, U., Bartha, A., Kuti, L., Abdaal, A., et al. (2011). Geochemical characterization of mine waste for the inert classification in Hungary. Final Report on the national programme, 2011. Geological Institute of Hungary (MAFI) (in Hungarian).

Jordan, G., PECOMINES Project. (2009). Sustainable mineral resources management: from regional mineral resources exploration to spatial contamination risk assessment of mining. Environmental Geology 58, 153-169.

Jordan, G., Rukezo, G., Fugedi, U., Carranza, E. J. M., Somody, A., Vekerdy, Z., Szebenyi, G., \& Lois, L. (2003). Environmental impact of metal mining on catchment drainage in the historic mining area of Recsk-Lahoca mines, Hungary. Proceedings, 4th European Congress on Reginal Geoscientific Cartography and Information Systems, 2003, Bologna, Italy, 2, pp. 713-715. Regione Emilia-Romagna, Servizio Geologoco, Italy.

Jordan, G., Szucs, A., Qvarfort, U., \& Szekely, B. (1997). Evaluation of metal retention in a wetland receiving acid mine drainage. Proceedings of the 30th IGC, Geochemistry, Xuejin X. (Ed.), Vol. 19: 189-206.

Jordan G., Van Rompaey A., Szilassi P., Csillag G., Mannaerts C., Woldai T. (2005). Historical land use changes and their impact on sediment fluxes in the Balaton basin (Hungary), Agriculture Ecosystems \& Environment 108: (2) pp. 119-13.

Kauppila, P. M., Tarvainen, T., \& Kauppila, T. (2011). Geochemistry for risk assessment of metal contaminated sites. Workshop abstracts in the 25th International Applied Geochemistry Symposium 2011, 22-26 August 2011. Rovaniemi, Finland. Vuorimiesyhdistys - Finnish Association of Mining and Metallurgical Engineers, Serie B92-3, 14 pages. http://www.iags2011.fi/25thIAGS2011_W2_net.pdf.

Kavouridis. K., Koukouzas, N. 2008. Coal and sustainable energy supply challenges and barriers. Energy Policy 36, 693-703.

Keefer, D. L., Kirkwood, C. W., \& Corner, J. L. (2004). Perspective on decision analysis applications, 1990-2001. Decision Analysis, 1, 4-22.

Kiss, J. and Jordan, G. (2012). Inventory and risk ranking of closed mine waste facilities. MBFH-ELGI Co-operation Project (E7). Final Report on the National Programme, 2012. MFGI Archives, Budapest. Contributors: Detzky G., Vertesy L., Abdaal A., Muller T., Zsámbok I., Paszera G., Gulyas A., Ori G., Sores L., Radi K., Albert J., Hermann V. and Jerabek C. http://www.mbfh.hu/gcpdocs-/201205/mwf2012.pdf.

Klauer, B., Rode, M., Schiller, J., Franko, U., \& Mewes, M. (2012). Decision Support for the Selection of Measures according to the Requirements of the EU Water Framework Directive. Water Resources Management, 26,775-798.

Komnitsas, K., Modis, K. (2006). Soil risk assessment of As and Zn contamination in a coal mining region using geostatisretics. The Science of the Total Environment 371, 190-196. 
Korhonen, J., Okkonen, L., \& Niutanen, V. (2004). Industrial ecosystem indicators-direct and indirect effects of integrated waste- and by-product management and energy production. Clean Technologies and Environmental Policy, 6, 162-173.

Korobova, E. (2010). Landscape and bio- geochemical strategy for monitoring transformation and reclamation of the soil mining sites. EGU General Assembly 2010, held 2-7 May, 2010 in Vienna, Austria, p.13426. http://meetingorganizer.copernicus.org/EGU2010/EGU201013426.pdf.

Kovanda, J., Weinzettel, J., \& Hak, T. (2009). Analysis of regional material flows: The case of the Czech Republic. Resources, Conservation and Recycling, 53, 243-254.

Kyoto Protocol, (1992). Kyoto Protocol to the the United Nations Framework Convention on Climatic Change. United Nations, New York.

Landis, W. G. (2005). Regional scale ecological risk assessment. In: Landis WG, editor. Using the relative risk model. CRC PRESS.

Larondelle, N., \& Haase, D. (2012). Valuing post-mining landscapes using an ecosystem services approach-An example from Germany. Ecological Indicators, 18, 567-574.

Lavrač, N., Bohanec, M., Pur, A., Cestnik, B., Debeljak, M., \& Kobler, A. (2007). Data mining and visualization for decision support and modeling of public health-care resources. Journal of Biomedical Informatics, 40, 438-447.

Lei, Liang-qi., Song, Ci-an., Xie, Xiang-li., Li, Yan-hong., WANG, Fei. (2010). Acid mine drainage and heavy metal contamination in groundwater of metal sulfide mine at arid territory (BS mine, Western Australia). Transactions of Nonferrous Metals Society of China 20, 14881493.

Leitão, A. B., \& Ahern, J. (2002). Applying landscape ecological concept and metrics in sustainable landscape planning. Landscape and Urban Planning, 59, 65-93.

Lemming, G., Hauschild, M. Z., \& Bjerg, P. L. (2010). Life cycle assessment of soil and groundwater remediation technologies: literature review. International Journal of Life Cycle Assessment, 15, 115-127.

Lenz, R., \& Peters, D. (2006). From data to decisions Steps to an application-oriented landscape research. Ecological Indicators, 6, 250-263

Lim, H-S., Lee, J-S., Chon, H-T., Sager, M. (2008). Heavy metal contamination and health risk assessment in the vicinity of the abandoned Songcheon Au-Ag mine in Korea. Journal of Geochemical Exploration 96, 223-230.

Li-Teh Lu, Cheng Chang, Teng-Yuan Hsiao, Yue-Hwa Yu and Hwong-Wen Ma, 2007. Identification of Pollution Source of Cadmium in Soil. Application of Material Flow Analysis and A Case Study in Taiwan. Environmental Science and Pollution Research, 14(1), 49-59.

Liu, Q., Jiang, P., Zhao, J., Zhang, Z., Bian, H., \& Qian, G. (2011). Life cycle assessment of an industrial symbiosis based on energy recovery from dried sludge and used oil. Journal of Cleaner Production, 19, 1700-1708.

Long, J., Fischhoff, B. (2000). Setting risk priorities: a formal model. Risk Analysis 20, 33951 .

Luo, W., Lu, Y., Zhang, Y., Fu, W.,Wang, B., Jiao, W.,Wang, G.,Tong, X.,Giesy, J. P. (2010). Watershed-scale assessment of arsenic and metal contamination in the surface soils surrounding Miyun Reservoir, Beijing, China. Journal of Environmental Management 91, 2599-2607. 
Marchant, A. P., Banks, V. J., Royse, K., Quigley, S. P., \& Wealthall, G. P. (2011). An initial screening tool for water resource contamination due to development in the Olympic Park 2012 site, London. Environmental Earth Sciences, 64, 483-495.

Marcomini, A., Suter II, G. W., Critto, A. (2009). Decision support systems for risk based management of contaminated sites. New York: Springer Verlag.

Mladenic, D., Lavrač, N., Bohanec, M., \& Moyle, S., (Eds). (2003). Data mining and decision support: integration and collaboration. Dordrecht: Kluwer, 2003.

Moreno-Jiménez, E., García-Gómez, C., Oropesa, A. L., Esteban, E., Haro, A., Carpena-Ruiz, R., Tarazona, J. V., Peñalosa, J. M., Fernández, M. D. (2011). Screening risk assessment tools for assessing the environmental impact in an abandoned pyritic mine in Spain. Science of the Total Environment 409, 692-703.

Mukherjee, A. B., Zevenhoven, R., Bhattacharya, P., Sajwan, K. S., \& Kikuchi, R. (2008). Mercury flow via coal and coal utilization by-products: A global perspective. Resources, Conservation and Recycling, 52, 571-591.

Naveh, Z. \& Liebermann, A. S. (1994). Landscape ecology, theory and application. Springer, New York.

Naveh, Z. (2000). What is Holistic Landscape Ecology? A Conceptual Introduction. Landscape and Urban Planning, 50. Elsevier Sciences B.V., Amsterdam, Niederlande, pp. 726.

Norton, G. A. (1984). Systems analysis and environmental impact assessment. In: Clark B. D. \& Gilad A. (Eds), Perspectives on environmental impact assessment. D. Reidel publishing Company, Dodrecht.

Nowack, M., Hoppe, H., \& Guenther, E. (2012). Review and downscaling of life cycle decision support tools for the procurement of low-value products International Journal of Life Cycle Assessment, doi: 10.1007/s11367-012-0401-3.

Odor, L., \& McCammon, R. B. (Eds), (1999). Deposit modelling and mining-induced environmental risks. Geologica Hungarica, Series Geologica, 24.

Odor, L., Wanty, R., Horvath, I., \& Fugedi, U. (1998). Mobilization and attenuation of metals downstream from a base-metal mining site in the Matra Mountains, northeastern Hungary. Journal of Geochemical Exploration, 65, 47-60.

Okkonen, L. (2008). Applying industrial ecosystem indicators: case of Pielinen Karelia, Finland. Clean Technologies and Environmental Policy, 10, 327-339.

Ostaszewska, K. (2010). The geochemical landscape concept and its usefulness in physical geography. Miscellanea Geographica, 14, 5-12.

Panagopoulos, I., Karayannis, A., Adamb, K., \& Aravossis, K. (2009). Application of risk management techniques for the remediation of an old mining site in Greece. Waste Management, 29, 1739-1746.

Passariello, B., Giulianoa, V., Quaresimaa, S., Barbaroa, M., Carolib, S., Forteb, G., Carellic, G., Iavicolic, I. (2002). Evaluation of the environmental contamination at an abandoned mining site. Microchemical Journal 73, 245-250.

Pauleit, S., \& Duhme, F. (2001). Assessing the environmental performance of land cover types for urban planning. Landscape and Urban Planning, 52(1), 1-20.

Peplow, D., \& Edmonds, R. (2005). The effects of mine waste contamination at multiple levels of biological organization. Ecological Engineering, 24, 101-119. 
Perger A. 2009. The role of coal in the Hungarian electricity sector. Short overview on the use of coal in the electricity sector. Energiaklub. http://energiaklub.hu/en/publication/the-role-ofcoal-in-the-hungarian-electricity-sector.

Pioneer Technical Services, (1994). Abandoned Hard Rock Mine Priority Sites, Abandoned and Inactive Mines Scoring System (AIMSS), Report to Montana department of State Lands, Abandoned Mines Reclamation Bureau, December.

Pizzol, L., Critto, A., Agostini, P., Marcomini, A. (2011). Regional risk assessment for contaminated sites Part 2: Ranking of potentially contaminated sites, Environment International 37, 1307-320.

Plant, J., Smith, D., Smith, B., \& Williams, L. (2001). Environmental geochemistry at the global scale. Applied Geochemistry, 16, 1291-1308.

Plumlee, G.S., Smith, K.S., Montour, M.R., Ficklin, W.H., and E.L. Mosier, 1999. Geologic Controls on the Composition of Natural Waters and Mine Waters Draining Diverse MineralDeposit Types. In: L.H. Filipek and G.S. Plumlee (Eds.), The Environmental Geochemistry of Mineral Deposits, Part B: Case Studies and Research Topics, Reviews in Economic Geology Vol. 6B, Society of Economic Geologists, 373-432.

Power, B. A., Tinholt, M. J., Hill, R. A., Fikart, A., Wilson, R. M., Stewart, G. G., Sinnett, G. D., \& Runnells, J. L. (2010). A risk-ranking methodology for prioritizing, historic potentially contaminated mine sites in British Columbia. Integrated Environmental Assessment and Management, 6(1), 145-154.

Puura, E., Marmo, L., \& D'Alessandro, M. (Eds), (2002). Proceedings of the Workshop on Mine and Quarry Waste - the Burden from the Past. Joint Research Centre of the European Commission, Ispra.

Pykh, Y., Hyatt, D.E., Lenz, R.J.M. (Eds.), 1999. Advances in Sustainable Development: Environmental Indices-Systems Analysis Approach. EOLSS Publisher, Oxford, p. 655.

Qiu, F., Tong, L., Zhang, H., and Zhang, N. 2009. Decomposition analysis on direct material input and dematerialization of mining cities in Northeast China. Chinese Geographical Science, 19(2), 104-112.

Quercia, F., Veccio, A., Falconi, M., Tarvainen, T., Vepner, M., \& Schamann, M. (2004). Towards an EEA Europe-wide assessment of areas under risk for soil contamination. PRAMS scoring model and algorithms. First Draft. European Environmental Agency, Koppenhagen.

Ramsey, M.H. (2009). Uncertainty in the assessment of hazard, exposure and risk. Environmental Geochemistry and Health, 31, 205-217.

Rapant, S., Dietzová, Z., Cicmanova, S. (2006). Environmental and health risk assessment in abandoned mining area, Zlata Idka, Slovakia. Environmental Geology, 51(3), 387-397.

Rebitzer, G., Ekvallb, T., Frischknechtc, R., Hunkelerd, D., Norrise, G., Rydbergf, T., Schmidtg, W. P., Suhh, S., Weidemai, B. P., \& Penningtonf, D. W. (2004). Life cycle assessment Part 1: Framework, goal and scope definition, inventory analysis, and applications. Environment International, 30, 701-720.

Reisinger, H., Schöller, G., Jakl, T., Quint, R., and Müller, B., et al. 2009. Lead, Cadmium and Mercury Flow Analysis - Decision Support for Austrian Environmental Policy. Österreichische Wasser- und Abfallwirtschaft 61(5-6), 63-69.

Ritsema, I. L. (2002). Asset life-cycle in the mining industry. How to improve economic and environmental decision-making by applying ICT. . In: Fabbri A. G., Gaal G., \& McCammon R. B. (Eds), Deposit and Geoenvironmental Models for Resource Exploitation and 
Environmental Security, NATO Science Series, 2. Environmental Security, 80, pp. 425-460. Kluwer Academic Publishers, Dordrecht.

Romic M., Hengl T., Romic D., Husnjak S. (2007). Representing soil pollution by heavy metals using continuous limitation scores. Computers \& Geosciences 33, 1316-1326.

Safe Quarry: Guidelines to the Safety, Health and Welfare at Work (Quarries) Regulations. (2008). (S.I. No. 28 of 2008). Published by the Irish Health and Safety Authority.

Sahnoun, H., Serbaji, M. M., Karray, B., \& Medhioub, K. (2011). GIS and multi-criteria analysis to select potential sites of agro-industrial complex. Environmental Earth Sciences, doi: 10.1007/s12665-011-1471-4.

Samadder, S. R. (2011). Impact of Arsenic Pollution on Spatial Distribution of Human Development Index. KSCE Journal of Civil Engineering, 15(6), 975-982.

Sarmiento, A. M., DelValls, A., Nieto, J. M., Salamanca, M. J., \& Caraballo, M. A. (2011). Toxicity and potential risk assessment of a river polluted by acid mine drainage in the Iberian Pyrite Belt (SW Spain). Science of the Total Environment, 409, 4763- 4771.

Scasny, M., Kovanda, J., \& Hak, T. (2003). Material flow accounts, balances and derived indicators for the Czech Republic during the 1990s: results and recommendations for methodological improvements. Ecological Economics, 45, 41-57.

Schaltegger, S. (1997). Economics of life cycle analysis: inefficiency of the present approach. Business Strategy and the Environment, 6, 1-8.

Schlesinger, W. H. (1991). Biogeochemistry An Analysis of Global Change. Academic Press, San Diego.

Selinus, O. (1988). Biogeochemical mapping of Sweden for geomedical and environmental research. In: Thornton I. (Ed.), Proceedings of the 2nd Symposium on Geochemistry and Health. Science Reviews, Northwood.

SENES, (2000). State-of-the-Art of Risk Assessment Application to ARD. A study prepared for INAP, 32714.

Shmelev, S. E. (2012). Industrial Ecology: Material and Energy Flows, Life Cycle Analysis. In Ecological Economics, 2012, Part 1, 19-34, doi: 10.1007/978-94-007-1972-9_2

Sinding, K. (1999). Environmental impact assessment and management in the mining industry. Natural Resources Forum, 23, 57-63.

Skoulikidis, N. T. (2009). The environmental state of rivers in the Balkans-A review within the DPSIR framework. Science of the Total Environment, 407, 2501-2516.

Slowanska, B. (ed.). (1997). Geology for environmental protection and territorial planning in the Polish-Lithuanian cross-border area. Polish Geological Institute-Geological Survey of Lithuania, Warsaw-Vilnius.

Smith K. (1996). Environmental Hazards: Assessing Risk and Reducing Disaster (second edition), Routledge, London and New York. No. of pages: xxiii+389.

Smith, D. B., Cannon, W. F., Woodruff, L. G., Garrett, R. G., Klassen, R., Kilburn, J. E., Horton, J. D., King, H. D., Goldhaber, M. B., \& Morrison, J. M. (2005). Major- and TraceElement Concentrations in Soils from Two Continental-Scale Transects of the United States and Canada. Open-File Report 2005-1253, U.S. Geological Survey.

Sollitto, D., Romic, M., Castrignan, A., Romic, D., Bakic, H. (2010). Assessing heavy metal contamination in soils of the Zagreb region (Northwest Croatia) using multivariate geostatistics. Catena 80, 182-194. 
Sommer, S., Bidoglio, G., D’Alessandro, M., Jordan, G., Puura, E., Vijdea, A. (2003). Linking regional scale inventory and watershed analysis to the impact assessment of mining activities - the PECOMINES concepts. Proceedings, 4th European Congress on Regional Geoscientific Cartography and Information Systems, 2003, Bologna, Italy 2, 685-687. Regione Emilia-Romagna, Servizio Geologico, Italy.

Spedding, P.J. (1988). Peat, review. FUEL, Vol. 67, July, 883-900.

Stanley, G., Jordan, G., Hamor, T., \& Sponar, M. (2011). Guidance Document for A RiskBased Selection Protocol for the Inventory of Closed Waste Facilities as required by Article 20 of Directive 2006/21/EC. 2011. http://www.geofond.cz/rroum/dokument/2011_GUIDANCE_DOCUMENT_PRE_SELECTI ON.pdf.

Steinmann, P., Shotyk, W. (1997). Geochemistry, mineralogy, and geochemical mass balance on major elements in two peat bog profiles (Jura Mountains, Switzerland). Chemical Geology, 138, 25-53.

Sun, Hong-fei, Li, Yong-hua, Ji, Yan-fang, Yang, Lin-sheng, Wang, Wu-yi, Li, Hai-rong. (2010). Environmental contamination and health hazard of lead and cadmium around Chatian mercury mining deposit in western Hunan Province, China. Transactions of Nonferrous Metals of Society. China 20, 308-314.

Sundseth, K., Pacyna, J. K., Pacyna, E. G., \& Panasiuk, D. (2012). Substance Flow Analysis of Mercury Affecting Water Quality in the European Union. Water, Air, \& Soil Pollution, 223, 429-442.

Szabo, L.P. (2004). Characterization of alginite humic acid content. Desalination, 163, 85-91.

Szilassi P., Jordan G, Van Rompaey A, Csillag G. (2006). Impacts of historical land use changes on erosion and agricultural soil properties in the Kali Basin at Lake Balaton, Hungary. Catena 68: pp. 96-108.

Szucs, A., Jordan, G., \& Qvarfort, U. (2002). Geochemical modelling of acid mine drainage impact on a wetland stream using landscape geochemistry, GIS and statistical methods. In: Thorneloe, S. A., Weitz, K., \& Jambeck, J. (2007). Application of the US decision support tool for materials and waste management. Waste Management 27, 1006-1020.

Turner, A. J. M., Braungardt, C., \& Potter, H. (2011). Risk-Based Prioritisation of Closed Mine Waste Facilities Using GIS. In: Rüde R. T., Freund A., \& Wolkersdorfer Ch.: Mine Water - Managing the Challenges. p. 667-671, Aachen, Germany. http://www.imwa.info/docs/imwa_2011/IMWA2011_Turner_311.pdf.

U.S. EPA, (1989). Risk assessment guidance for Superfund, Volume I. Human health evaluation manual. U.S. Environmental Protection Agency, Washington D.C. http://www.epa.gov/oswer/riskassessment/ragsa/pdf/preface.pdf.

U.S. EPA, (1991). Guidance for performing Preliminary Assessments under CERCLA, EPA/540/G-91/013. http://www.epa.gov/superfund/sites/npl/hrsres/pa/patoc.pdf.

U.S. EPA, (1992). Hazard Ranking System Guidance Manual, EPA-R-92-026. http://www.epa.gov/superfund/sites/npl/hrsres/hrsgm/toc.pdf.

U.S. EPA, (1998). Guidelines for Ecological Risk Assessment. U.S. Environmental Protection Agency, Washington D.C. EPA630-R-95-002F. http://www.epa.gov/raf/publications/pdfs/ECOTXTBX.PDF.

U.S. EPA, (2001). Abandoned mine site characterisation and cleanup handbook. U.S. Environmental Protection Agency, Denver. EPA530-C-01-001. http://www.techtransfer.osmre.gov/nttmainsite/Library/hbmanual/epa530c.shtm. 
U.S. EPA, (2002). Supplementary guidance for developing soil screening levels for Superfund sites. U.S. Environmental Protection Agency, Denver. http://www.epa.gov/reg3hwmd/risk/human/rbconcentration_table/chemicals/SSG_nonrad_supplemental.pdf.

U.S. EPA, (2007). Framework for metal risk assessment. U.S. Environmental Protection Agency, Denver. EPA120-R-07-001. http://www.epa.gov/raf/metalsframework/pdfs/metalsrisk-assessment-final.pdf.

Udo de Haes, H., Heijungs, R., Huppes, G.,van der Voet, E., \& Hettelingh, J. P. (2000). Full mode and attribution mode in environmental analysis. Journal of Industrial Ecology, 4, 45-56.

Uuemaa E., Mander U., Marja R. (2013). Trends in the use of landscape spatial metrics as landscape indicators: A review. Ecological Indicators 28, 100-106.

Uuemaa E., Roosaare J., Mander U. (2005). Scale dependence of landscape metrics and their indicatory value for nutrient and organic matter losses from catchments. Ecological Indicators 5, 350-369.

UNEP (United Nations Environmental Programme), (1996). Life-cycle assessment: What it is and how to do it. UNEP, Industry and Environment, Paris.

Uy, P. D., \& Nakagoshi, N. (2008). Application of land suitability analysis and landscape ecology to urban greenspace planning in Hanoi, Vietnam. Urban Forestry \& Urban Greening, $7,25-40$.

Van Leuwen, C. J., \& Hermens, J. L. M. (Eds), (1996). Risk Assessment of Chemicals. An Introduction. Kluwer Academic Press, Dodrecht.

Van Rompaey, A., Notebaert, B., Bats, M., Jordan, G., Somody, A., \& Van Dessel, W. (2005). Optimal land use scenarios for the minimalization of polluted mining waste export: a case study in the uplands of the Tisza River (Hungary). International Conference on European Union Expansion: Land Use Change and Environmental Effects in Rural Areas, 4-7 September 2005, Luxembourg, Luxembourg. Abstracts, p. 61.

Vass, D., Bublinec, E., Halás, L., Beláček, B. (2003). Overview of Pinciná alginite fertility. Földtani Kutatás 15, 75-80.

Veliciu, S., Stratulat, P. (2004). Mining, mining waste and related environmental issues in Romania. In: Jordan G, D'Alessandro M. (eds) Mining, mining waste and related environmental issues: problems and solutions in the Central and Eastern European candidate countries. Joint Research Centre of the European Commission, Ispra. LB-NA-20868-EN-C, $127-138$.

Wanty, R., Berger, B. R., Plumlee, G. S., \& King, T. V. V. (2002). Geoenvironmental models: an introduction. In: Fabbri A. G., Gaal G. \& McCammon R. B. (Eds), Deposit and Geoenvironmental Models for Resource Exploitation and Environmental Security, NATO Science Series, 2. Environmental Security, 80, pp. 3-42. Kluwer Academic Publishers, Dordrecht.

Wathern, P. (1984a). Methods for assessing indirect impacts. In: Clark B. D. \& Gilad A. (Eds), Perspectives on environmental impact assessment. D. Reidel publishing Company, Dodrecht.

Wathern, P. (1984b). Ecological impact assessment. In: Clark B. D., \& Gilad A. (Eds), Perspectives on environmental impact assessment. D. Reidel publishing Company, Dodrecht.

Wathern, P. (1988). An introductory guide to EIA. In: Wathern P. (Ed.), Environmental impact assessment. Theory and practice. Unwin Hyman, London. 
Weaver, A., \& Caldwell P. (1999). Environmental impact assessment for mining projects. In: Petts J. (Ed.), Handbook of environmental impact assessment. Environmental impact assessment in practice: impact and limitations. Blackwell Science, London.

Welford, R. (1996). Corporate environmental management. Earthscan, London.

White, R. (1994). Preface. In: Allenby B. R., \& Richards D. J. (Eds), The greening of industrial ecosystems. Pp. V-VI. National Academy of Engineering, National Academy Press, Washington, D. C.

Wood, C. (1995). Environmental impact assessment. A comparative review. Longman Scientific and Technical, London.

Wu M.Y., Xu L., Ji W.B., Xiong Q.X., Ai T.C., Li, B.L. (2012). Modelling the Linkage Between Landscape Metrics and Water Quality Indices of Hydrological Units in Sihu Basin, Hubei Province, China: An Allometric Model. Procedia Environmental Sciences 13, 2131 2145.

Xia, L.L. Liu, R.Z. Zao, Y.W. (2012). Correlation Analysis of Landscape Pattern and Water Quality in Baiyangdian Watershed. Procedia Environmental Sciences 13: 2188 - 2196.

Relating landscape characteristics to non-point source pollution in mine

waste-located watersheds using geospatial techniques

Xiao, H. \& Ji W. (2007). Relating landscape characteristics to non-point source pollution in mine waste-located watersheds using geospatial techniques. Journal of Environmental Management 82, 111-119.

Yenilmez, F., Kuter, N., Emil, M. K., Aksoy, A. (2011). Evaluation of pollution levels at an abandoned coal mine site in Turkey with the aid of GIS. International Journal of Coal Geology 86, 12-19.

Yi, Y. J., Yang, Z., Zhang, S. (2011). Ecological risk assessment of heavy metals in sediment and human health risk assessment of heavy metals in fishes in the middle and lower reaches of the Yangtze River basin. Environmental Pollution 159, 2575-2585.

Younger, P. L., Banwart, S. A., \& Hedin, R. S. (2002). Mine Water. Hydrology, Pollution, Remediation. Kluwer Academic Publishers, Dodrecht.

Younger, P. L., Coulton, R. H., \& Froggatt, E. C. (2005). The contribution of science to riskbased decision-making: lessons from the development of full-scale treatment measures for acidic mine waters at Wheal Jane, UK. Science of the Total Environment, 338, 137-154.

Zaredar, N., \& Zarkesh, M. M. K. (2012). Examination of compensatory model application in site selection. Environmental Monitoring and Assessment, 184, 3 97-404.

Ziemanna, S., Weila, M., \& Schebeka, L. (2012). Tracing the fate of lithium -The development of a material flow model. Resources, Conservation and Recycling, 63, 26-34.

Zobrist, J., Sima, M., Dogaru, D., Senila, M., Yang, H., Popescu, C., Roman, C., Bela, A., Frei, L., Dold, B., Balteanu, D. (2009). Environmental and socioeconomic assessment of impacts by mining activities-a case study in the Certej River catchment, Western Carpathians, Romania. Environmental Science and Pollution Research, 16 (Suppl. 1), S14-S26.

Websites:

Hungarian Central Statistical Office. www.ksh.hu

Hungarian Central Directorate of Water and Environment (VKKI). http://www.vkki.hu

EEA website/ Data and maps/ Datasets/ Waterbase-Groundwater. http://www.eea.europa.eu/data-and-maps/data/waterbase-groundwater-6 
CORINE Land Cover datasets. http://www.eea.europa.eu/publications/COR0-landcover The V-late (vector-based landscape analysis tools extension) within ArcGIS $10^{\circledR}$. http://www.arcgis.com/home/item.html?id=36f9728a895e4f5386bdec68be6d08ac 


\section{Summary}

Major incidents involving mine waste facilities and poor environmental management practices have left the legacy of thousands of contaminated sites in historic mining areas like the Carpathian Basin. These mining-specific problems require special tools to address the complexity of the environmental problems of the mining-related contamination. Associated environmental risks have triggered the development of EU environmental legislation to prevent such incidents and minimize the probability of the environmental catastrophes.

In order to evaluate some of the most important decision support methods that were developed and applied to mining contamination a thorough review has been published (Jordan and Abdaal 2013) that compares the 'holistic' approaches including (1) landscape ecology (LE), (2) industrial ecology (IE), (3) landscape geochemistry (LG), (4) geo-environmental models (GEM), (5) environmental impact assessment (EIA), (6) environmental risk assessment (RA), (7) material flow analysis (MFA), and (8) life cycle assessment (LCA). This published study, as a part of the PhD thesis, concluded that none of the methods alone can address all of the environmental problems of mining. Methods of LE, IE, LG and GEM put the emphasis on the study of natural systems while EIA, RA, MFA and LCA study more the decision making process within the human socio-economic systems.

The common in all of these methods is that they try to bridge the gap between socio-economic and natural sciences in order to support decisions on the management of the environment. Among natural science techniques an integrated use of the LG with MFA seems to be the most efficient for contamination studies of mining. Among socio-economic techniques, asset LCA may provide the broadest and the most 'holistic' framework to bring together EIA, RA and decision analysis, in general. In the European legislative context, the Strategic Environmental Assessment Directive (Directive 2001/42/EC) is the most holistic European directive that integrates many of the different methods considered in this study (Jordan and Abdaal 2013). In the case of abandoned mines LCA and EIA have no application in making decisions on the necessary site remediation in the lack of mine site operator. In accordance with the EU environmental legislation contamination Risk Assessment received a specific attention and a detailed comparison of the key parameters such as heavy metal content, topographic slope beneath mine waste facility for the source parameters $\backslash$ distance to nearest protected Natura 2000 areas or presence of high permeable layer beneath the waste for 11 internationally recognized pre-screening RA methods of mine waste sites has been developed .The Mine Waste Directive (2006/21/EC) requiress the risk-based inventory of all mine waste sites in Europe. In order to address the problem a standard risk-based pre-selection protocol has been developed by the EU Commission consisting of 18 simple questions about contamination source, pathway and receptor, for example, if the mine waste contains sulphide minerals (Q2) or heavy metals (Q3) for the contamination source, or if there is a high permeability layer beneath the mine waste site (Q12) for the pathways, and, for the sensitive receptor, if a settlement with $>100$ inhabitants is located within $1 \mathrm{~km}$ of a waste site (Q15).

The first objective of this study is the evaluation of the EU MWD Pre-selection Protocol (Stanley et al. 2011) by applying it to real-life cases and adopting it to country-specific 
conditions. The data derived for the implementation of the Protocol such as the distance to the nearest stream or the size of the contamination source mine waste site is compared to those resulted from the 'Pre-screening of problem areas' according to the European Environmental Agency (EEA) Preliminary Risk Assessment Model for Soil contamination in Europe (PRAMS) in order to assess the sensitivity of mine waste site risk assessment in response to various methods. Altogether 145 ore mine waste sites in Hungary were selected for scientific testing and evaluation using the EU MWD Pre-selection Protocol. Questions of the EU MWD Pre-selection Protocol are linked to a GIS system and key parameters such as the topographic slope and distance to the nearest streams, lakes and groundwater bodies, to settlements and the Natura2000 protected areas were calculated and statistically evaluated in order to adjust the RA models to country-specific conditions in Hungary.

According to the number of YES responses to the Protocol questions, a risk-based site ranking was performed resulting in 127 sites are directed to 'Examine Further' using the EU thresholds (slope $\leq 5^{\circ}, 1 \mathrm{~km}$ distance to the pathways and sensitive receptors) and number of people in the nearest settlement $\geq 100$ ). 129 sites are directed to 'Examine Further' using local Median-based thresholds that defined by (1) the highest natural break in the parameter (slope (Q10) and the lowest natural break for the nearest distance (Q11, Q15-18)) cumulative distribution curves (corresponding to local minima in the frequency histogram and by (2) the median value of these parameters (Median-based threshold). Similarly, 18 and 16 sites with no risk (have no pathway) based on the EU and local thresholds. In the case of using the local threshold (lowest group boundary) (Table 3) in Q10 (5 $)$, Q11 (270m), Q15 (319m), Q16 $(0 \mathrm{~m})$, Q17 $(0 \mathrm{~m})$ and Q18 $(167 \mathrm{~m}), 118$ sites are directed to EXAMINE FURTHER and 27 sites have no risk (19 sites with no Pathway and 8 sites with no Receptor). While by using the local threshold in Q10 $\left(29^{\circ}\right)$, Q11 (3,643m), Q15 (4,083m), Q16 (13,635m), Q17 $(2,732 \mathrm{~m})$ and Q18 (3,956m), all the 145 mine waste sites are directed to EXAMINE FURTHER. It is obvious that this threshold selection represents the worst case scenario and follows the precautionary principle.

The proportion of uncertain responses to the questions in the EU MWD Pre-selection Protocol for each mine waste site gives an insight to the specific and overall uncertainty in the data used. An interesting outcome of the study is that the highest uncertainty is associated with the engineering conditions of the waste facilities, such as the heights and size of the waste dumps. Similarly, the number of YES responses can be accumulated for each site for the source, pathway and receptor questions separately which may indicate the presence of multiple contamination source, multiple pathways or receptors. The results show that the key parameter-questions of the MWD Pre-selection Protocol are Q3, Q10, Q12, Q17 and Q18.

Results of the pre-screening EEA PRAMS Model show that the number of waste sites that classified as potential problem areas of EU interest, increased from 19 (in question A6) to 88 sites in question B4. This decision is based on the availability of known data to answer the questions of ' $\mathrm{B}$ ' criteria. It is important to note that this study has no relationship to the reported national inventory by any means and the site data used for this scientific study is not based on the reported inventory. 
The second objective of this study is the heavy metal contamination risk assessment (RA) for a number of selected quarries in order to study the inert characteristics of the potentially generated mine wastes, in accordance with the EU MWD legislation. Altogether 30 waste sites (including both abandoned mines and active quarries) were selected for scientific testing using the Pre-selection Protocol. Ninety three field samples were collected from the waste sites including andesite, rhyolite, coal (lignite and black coals), peat, alginite, bauxite, clay and limestone mines. Laboratory analyses of the total toxic element content (aqua regia extraction), the mobile toxic element content (deionized water leaching) were carried out according to the Hungarian national standards (GKM Decree No. 14/2008. IV.3) concerning mining waste management. A detailed geochemical study together with spatial analysis using ArcGIS was performed to derive a geochemically sound contamination RA of the mine waste sites. Key parameters such as heavy metal content and distance to the nearest surface and ground water bodies, or to sensitive receptors such as settlements and protected areas, were calculated and statistically evaluated in order to calibrate the RA methods. The median-based thresholds based on the natural-breaks found in the corresponding cumulative histograms of the Pre-selection Protocol parameters adapted to local conditions in Hungary. are $10^{\circ}$ for slope (Q10), 631m for distance to nearest surface water courses, $150 \mathrm{~m}$ for distance to nearest settlement (Q15), $0 \mathrm{~m}$ for distance to groundwater bodies, $224 \mathrm{~m}$ for ditance to nearest protected Natura 2000 area and $0 \mathrm{~m}$ for distance to nearest agricultural areas. This calls for immediate special attention if landscape protection is a priority.

Total concentrations of heavy metals defined by aqua regia extraction were compared to the environmental limit values in Hungary and to the European environmental geochemical background values based on the FOREGS European Geochemical Atlas (Table 11) as follow: the Mean of As $(18.17 \mathrm{mg} / \mathrm{kg})$ exceeds the tolerated limit in Hungarian soils $(15 \mathrm{mg} / \mathrm{kg})$ and exceeds the Mean value of EU FOREGS geochemical background value $(10 \mathrm{mg} / \mathrm{kg})$. At the same time, the Mean of Cd $(0.33 \mathrm{mg} / \mathrm{kg})$ is less than the Hungarian limit $(1 \mathrm{mg} / \mathrm{kg})$ and exceeds the Mean of EU FOREG background value. The Mean of Ni $(61 \mathrm{mg} / \mathrm{kg})$ exceeds Hungarian limit (40 mg/kg) and exceeds Mean of EU FOREGS background value (31 $\mathrm{mg} / \mathrm{kg})$. Moreover, the median of $\mathrm{Cu}(12.3 \mathrm{mg} / \mathrm{kg})$ exceeds the median of EU FOREGS (12 $\mathrm{mg} / \mathrm{kg}$ ). In case of central tendency expressed by the Median, the analyzed heavy metals are in descending order; $\mathrm{Zn}>\mathrm{V}>\mathrm{Cu}>\mathrm{Cr}>\mathrm{Pb}>\mathrm{Co}>\mathrm{Ni}>\mathrm{As}>\mathrm{Mo}>\mathrm{Cd}$. This result shows that $\mathrm{Zn}$ has the highest median $(24.6 \mathrm{mg} / \mathrm{kg})$ and $\mathrm{Cd}$ has the lowest Median $(0.11 \mathrm{mg} / \mathrm{kg})$. In case of spread expressed by IQR/Med (Interquartile range/Median), the heavy metals are in descending order; $\mathrm{Ni}>\mathrm{As}>\mathrm{Cr}>\mathrm{V}>\mathrm{Pb}>\mathrm{Co}>\mathrm{Cd}>\mathrm{Zn}>\mathrm{Cu}$. It is obvious that $\mathrm{Ni}$ has the highest spread (5.11) and $\mathrm{Cu}$ has the lowest (1.11). Spearman correlations show those elemental pairs of Aqua regia leaching ( $\mathrm{As}$ and $\mathrm{Cd}, \mathrm{r}=0.45$ ), $\mathrm{Pb}$ and $\mathrm{Zn}, \mathrm{r}=0.63$, $\mathrm{Ni}$ and $\mathrm{Pb}, \mathrm{r}=0.71$ ) were significantly correlated at $\mathrm{P}<0.05$ level (Table 12). While elemental pairs of deionized water leaching (As and $\mathrm{Co}, \mathrm{r}=0.2, \mathrm{Cd}$ and $\mathrm{Ni}, \mathrm{r}=0.3, \mathrm{Cu}$ and $\mathrm{Zn}, \mathrm{r}=0.47$ ) were significantly correlated at $\mathrm{P}<0.05$ level (Table 13). For the deionized water leaching, Ficklin Diagram (showed that acid generation potential $(\mathrm{pH}<5.5)$ is for coal, lignite and peat rocks, in addition to a bauxite sample. Elevated mobile heavy metal content is associated with coal, andesite and some clay and a bauxite samples. 
A multi-level decision support scheme for the inert classification of waste rock material applied in this study including: 1) expert judgment, 2) data review, 3) representative field sampling and laboratory analysis and testing of rock formations listed in the National Inert Mining Waste List, and 4) requesting available laboratory analysis data from selected operating mines. According to the geochemical results in this study, the rock formations were classified into three categories. A: inert B: probably inert, but has to be checked C: probably not inert, has to be examined. Results show that coal (black coal and lignite) and peat samples are not inert and classified into $\mathrm{C}$ group. While alginite, bauxite, rhyolite tuffs and clay samples are probably inert and classified into B group. Moreover limestone and clay samples are inert (A group). Results show that 5 andesite samples with higher heavy metal concentrations than the Hungarian standards could classify the andesite rock formation into B or $\mathrm{C}$ group. Thus, RA needs more further spatial and petrological examination with special care to rock and mineral deposit genetics.

In the third objective of this study, the linkage between the water quality variables from streams near by the mining waste sites and the landscape metrics of 33 watersheds enclosing those mining sites. The water quality variables $\mathrm{Ni}, \mathrm{Mn}, \mathrm{Cr}, \mathrm{Zn}$ and conductivity that represent the total pollution of water in Hungary were investigated and analyzed. Several recent studies have shown the strongest statistical relationship between the landscape pattern and the water quality in case of the percentage cover of forests and the non-point source pollutions of water such as nitrate, nitrite contamination (e.g. Wu et al. 2012; Xiao and Ji 2007; Romic et al. 2007; Uuemaa et al. 2005; 2013). This is the reason for why, beside the landscape metric parameters, the percentage of the main land cover classes (such as artificial surfaces (CLC1), agricultural areas (CLC2) and forest and semi-natural areas (CLC3)) was investigated in the studied watersheds too. The following landscape indices; Total Number of Patches (NP), Core Area (CA), length of Total Edge (TE) Splitting Index (SPLIT), Division Index (DIVISION), Effective Mesh Size (MESH), Main Patch Size (MPS), Patch Size Standard (PSSD), Deviation Mean Patch Ratio (MPE), Mean Shape Index (MSI) Mean Perimeter Area Ratio (MPAR) and Mean Fractal Dimension Index (MFRACT), were calculated for each watershed based on regional scale 1:100,000 CORINE land cover database from years 2000 and 2006. The V-late (vector-based landscape analysis tools extension) within ArcGIS $10^{\circledR}$ and the STATGRAPHICS $^{\circledR}$ software were used for spatial and statistical analyses.

Spearman correlations were calculated for all landscape metrics and the minimum, median, average and maximum values of stream water quality data pairs of years 2000 and 2006, resulting in 2000 data median $\mathrm{Ni}$, minimum and maximum $\mathrm{Zn}$ and average conductivity values were significantly correlated with MSI, median Mn with MESH, average Mn with CA, TE, MPE and MPAR, maximum Mn with artificial surfaces (CLC1), minimum Conductivity with MPS, PSSD, MFRACT, agricultural areas (CLC2) and forest and semi-natural areas (CLC3). However, Cr showed no correlation with the landscape indices. For 2006 data, minimum and average Ni values were significantly correlated with DIVISION and SPLIT, minimum Mn with NP, PSSD, CA, TE, MPE and MESH, median Mn with CA and TE, minimum Conductivity with MFRACT, median Conductivity with MPAR, average Conductivity with MSI and MFRACT, maximum Conductivity with MSI, MPAR and MFRACT. In this case all $\mathrm{Cr}$ and $\mathrm{Zn}$ values showed no significant correlation with the 
landscape indices. However, there is no such stream water quality variable had a significant correlation with Main Patch Size (MPS), Artificial surfaces (CLC1), Agricultural areas (CLC2), and Forest and semi-natural areas (CLC3).

It is concluded that the Mean Shape Index (MSI) is the most important "key" landscape index in 2000 and the Main Fractal Dimension Index (MFRACT) in 2006, from the stream water quality heavy metal contamination point of view. Based on these statistical results we conclude that in case of the further modification of the RA methods, at least these two landscape indices should take under consideration, and to be integrated into the RA methods. The median $\mathrm{Ni}$, average $\mathrm{Mn}$, average $\mathrm{Zn}$ and minimum conductivity water quality variables were the most significantly correlated with the landscape indices in 2000 . While minimum and average $\mathrm{Ni}$, minimum and median $\mathrm{Mn}$, average and maximum conductivity variables were the most significantly correlated with the landscape indices in 2006. 


\section{1. Összefoglalás}

A Kárpát-medencében több ezer olyan szennyezett területtel találkozhatunk, melyek az egykori bányászathoz köthetőek, valamint melyek e területek nem megfelelő környezetvédelmi kezelése miatt alakultak ki. E ajátosnyersanyag-kitermeléshez kapcsolható környezeti problémák megoldása csak olyan speciális eszközökkel lehetséges, melyek a bányászati eredetű szennyeződéseket és környezeti problémákat komplex módon értékelik. A bányászat okozta környezeti kockázatok olyan új Európai Uniós jogszabályok kimunkálását eredményezték, melyek révén minimalizálhatjuk a környezeti katasztrófák kialakulásának lehetőségét.

A bányászat okozta környezeti problémák csökkentésére szolgáló döntéstámogató módszerek áttekintése során, csak az alábbi holisztikus megközelítésü, értékelési eljárásokat hasonlítottuk össze egymással (Jordan and Abdaal 2013): 1, tájökológiai módszerek (TÖM), 2, ipari ökológia (IÖ), 3, táj-geokémia (TGK), 4, környezetföldtani modellek (KFM), 5, Környezeti hatásértékelés (KHÉ), 6, Környezeti kockázatértékelés (KK), 7, anyag áramlás modellek (AM), 8, életciklus elemzés (ÉE). A korábbi publikációnk és e dolgozatban is közölt eredményeink szerint e módszerek egyike sem alkalmas önmagában a bányászat okozta környezeti problémák teljes körü elemzésére. A TÖM, IÖ, és a TGK, módszerek a természeti, míg a KHÉ, KK, AM és ÉE módszerek inkább - döntés elökészítő jellegük miatt - a társadalmi-gazdasági folyamatok felől közelítenek ehhez a kérdéshez.

Valamennyi módszer közös eleme, hogy igyekeznek hidat képezni a természeti és társadalomtudományok között, hogy ez által is támogassák a környezetmenedzsmenttel kapcsolatos döntések előkészítését. A természettudományos módszereken alapuló értékelési eljárások közül a táj-geokémiai (TGK) és az anyagáramlási modellek (AE) alkalmasak a leginkább a bányászat okozta szennyezések vizsgálatára. A társadalmi-gazdasági rendszerek felől az életciklus elemzés (ÉE), a környezeti hatásvizsgálattal (KHV), valamint a környezeti kockázatelemzés (KKÉ) kísérli meg a legszélesebb körü holisztikus szemléletű elemzést. Az Európai Uniós jogszabályok közül a Stratégiai Környezeti Vizsgálat Direktívája (2001/42/EC direktíva) jelenti azt a leginkább holisztikus szemléletü keretet, melyben számos, a dolgozatban is említett módszer megjelenik (Jordan and Abdaal 2013). A felhagyott bányák remediációjára vonatkozó döntések előkészítéséhez azonban sem a környezeti hatásvizsgálat sem a környezeti kockázatelemzés nem ad támpontot.

A Bányákra és Hulladéklerakókra vonatkozó EU direktíva kiemelt figyelmet fordít a különféle kulcs paraméterek összehasonlító elemzésére, mint például a nehézfém koncentrációra, a bányaterület lejtőszögére, mint a szennyezőforrást jellemző paraméterre, a legközelebbi NATURA 2000-es területekre, a bányaterületek alatti vízzáró rétegek jelenlétére mint a szennyeződés szállítási útvonalaival kapcsolatos tényezőre, - és végül ezeket a paramétereket együttesen értékeli az a 11 nemzetközileg elfogadott Előzetes Elemzési Protokoll, melyet bányászati eredetü hulladéklerakókra dolgoztak ki.

A Bányákra és Hulladéklerakókra vonatkozó EU direktíva (2006/21/EC) értelmében el kell végezni az Európai Unió összes bányájának környezeti kockázat alapú felmérését. A 
bányászattal érintett területek környezeti problémáinak azonosításához az Európai Unióban az Európai Környezetvédelmi Ügynökség (EKÜ) munkatársai standardizált kockázat-alapú előzetes értékelési eljárást (protokollt) dolgoztak ki. A protokoll 18 egyszerü kérdést tartalmaz a szennyezések forrásairól, valamint azok lehetséges szállítóközegével és felvevő közegével (receptorával) kapcsolatban, mint például a szennyezőforrásokra vonatkozó kérdések közül, hogy tartalmaz-e szulfid ásványokat vagy nehézfémet (Q3) a meddő, (Q2), a szennyezések lehetséges útvonalával kapcsolatban, hogy található-e erősen vízzáró réteg a bányaterület alatt (Q12), vagy hogy található-e 100 lakos feletti lakosságszámú település a bánya vagy hulladéklerakó 1 km-es körzetében).

A disszertáció célja egyrészt értékelni a vonatkozó EU direktíva által meghatározott kockázat-alapú előzetes értékelési eljárást (KAEÉE) (Stanley et al. 2011) valós esettanulmányok alkalmazásával, majd adaptálni azt az ország-specifikus jellemzők alapján.

A protokoll alkalmazásához szükséges adatokat, mint például a legközelebbi vízfolyástól mért távolságot, vagy a szennyezőforrás mérete a Európai Környezetvédelmi Ügynökség (EKÜ) által elvégzett „A problémás területek előzetes elemzésére” alapját képező Európai Talajszennyezésekre vonatkozó Előzetes Kockázatelemzési Modell szerint, a szennyezett bányaterületekre kidolgozott értékelési eljárásokra adott válaszok alapján kaptam meg.

Összesen 145 bányászati hulladéklerakót választottam ki az EU direktíva által meghatározott kockázat-alapú előzetes értékelési eljárást KAEÉE protokoll tudományos alapú teszteléséhez, és értékeléséhez. Az EU direktíva (KAEÉE protokoll kérdéseit a Földrajzi Információs Rendszer segítségével előállított kulcs paraméterek alapján válaszoltam meg, kiszámítva és statisztikai módszerekkel értékelve például a vizsgált bányák és hulladéklerakók átlagos lejtőszögét, NATURA 2000 területektől, legközelebbi településtől, legközelebbi vízfolyástól, állóvíztől, talajvíztől mért távolságát azért, hogy a kockázat elemzési modell magyarországi adaptálását ország-specifikus adatok alapján végezhessük el.

A protokoll kérdéseire adott IGEN válaszok száma alapján sorba rendezve a kockázat alapján a helyszíneket, 127 kapott „TOVÁBBI VIZSGÁLAT SZÜKSÉGES” minősítést (lejtőszöge $\leq$ $5^{\circ}$, a hulladéklerakó $1 \mathrm{~km}$-nél közelebbi távolságra a szállítóközegtől vagy érzékeny ,receptor” területtől). 129 helyszín kapott „TOVÁBBI VIZSGÁLAT SZÜKSÉGES” minősítést a helyi tényezők kummulatív hisztogramján látható természetes töréspontjai és medián-alapú küszöbértékei alapján: (1) A legmagasabb értékü természetes töréspont a lejtőszög (K10) és a legalacsonyabb természetes töréspont a legközelebbi távolságok (K11, K15-18) hisztogram minimumjához legközelebbi értékei, illetve (2) a fenti paraméterek medián alapú küszöbértékei alapján (medián-alapú értékelési eljárás). Ehhez hasonló módon 18 illetve 16 helyszínt minősíthetünk „kockázatmentes”-nek, (mivel nincs lehetőség a szennyeződések mozgására). A helyi adatok értékelését a legalacsonyabb csoport-határ értékeit figyelembe véve a K10 kérdésnél $\left(5^{\circ}\right)$, K11 kérdésnél $(270 \mathrm{~m})$, K15 kérdésnél (319m), K16 kérdésnél (0m), K17 kérdésnél (0m) 118 helyszínt „TOVÁBBI VIZSGÁLAT SZÜKSÉGES” kategóriába, és 27 helyszínt a „nincs kockázat” kategóriába (19 helyszínt a szállítási útvonal hiánya miatt, 8 helyszínt, pedig a receptor hiánya miatt). Ha az adatok értékeléséhez a legmagasabb csoport-határ értékeit vettem figyelembe (melyet az 1 A, B, C ábrákon folyamatos vonallal ábrázoltam) a K10 kérdésnél $\left(29^{\circ}\right)$, K11 kérdésnél (3643m), K15 
kérdésnél (4083m), K16 kérdésnél (13635m), K17 kérdésnél (2732m) K18 kérdésnél (3956m) határértékek mellett az összes 145 helyszín a „TOVÁBBI VIZSGÁLAT SZÜKSÉGES” kategóriába került. Nyilvánvaló, hogy ez utóbbi értékelési eljárás adja a legkedvezőtlenebb kockázati eredményt egyben ez jelenti legóvatosabb scenáriót is.

Az EU kockázat-alapú előzetes értékelési eljárást (KAEÉE) protokoll kérdéseire adott bizonytalan válaszok statisztikai eloszlásának vizsgálata révén képet kaphatunk a modell általános és speciális bizonytalanságáról is. Gyakorlati szempontból is érdekes, hogy a kapott eredmények bizonytalanságára a zagytározók (hulladéklerakók) esetében a kialakításuk főbb paramétereivel (mint például a gátak magasságával és méretével) is összefüggést mutat.

Ehhez hasonlóan érdekes, hogy a protokoll kérdései közül a szennyeződés forrásaira, a szállítási útvonalakra, és a szennyeződést felvevő receptorokra vonatkozó külön-külön feltett IGEN válaszok számának növekedése együtt jár az e forrásokból származó szennyeződések többszöröződésével. Eredményeim alapján a KAEÉE protokoll eredményeire gyakorolt hatásai alapján K3, K10 és K12-es és a K 18-as kérdésekre adott válaszokat tekinthetjük kulcs paramétereknek.

Az előzetes értékelési eljáráshoz kidolgozott EKÜ PRAMS modell szerint a potenciális környezeti problémával jellemezhető helyszínek száma 19-ről 88-ra emelkedett a B4 kérdés alapján. A B kritérium kérdése a döntésekhez szükséges adatbázisok elérhetőségére kérdez rá. Fontos megjegyeznünk, hogy a dolgozatom eredményei nem mutatnak semmiféle adat egyezést semmilyen korábbi felméréssel, a bányászati és hulladéklerakó helyszínekre vonatkozó adatokat nem a korábban publikált adatokból, hanem az általam felépített adatbázis elemzése révén nyertem.

Dolgozatom második célja a magyarországi bányaterületekből, és hulladéklerakókból származó nehézfém terhelés környezeti kockázatának értékelése (KKÉ). Összesen 30 területet (felhagyott és jelenleg is müködő bányákat) vizsgáltam az EU kockázat-alapú előzetes értékelési eljárása (KAEÉE) szerint. Összesen 93 terepi helyszínről (andezit, riolit, szén (lignit és feketeszén) tőzeg, alginit, bauxit, agyag és mészkőbányákból) gyüjtöttem mintát. A minták összes toxikus elemre vonatkozó laboratóriumi elemzését királyvizes feltárással végeztem, a mobilis toxikus elemeket pedig desztillált vízzel történő kioldással tártam fel a bányászati hulladékok kezeléséről szóló 14/2008. (IV.3)-as GKM rendelet szerint. A részletes geokémiai vizsgálatok mellett ArcGIS $10^{\circledR}$ szoftver segítségével elemeztem a bányaterületekről származó szennyezések környezeti kockázatát. Olyan kulcs paramétereket elemeztem, mint amilyen a nehézfém koncentráció, a legkisebb távolság a legközelebbi felszíni és felszín alatti vizektől, vagy az érzékeny területektől (receptoroktól) vagy védett természeti területektől mért távolsága.

A bányaterületekről származó minták királyvizes feltárása során kapott összes nehézfém koncentráció $(\mathrm{mg} / \mathrm{kg})$ becsült értékekeit összehasonlítottam a magyarországi talajok szennyezettségére vonatkozó jogszabályi határértékeivel, illetve az EU Geokémiai Atlaszában a feltalajra vonatkozó alábbi geokémiai háttérértékekkel. Az arzén (As) koncentráció átlaga $(18,17 \mathrm{mg} / \mathrm{kg})$ egyaránt meghaladja a magyarországi talajokra vonatkozó $(15 \mathrm{mg} / \mathrm{kg})$ 
határértéket és az EU FOREGS Geokémiai Atlasz határértékét is $(10 \mathrm{mg} / \mathrm{kg})$. Ugyanakkor a kadmium $(\mathrm{Cd})$ koncentráció átlaga $(0,33 \mathrm{mg} / \mathrm{kg})$ alacsonyabb a magyarországi határértéknél $(1 \mathrm{mg} / \mathrm{kg})$. A nikkel $(\mathrm{Ni})$ átlaga $(61 \mathrm{mg} / \mathrm{kg})$ meghaladja a magyarországi határértéket, és meghaladja az EU FOREGS Geokémiai Atlasz határértékét is $(30 \mathrm{mg} / \mathrm{kg})$. Ezen kívül a réz $(\mathrm{Cu})$ átlag értéke, $(12,3 \mathrm{mg} / \mathrm{kg})$ meghaladja az EU FOREGS atlasz határértékét (12 mg/kg).

A minták nehézfémtartalma tekintetében az egyes elemek koncentrációinak átlagai az alábbi sorozatot szerint változnak: $\mathrm{Zn}>\mathrm{Ni}>\mathrm{Cr}>\mathrm{Cu}>\mathrm{V}>\mathrm{Pb}>\mathrm{Co}>\mathrm{As}>\mathrm{Mo}>\mathrm{Cd}$. A minták cink ( $\mathrm{Zn}$ ) tartalma a legmagasabb (átlagosan 84,28 mg/kg), míg a kadmium (Cd) a legalacsonyabb koncentrációban elöforduló elem (átlagosan $0,33 \mathrm{mg} / \mathrm{kg}$ ), és a kadmiumnak van a legalacsonyabb medián értéke is $(0,11 \mathrm{mg} / \mathrm{kg})$. A vizsgált elemkoncentrációk relatív szórása az IQR/MED (Interkvartilis/medián) módszer alapján az alábbi módon alakul: $\mathrm{Ni}>\mathrm{As}>\mathrm{Cr}>\mathrm{V}>\mathrm{Pb}>\mathrm{Co}>\mathrm{Cd}>\mathrm{Zn}>\mathrm{Cu}$. Nyilvánvaló, hogy a nikkel (Ni) esetében a legnagyobb a koncentrációk szórása $(5,11)$, míg a réz $(\mathrm{Cu})$ esetében a legkisebb $(1,11)$. Spearman korreláció segítségével vizsgálva a királyvizes feltárással kapott eredményeket, az elemek közötti kapcsolatra az alábbi értékeket kaptam As és $\mathrm{Cd}, \mathrm{r}=0,45, \mathrm{~Pb}$ és $\mathrm{Zn}, \mathrm{r}=0,63$, Ni és Pb, $\mathrm{r}=0,71) \quad \mathrm{P}<0,05$ szignifikancia szinten. Míg a desztiláltvizes feltárás során kapott eredmények közti kapcsolat erőssége (As és Co, r = $0,2, \mathrm{Cd}$ és Ni, r =0,3, Cu és Zn, r =0,47) értékü volt $\mathrm{P}<0,05$ szintü szignifikanciaszinten.

A desztillált vízzel történő feltárás eredményeit Ficklin-diagramon ábrázoltam, mely szerint a savképző potenciál $(\mathrm{pH}<5,5)$ a feketekőszén, a lignit és a tőzeg, valamint a bauxit esetében van jelen. A megnövelt mobil nehézfémtartalom a kőszén, az andezit és néhány agyag és bauxit minta esetén kimutatható.

A dolgozatomban a meddőhányók minősítésére kidolgozott többszintü döntéstámogató módszer az alábbi lépéseket tartalmazza: 1) szakértői döntéshozatal 2) adatbázis felülvizsgálata 3) reprezentatív terepi mintavétel és laboratóriumi elemzések, majd a kőzettani formációk listájának elkésztése a Nemzeti Meddőhányó Kataszter szerint, 4) újabb laboratóriumi vizsgálatok igénylése a kiválasztott bányákból. A szakértői vélemények alapján a kőzet formációkat az alábbi három kategóriába soroltam: A) inert, B) valószínüsíthetően inert, de további ellenőrzést igénylő, C) valószínüleg nem inert, további vizsgálatot igényel. A dolgozatomban szereplő geokémiai elemzések alapján a kőszén (feketekőszén és lignit) és tőzeg minták inertnek minősíthetők, így a C kategóriába sorolhatók. Ezzel szemben az alginit, bauxit és riolittufa, valamint agyag minták a B csoportba, azaz a valószínúleg inert kategóriába sorolhatjuk. Csupán a mészkő és az agyag minták sorolhatók az inert (A) kategóriába. Eredményeim alapján 5 magasabb nehézfém koncentrációjú andezit mintát át kell sorolni a $\mathrm{B}$ és $\mathrm{C}$ csoportokba. Eredményeim rámutatnak arra, hogy a regionális léptékü kockáztat elemzések részletesebb térbeli, és kőzettani elemzést vizsgálatot igényelnek, különös tekintettel a kőzetek és ásványok keletkezési körülményeire.

Kutatásaim harmadik célja a bányaterületek vízfolyásainak vízminőség adatai (nehézfémek $\mathrm{Ni}, \mathrm{Mn}, \mathrm{Cr}, \mathrm{Zn}$, és az elektromos vezetőképesség) és a tájmintázat közötti kapcsolat vizsgálata és elemzése 33 vízgyüjtőterületen. Vízminőség adatok közül a $\mathrm{Ni}, \mathrm{Mn}, \mathrm{Cr}, \mathrm{Zn}$ és az elektromos vezetőképességet vizsgáltam, melyek reprezentálják Magyarország felszíni vizeinek összegzett vízminőségét is. Az utóbbi években számos publikációban mutattak ki 
szoros statisztikai összefüggést a vízgyüjtőterületek diffúz szennyezései mint például a nitrit, nitrát szennyezések, és a felszínborítás típusok (pl. erdő) százalékos aránya között (Pl. Wu et al. 2012; Xiao and Ji 2007; Romic et al. 2007; Uuemaa et al. 2005; 2013).

Ez okból a tájmintázat jellemzőit leíró tájmetriai paraméterek mellett a főbb felszínborítás típusok százalékát is vizsgáltam. Kiszámoltam a föbb CORINE felszínborítás kategóriák százalékos arányait, és vizsgáltam vízminőséget befolyásoló szerepüket. A mesterséges felszínek (CLC1), mezőgazdasági területek (CLC2), erdők és félig természetes felszínek (CLC3) százalékos értékeket valamennyi vizsgált vízgyüjtőterületre kiszámoltam.

Az alábbi tájmetriai paramétereket: Total Number of Patches (NP), Core Area (CA), length of Total Edge (TE) Splitting Index (SPLIT), Division Index (DIVISION), Effective Mesh Size (MESH), Main Patch Size (MPS), Patch Size Standard (PSSD), Deviation Mean Patch Ratio (MPE), Mean Shape Index (MSI) Mean Perimeter Area Ratio (MPAR) and Mean Fractal Dimension Index (MFRACT), az 1: 100000 méretarányú CORINE felszínborítási adatbázis 2000-ben és 2006-ban készült digitális térképei alapján számítottam ki. A ArcGIS $10^{\circledR}$ V-late kiegészítésével, valamint a STATGRAPHICS ${ }^{\circledR}$ szoftver segítségével végeztem el a térbeli és statisztikai elemzéseket.

A Spearman korreláció segítségével vizsgáltam az összes tájmetriai mutató és a vízminőség mutatók minimum, medián, átlag és maximum adatpár értékei közötti kapcsolatot 2000, és 2006 években. A 2000 évi adatok alapján a nikkel (Ni), minimum és maximum a cink (Zn) és az elektromos vezetőképesség átlagai szignifikáns korrelációt mutatnak az MSI, mediánjával a mangán (Mn) a MESH indexszel, az átlagos mangán (Mn) a CA, TE, MPE és MPAR indexszekkel, a mangán (Mn) maximuma a mesterséges felszínek (CLC1) értékeivel, az elektromos vezetőképesség az MPS, PSSD, MFRACT indexszek pedig a mezőgazdasági területekkel (CLC2) és az erdőkkel, félig-természetes területekkel (CLC3) mutatnak összefüggést. A króm (Cr) egyik tájmetriai mutatóval sem mutat összefüggést.

A 2006-os adatok esetében a nikkel minimum és átlag értékei szignifikánsan korrelálnak a DIVISION és a SPLIT indexszekkel, Mn a minimum értékeke a NP, PSSD, CA, TE, MPE és a MESH, tájmetriai mutatókkal, A mangán koncentráció (Mn) a CA és TE indexszekkel, az elektromos vezetőképesség minimuma a MFRACT indexszel, elektromos vezetőképesség mediánja az MPAR indexszel, elektromos vezetőképesség átlaga az MSI és a MFRACT indexszel, elektromos vezetőképesség maximuma az MSI, MPAR és aMFRACT. Ebben az évben a króm $(\mathrm{Cr})$ és a cink ( $\mathrm{Zn}$ ) vízminőség értékek nem mutatnak szignifikáns korrelációt a tájmetriai értékekkel. Emellett ebben az évben az egyik vízminőség paraméter sem korrelál a Main Patch Size (MPS), mesterséges felszínek (CLC1), mezőgazdasági területek (CLC2), és a z Erdők félig-természetes területekkel (CLC3).

Konklúzióként megállapíthatjuk, hogy a Mean Shape Index (MSI) a legfontosabb "kulcs metrika" 2000-os adatok alapján, és a Fractal Dimension Index (MFRACT) a 2006, a vízminőséget befolyásoló tájmetriai paraméterek közül. A fenti statisztikai elemzések alapján megállapíthatjuk, hogy a környezeti kockázatelemző módszerek jövőbeli fejlesztése során e két tájmetriai mutatószámot figyelembe kell venni, és integrálni kell a kockázatelemzési 
eljárásba. A nikkel (Ni) és a mangán ( $\mathrm{Mn}$ ) medián értéke, a cink ( $\mathrm{Zn})$ átlaga és az elektromos vezetőképesség minimuma mutatta a legerősebb korrelációt 2000-ben. Ezzel szemben 2006ban a minimum és átlagos nikkel $(\mathrm{Ni})$, minimum és medián mangán $(\mathrm{Mn})$, átlagos és maximum elektromos vezetőképesség mutattál a legerősebb korrelációt. 
Annex 1. The EU MWD Pre-selection Protocol flowchart (Stanley et al. 2011).

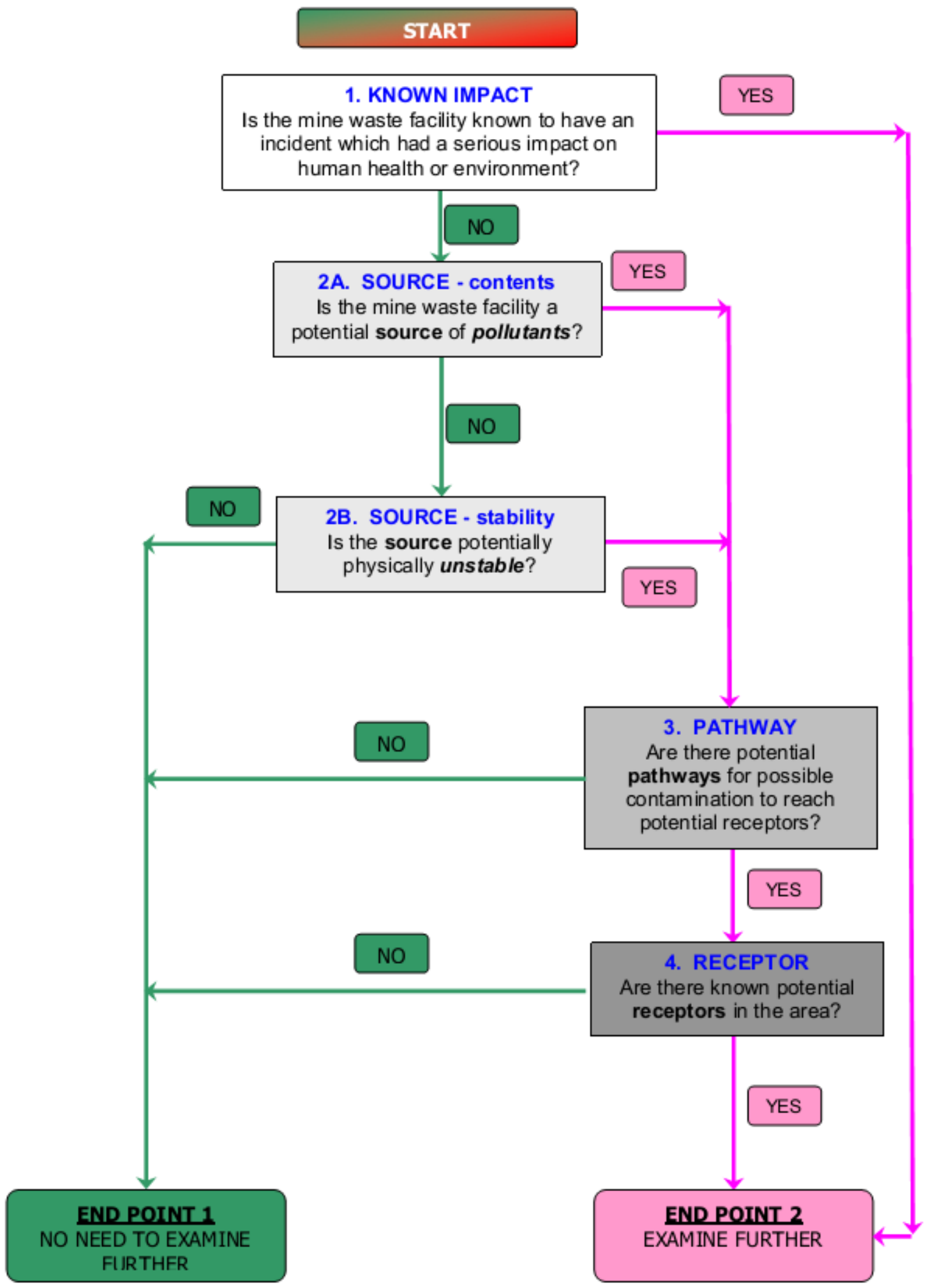


FLOWCHART 1.

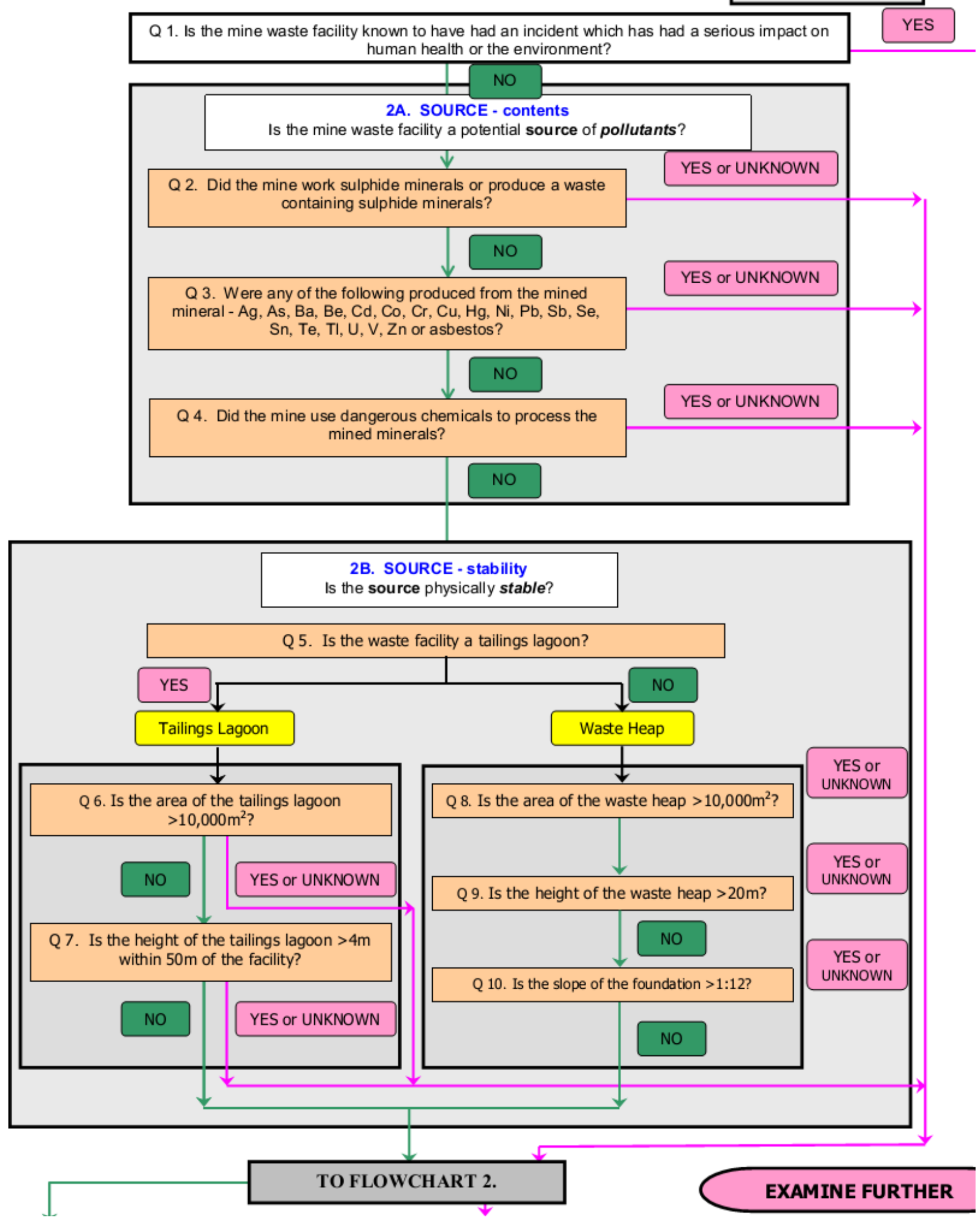




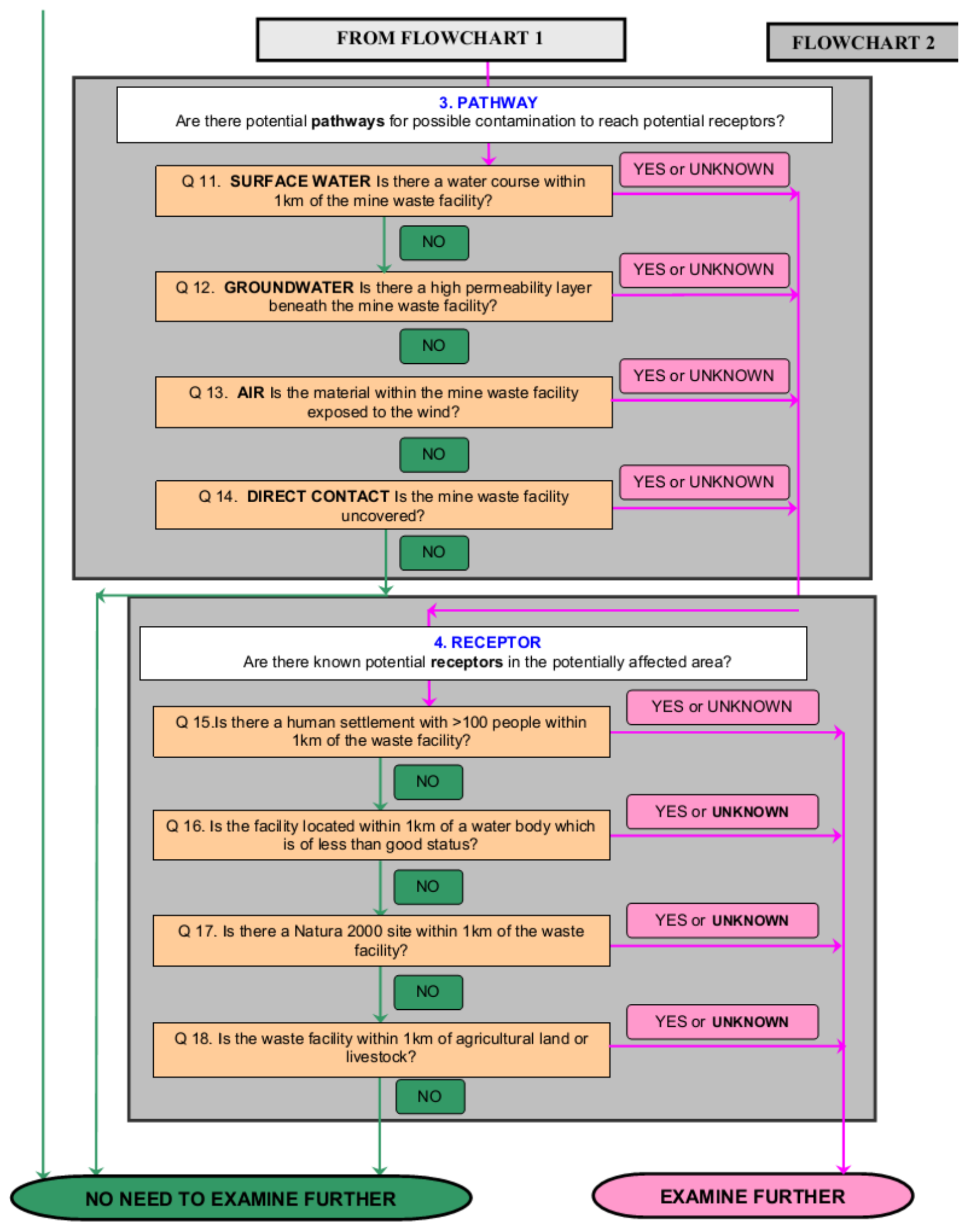




\section{Annex 2. Logic of the EU MWD Pre-selection Protocol}

The logic of the pre-selection protocol is designed to answer the target single yes-or-no question: should the closed waste facility be FURTHER EXAMINED? Or the question formulated as a Boolean true-false (yes-no) statement: The site should be further examined. According to the Mine Waste Directive this means that the 'facility poses the risk of serious environmental impact'. Dictated by rules of formal mathematical logic, the pre-selection procedure has to be designed to provide an unambiguous conclusion to decide if this statement is TRUE or FALSE. In this pre-selection procedure, these two logic values are expressed as 'YES' or 'NO' answers to the target question, respectively.

Further examination is required if and only if the facility pose risk at human health or the environment. A facility poses risk only if all the three risk components are present that is if there is a contamination source, a pathway for contamination transport and a sensitive receptor. The lack of any of these three components zeros out environmental risk. Therefore, there is a Boolean AND logical link between the Source, Pathway and Receptor compartments (see Annex 1). Expressed by mathematical formula:

EXAMINE FURTHER $\Rightarrow$ (Source) AND (Pathway) AND (Receptor)

This statement is true only if all three sub-statement are true, that is, if all three components exist. A compartment exists if it has a true logic value; that is if it receives a YES answer in the Protocol.

The existence of a component is decided based on the answers to the questions within the compartment. Each of the three main compartments contains a series of simple yes-or-no questions, i.e. true or false statements. Each of the questions within a compartment asks about different aspect of the waste facility, designed in a way that if any of the questions receives YES answer (the statement is true) then the whole compartment becomes true. In other words, if there is a single YES within the compartment, the compartment exists. For example, if the mine used dangerous chemicals (Q4) then the 'dangerous' Source exist, and the whole Source compartment receives true value irrespective if the answers were all NO to the other nine questions (Q2-Q10) on the Source. Similarly, if there is a water course within $1 \mathrm{~km}$ of the facility (Q11), there is a pathway for contamination, thus the whole Pathway compartment is true, or in other words, there is a possible pathway for contamination transport. Therefore, there is a Boolean OR logic link between the questions within each of the Source, Pathway and Receptor compartments. Expressed by mathematical formula:

SOURCE $\quad \Rightarrow(\mathrm{Q} 2)$ OR (Q3) OR (Q4) OR (Q6) OR (Q7) OR (Q8) OR (Q9) OR (Q10)

('there is a source for significant risk')

PATHWAY $\Rightarrow(\mathrm{Q} 11)$ OR (Q12) OR (Q13) OR (Q14)

('there is a possibility of material transport')

RECEPTOR $\Rightarrow(\mathrm{Q} 15)$ OR (Q16) OR Q17) OR (Q18) 
Summarizing the logic of the pre-selection procedure:

EXAMINE FURTHER $\Rightarrow$

[(Q2) OR ... OR (Q10)] AND [SOURCE]

[(Q11) OR ... OR (Q14)] AND [PATHWAY]

[(Q15) OR ... OR (Q18)] [RECEPTOR]

If this statement is true then the facility bares risk and therefore it has to be classified as EXAMINE FURTHER. Q5 in the Source component asks if the facility is a tailings lagoon and therefore it has a guiding role and does not form a part of the risk assessment logic discussed.

We think that if there is uncertainty in our knowledge, information or data about the facility that leads to uncertainty in the answer to the yes-or-no questions in the pre-selection procedure, the facility should be FURTHER EXAMINED. This is according to the precautionary principle. Logically, this is represented in the pre-selection procedure as follows. First, in order to simplify the procedure, uncertainty is expressed in terms of the answer 'unknown'. This means that if there are no relevant data, information or knowledge about the given question or any level of uncertainty emerges, the question receives an 'UNKNOWN' response. This response is equivalent with the 'YES' answer in this procedure. That is the risk exists (YES) or may exist (UNKNOWN). This is identical to posing each question as the following, using Q4 as an example: "Q4. Did the mine use dangerous chemicals to process the ore? OR Is it unknown?" If we know the answer with a definite YES or NO without uncertainty and thus the answer to the second sub-question is NO, the direction of further processing in the procedure is defined by the first sub-question. If there is uncertainty and thus the answer to the second sub-question is YES, the statement becomes TRUE anyway irrespective to the logic value of the first sub-question. Expressed by mathematical formula:

QUESTION $(\mathrm{QK}) \Rightarrow$ [Question QK] OR [Question QKU: It is unknown], where

Question QK is the question in the Questionnaire, $\mathrm{K}=2$ to18 except for Q5, and Question $\mathrm{QKU}$ is the corresponding question "Is it unknown?" (“Is there uncertainty in the response?").

Finally, there is an additional special question in the procedure. The preliminary question Q1 asks if the mine waste facility is known to have existing serious impact. These facilities with known serious impacts classify directly as 'examine further' and do not require further preselection inquiries. While the above Source-Pathway-Receptor process tests for the possibility of serious impacts, the preliminary question tests for the known existing and documented serious impacts. Therefore there is a Boolean OR logic link between the above SourcePathway-Receptor and the existing serious impact. In this question uncertainty does not emerge since we ask about existence of known, documented and proven impact, therefore a YES answer implies perfect certainty about the existence of an impact. A NO answer also 
implies both the lack of impact and the absence of certain knowledge on impact. Expressed by mathematical formula:

EXAMINE FURTHER $\Rightarrow[$ Known Impact] OR [(Source) AND (Pathway) AND (Receptor)] (7)

Summarizing all of the above discussion, the logic of the pre-selection procedure is expressed as follows:

EXAMINE FURTHER $\Rightarrow$

[Existing Impact, Q1] OR [(Source) AND (Pathway) AND (Receptor)], where

SOURCE $\quad \Rightarrow(\mathrm{Q} 2)$ OR (Q3) OR (Q4) OR (Q6) OR (Q7) OR (Q8) OR (Q9) OR (Q10)

PATHWAY $\quad \Rightarrow(\mathrm{Q} 11)$ OR (Q12) OR (Q13) OR (Q14)

RECEPTOR $\quad \Rightarrow(\mathrm{Q} 15)$ OR (Q16) OR Q17) OR (Q18).

$\mathrm{Q} 2, \mathrm{Q} 3, \ldots, \mathrm{Q} 18$ denote the questions of the pre-selection procedure, and $\mathrm{QK}=(\mathrm{QK}) \mathbf{O R}(\mathrm{QKU})(\mathrm{K}=2$ to 18 , without Q5), where QK is the question in the Questionnaire and QKU is the corresponding question "Is it unknown?". 